Portland State University

PDXScholar

$1-1-1985$

\title{
Special education labeling relationships with learning disabled student self-concept
}

Nancy Kathryn Godinet

Portland State University

Follow this and additional works at: https://pdxscholar.library.pdx.edu/open_access_etds Let us know how access to this document benefits you.

\section{Recommended Citation}

Godinet, Nancy Kathryn, "Special education labeling relationships with learning disabled student selfconcept" (1985). Dissertations and Theses. Paper 792.

https://doi.org/10.15760/etd.792

This Dissertation is brought to you for free and open access. It has been accepted for inclusion in Dissertations and Theses by an authorized administrator of PDXScholar. Please contact us if we can make this document more accessible: pdxscholar@pdx.edu. 
SPECIAL EDUCATION LABELING RELATIONSHIPS WITH

LEARNING DISABLED STUDENT SELF-CONCEPT

By

Nancy Kathryn Rhoden Godinet

A dissertation submitted in partial fulfillment

of the requirement for the degree of

DOCTOR OF EDUCATION

in

PUBLIC SCHOOL ADMINISTRATION AND SUPERVISION

\author{
Portland State University \\ The University of Oregon \\ (c) 1985 Nancy Kathryn Rhoden Godinet
}


TO THE OFFICE OF GRADUATE STUDIES AND RESEARCH:

The members of the Committee approve the dissertation of Nancy Kathryn Rhoden codinet aresented Tulv 18, 1985.
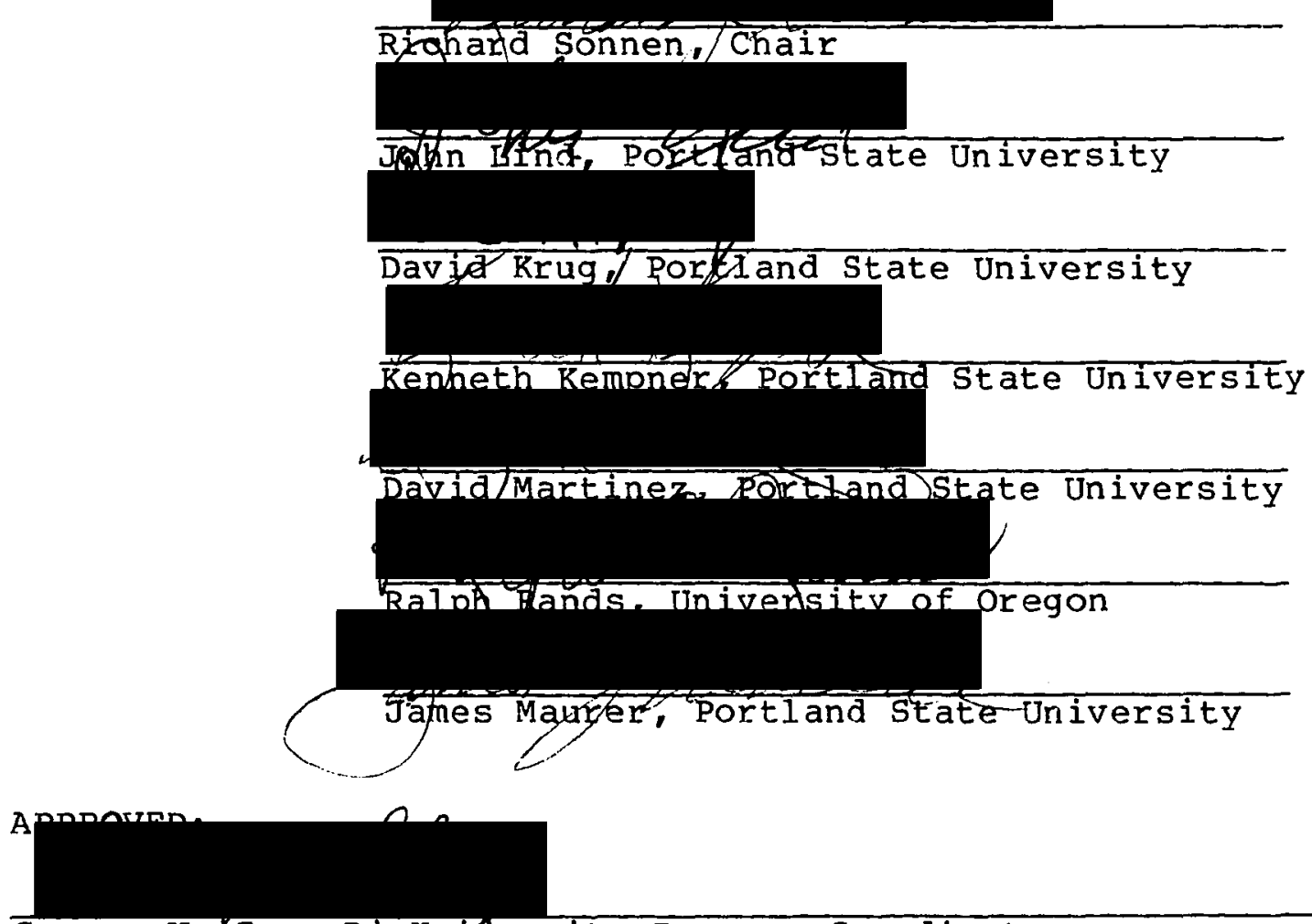

George V. Guy, Bi-Unifersity Program Coordinator portland State University

Richard A. Schmuck, Bi-University Program Coordinator University of Oregon

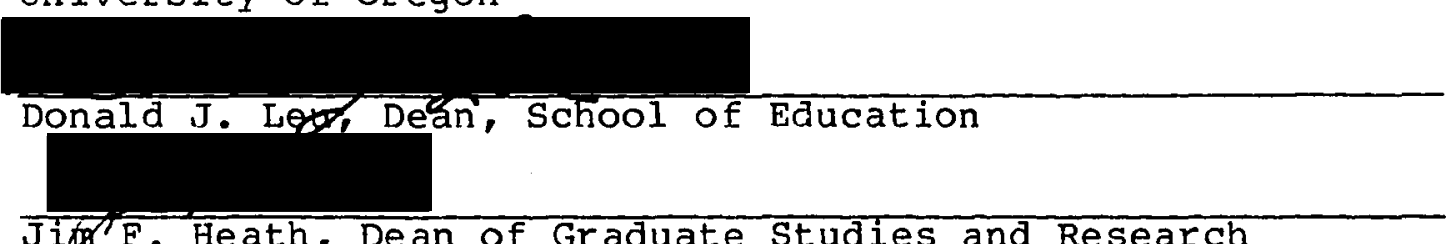

Jith F. Heath, Dean of Graduate Studies and Research 
AN ABSTRACT OF THE DISSERTATION OF Nancy Kathryn Rhoden Godinet for the Doctor of Education in Public School Administration and Supervision presented July 18, 1985.

Title: Special Education Labeling Relationships with Learning Disabled Student Self-Concept

APPROVED BY MEMBERS OF THE DISSERTATION COMMITTEE :
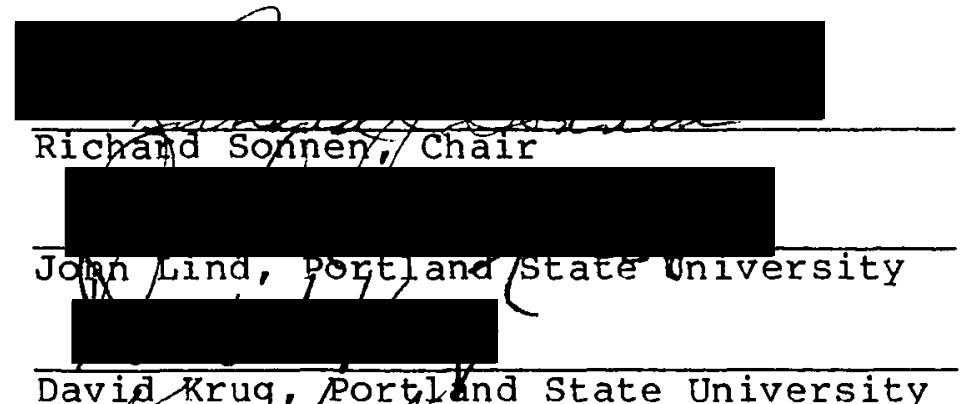

Kenneth Kempnet, Portlandstate Universit David Martinez, Portlang State University

Ralph Rands, Univensity of Oregon

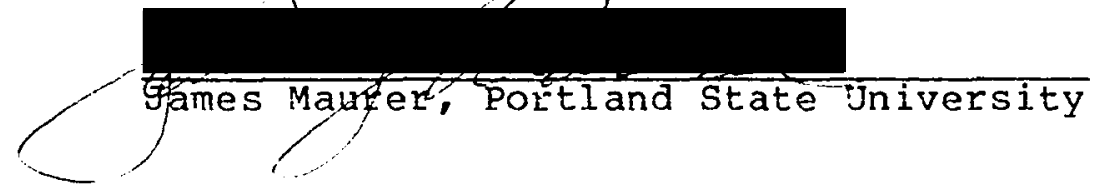

In order to explore special education (LD) labeling interactions with measured student self-concept, this study was designed to examine the influential self-concept variables. Major variables cited in the literature as 
impacting self-concept were determined to be: achievement (not IQ), age, sex, socioeconomic status, ethnic origin, place in family, significant others and special class placement. Subjects were drawn from the Fall 1983 fifth grade student population from three Pacific Northwest school districts. The specific study group was further defined by the predetermined selection criterion of Spring Portland Achievement Test combined Math and Reading RIT score ranges. Learning disabled (LD) students' RIT scores were statistically analyzed. A mean and standard deviation of this group were used to determine an equivalent achievement band range. All LD students having combined RIT scores which fell within the band range of 1 SD below the mean and $0.5 \mathrm{SD}$ above the mean were asked to participate in the study. A control group of regular students who were not labeled but had RIT scores which fell within the established band range of the study, was randomly selected from the three district population. From a total of 127 subjects who were requested to participate in the study, 44 subjects and their families elected to participate. The final study sample included 18 (LD) subjects and 26 regular classroom students. Collection of data for use in this research occurred on two levels. Parents and subjects completed consent and demographic information sheets. The demographic information sheets provided information to assist in 
controlling for external variables, which research has shown to impact self-concept, as well as for probina parental perceptions of subject association with and internalization of handicapping condition labels. Once parents and subjects consented to participate in the study, subjects from both groups were drawn from their respective classrooms and administered the Piers-Harris Self-Concept Scale: The Way I Feel About Myself. Subjects also completed a researcher developed Student Information Sheet (SIS). Data were gathered and analyzed to detexmine how much explained variance could be attributed LD labeled students as compared to regular education students. The t-test, Analysis of Variance (ANOVA) and Chi Square were used to examine whether the major variables impacting self-concept (age, sex, socioeconomic status, ethnic origin, place in family, significant others, or special placement - achievement had been controlled by stratified random sampling) were significantly different between the two groups. Through examination of these independent variables, this study found significant $(p<.05)$ between group differences for age $(p=.0034)$ and placement $(p=.000)$. Between group differences on sex were approaching significant $(p=.074)$. Findings indicated that special education students (1abeled LD) had approaching significantly lower global self-concept scores on the PiersHarris Self-Concept Scale than regular education students 
with equivalent achievement band range scores in reading and mathematics ( $\underline{t-t e s t ~} p=.079$, ANOVA $p=.051)$. These significant between group differences on global self-concept scores might be attributed to four independent or interacting external variables: age, placement, sex, or labeling influences. 


\section{ACKNOWLEDGEMENTS}

Over the years wherein this dissertation was conceptualized and actualized, there have been many people who were sources of support and encouragement. I would like to dedicate this research to the memory of my grandmother, Mrs. Plumah Bonicelli, and with love to my son Andre and my husband Lahey. Their help and understanding through the course of this project has been immeasurable.

Throughout the evolution of my doctoral program, and this research in particular, my doctoral committee has been a constant source of stimulation. I wish to thank them for their wise guidance and continuous encouragement. I know that the lessons which they have taught me will be regularly applied and serve as cherished memories of our times together. I am grateful to each of them for providing me with an exceptional educational experience. Particularly, I would like to thank Dr. Richard Sonnen for being a constant source of inspiration and cheer.

I would like to extend my appreciation to Centennial, David Douglas and Reynolds School Districts for participating in this research. Arlene Anderson, Donnise Brown, Bob Chuddick and Levonne Sedgwick devoted considerable time and 
energy to make this research a reality in their respective school districts.

Also, I wish to thank Joel Arick and Ken Rempner for their support in the development, implementation and evaluation of this research. Their perceptiveness and insights into the areas of research design and data analysis were instrumental in the development of this dissertation.

A special thanks to Deborah Grossman Garber for being the caring and remarkable person that she is. Her help and friendship are indeed treasured and served as a mainstay during the final throes of this dissertation. 
ACRNOWLEDGEMENTS . . . . . . . . . . . . . . i ii

LIST OF TABLES •. . . . . . . . . . . . . . . . ix

LIST OF FIGURES • • • • • • • • • • • • • • • • •

CHAPTER

I Introduction . . . . . . . . . . . 1

Introduction to the Chapter . . . . . 1

Definitions . . . . . . . . . . . 3

Self

Self-Concept

Self-Esteem .............. . . 5

Self Image and Self Conception . . . 6

Self Attributes . . . . . . . . . . 7

Self-Concept Theoretical Foundations

A Historical Overview . . . . . . . 7

A Synthesis of Self-Concept Theory . . • 19

Social Comparison Theory . . . . . 20

Reflected Appraisal Theory . . . . . 20

Social Interaction Theory . . . . . . 21

Anxiety Avoidance Theory . . . . . 21

Idealized Self Theory . . . . . . . 21

Self-Esteem Theory . . . . . . . . 22

Self-Consistency Theory. . . . . . . . 23

Self-Concept Characteristics . . . . . 23

Stability and crystalization. . . 24

Social Identity and Dissonance. . . 24

Self-Concept Development Staqes . . . 25

Self-Concept Developmental Crises . . . 26

Interactive Self-Concept Influences • • 27

Self-Valuation . . . . . . . . . 28

School Impacts . . . . . . . . . 29

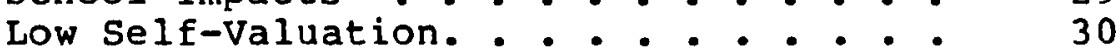

High Self-Valuation . . . . . . . . 34 
Related Measurement Tool Research . . . 38 Directed Observational Report.. . . . 40 Behavioral Trace Reports. . . . . . . 40 Projective Techniques . . . . . . . 40 Self Reports.............. 41 Summary . . . . . . . . . . . . . 43

II LITERATURE REVIEW OF SELF-CONCEPT AND LABELING IN THE SCHOOL • • • • • • • •

Variables Exerting Influence Upon SelfConcept ............. . 50

Self-Concept and Academic Achievement . . 52 Grade/Age . . . . . . . . . . 58

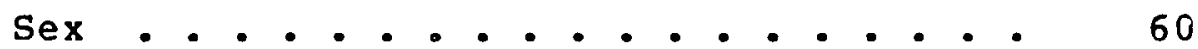

Minority Group Membership . . . . . . 61

Socioeconomic status . . . . . . . 65

Place in Family . . . . . . . . . 67

Significant others . . . . . . . . 68

Parents . . . . . . . . . . . . 69

Peers . . . . . . . . . . . . . 71

Teachers . . . . . . . . . . . . 71

Self-Fulfilling Prophecy . . . . 76

Labeling Theory and Research . . . . . 81

Labeling Theory - . . . . . . . . 81

Labeling Theory of Deviance . . . . . 83

Labeling Research . . . . . . . . . 86

Concern in Special Education Over

Self-Concept ...... . . . . 92

LD Self-Concept Research . . . . . . 95

Academic Achievement of LD SelfConcept . . . . . . . . . 96

Placement . • • • . . . • • • . • . . 99 Juvenile Delinquency and the LD . . 104 
vii

CHAPTER

PAGE

Self-Concept and special Education

Label.ing Research . . . . . . . 107

Labeling and the Mentally Retarded . 108

Labeling anc the Learning Disabled . 112

Statement of the Problem . . . . . 118

Purpose of the study ........ 122

Contents and/or Methodological Limitattions of Previous Studies Leading to

this study ............. 123

III METHODS AND PROCEDURES . . . . . . . . 125

Research Question . . . . . . . . 125

Hypothesis . . . . . . . . . . 125

Design of the Investigation . . . . . 126

Subjects . . . . . . . . . . . 134

Description of subjects . . . . . 134

Sampling Procedures . . . . . . . 135

Data Gathering .. . . . . . . . . 136

Apparatus • . • . - . . . . 139

Family Information . - . . . 139

Piers-Harris Self-Concept Scale . 140

Reliability . . . . . . . . 140

validity . . . . . . . . . 142

Student Information Sheet . . . . . . 144

Data Analysis . . . . . . . . . 145

Limitations . . . . . . . . . . 145

IV FINDINGS . . . . . . . . . . . . . 148

Crosstab Analysis of Respondent
Representation ........... 148

Rey Variable Analysis . . . . . . 151

Hypothesis Data Analysis . . . . . 156 
LIST OF TABLES

Table

PAGE

I Respondent Representations on SelfConcept Variable ..........

I Nonparametric Variable Analysis Using Chi Square... . . . . . . . .

II t-test Parametric Variable Analysis . .

iv anOVA Analysis . . . . . . . . . .

155

$V \quad t$-test Self-Concept Measure Total Score Analysis .... . . . . . . . .

VI ANOVA Self-Concept Measure Total Score Analysis .............. .

VII ANCOVA of Piers-Rarris by Special Fd. LD/ Regular Ed. with Age... . . . . .

VIII ANCOVA of Piers-Harris by Special Ed. LD/ Regular Ed. with Placement... . .

IX Student Uses Handicap Labels for SelfDescription. . . . . . . . . .

$x$ Parental Reports of Handicap Labels Used by Their Child..... . . . . .

XI Frequency of student Responses . . . .

XII Frequency of Student Responses Probing the "Teacher Helps Me To Feel Good About Myselfn . . . . . . . . . . . .

XIII Frequency of Student Responses for "MY Teachers Help Me To Enjoy Schooln".

XIV Frequency for how students Perceive their Teachers as Feeling about Their SchoolWork . . . . . . . . . . . . 


\section{LIST OF FIGURES}

\section{F IGURE}

PAGE

1 Variable Labels . . . . . . . . .

132

2 Study Design . . . . . . . . . .

133

3 Data Collection Procedures . . . . .

138

4 Students Use Handicap Labels to Describe Themselves . . . . . . . . . . 


\section{CHAPTER I}

\section{Introduction}

Recent federal and state leqislation assuring the right of all children with handicapping conditions to have a free appropriate public education is responsible for a high level and conscious thrust to meet the particular learning needs of every exceptional student. Extensive legal mandates geared towards special student advocacy have given rise to modifications in administration of services and teacher delivery systems. In the course of striving to meet the individual needs which special students evidence, concern has arisen over possible impacts upon the student's self-concept which migıt be imposed as a result of the special education labeling process. Sanctioned by the laws which compel districts to serve all of their student population evidencing handicapping conditions, special education labels have become an integral part of district assessment, placement and reporting procedures which are used by teachers and administrators. The practice of labeling and categorizing children receiving special education services has become the focus of considerable debate. Concerns center upon the fact 
that for special education purposes, children are labeled by a medically diagnostic approach rather than on a functional, educational basis. Currently utilized PL 94-142 special education labels are deficit oriented. Therein arises the implication that labels concentrating on pathology, instead of accomplishment, could be responsible for stigmatizina students and result in negative impacts on self-concept.

Teachers have been found to hold conscious or subconscious stereotypical expectations for learning disabled (LD) labeled students (Bem, 1972; Dworkin \& Dworkin, 1979; Florio-Forslund, 1978). Stereotyping can manifest itself in different treatment of the labeled child which in turn could result in modified self-concept for the child (Buddoff \& Siperstein, 1978; Foster, 1976; Prieto \& McCoy, 1979; Ysseldyke \& Foster, 1978). This study is designed to examine special education LD labeling effects with measured student self-concept.

Before focusing upon the effects that labeling may have upon self-concept, a common understanding of selfconcept definition and theoretical foundations must occur. Without a clear understanding of what constitutes self-concept, how self-concept evolves, the ways selfconcept is measured, it is impossible to proceed to discussions of labeling and self-concept interactions. The first chapter will cover terminology which has been usea 
interchangeably with the term "self-concept." It will provide insights into the definitions attributed to this varying terminology. Self-concept theory will be explored as it relates to the development of an individual's selffeelings. Types of measurement tools currently used in self-concept research will also be surveyed.

\section{DEFINITIONS}

Innumerable terms have been used interchangeably with self-concept (i.e., the self, self-image, selfesteem, self-worth, self-attitudes, etc). Considerable confusion has arisen over the lack of tangible, universalIy accepted definitions for the terms used in self-concept literature. The area of self-concept investigation is replete with definitional confusion and contradiction. The following reviews attempt to mitigate this confusion.

SeIf. Jersild (1952) uses the word "self" freely in his writings.

The self is a composite of thoughts and feelings which constitute a person's awareness of his individual existence, $h$ is conception of who and what he is. (Jersild p. 9)

Carrying the thought a step further, sheerer (1949) posits that, "... One's attitudes toward others are related, to a decidedly significant degree to the attitudes one holds towards one's self." (Sheerer, p. 174).

Self-concept. According to Rosenberg (1979), the self-concept is comprised of three broad regions: the ex- 
tant self, the desired self and the presenting self. The extant self encompasses how the person sees herself and includes the elements of: social identity, physical characteristics, attitudes or traits. These elements vary in their levels of importance to the individual and can interact among themselves or the global self-concept. Rosenberg explains that the desired self is the mental picture of what the person wishes to be. Self evaluations are ongoing between the desired self and the extant self. Used as a standard of comparison, the desired self serves as a model which the extant self strives to attain. Lastly, Rosenberg portrays the presenting self as a varying role which is situationally motivated. Depending upon which end the self wishes to accomplish "...there are several objectives in presenting certain selves: (1) the fulfillment of ends, goals, or values; (2) the selfconsistency and self-esteem motives, and (3) the internalization of social roles" (Rosenberg, 1979, p. 47).

Accrediting the self-concept with a fundamental role or frame of reference for the indiviaual, Rosenberg (1979) explains that almost all persons' actions are predicated on the basis of their self-concepts. Defining selfconcept in a fashion which closely mirrors the definition set forth by Rogers (1951), Rosenberg states that the self-concept is "...the totality of the individual's thoughts and feelings having reference to himself as an 
object" (Rosenberg, p. 9). "...Self-concept is the fundamental structure or theory that guides one through life; it is persistent, omnipresent, inescapable, powerful" (Rosenberg \& Kaplan, 1982, p. 339).

....Self-concept can be defined as the way we perceive ourselves and our actions, and our opinions regarding how others perceive us...The key dimensions of the general self-concept are the sense of (1) body self, (2) cognitive self, (3) social self, and (4) self esteem (Silvernail, p. 9).

The self-concept is the substantive description one employs to identify his nature, and is also used by individuals to compare themselves to others (Calhoun \& Morse, 1977, p. 319).

Voicing concern over what is often an interchangeable use of nonequivalent terms, silvernail (1981) distinguishes between self-concept and self-esteem. "While our self-concept describes our perceptions, our selfesteem evaluates these perceptions" (Silvernail, p. 9). Self-esteem. Coopersmith (1967), Rugle and Clements (1980) agree to this further differentiation of selfesteem from self-concept. "By self-esteem we refer to the evaluation which the individual makes and customarily maintains with regard to himself: it expresses an attitude of approval or disapproval, and indicates the extent to which the individual believes himself to be capable, significant, successful and worthy" (Coopersmith, 1967. p. 4). 
Self-esteem is the result of the process of personal evaluation whereby the individual appraises, perceived aspects of self-conception. "An individual's level of self-esteem will be determined by how well self-images or behaviors, match self-conception" (Rugle \& Clements, 1980, p. 2).

Purkey (1970) describes self-esteem as a set of categories and attributes. The categories represent the many life roles which the person fills such as: mother, father, woman, man, friend, foe, etc. Attributes are characteristics which the individual holds dear like being: smart, loving, caring, proud, efficient, skillful, etc. Categories and attributes can vary in their levels of personal importance. Those categories and attributes which are more highly valued are core personal descriptors. When self-images related to core descriptors are threatened over time by failure-oriented feedback, selfesteem can resultingly be lowered. Purkey (1970) holds that self-conceptions can and do vary over time.

\section{Self-Image and Self-Conception}

Moving to further define and delimit the terminology, Kugle and Clements (1980) divide the self-concept into two additional dimensions. These two dimensions are the self-image and self-conception. The self-image can 
assume many fleeting forms. It is one's self-picture at a given moment in time.

Reflecting a more far-reaching sense of oneself is self-conception. Self-conception draws from previous experiences, values, goals and personal views of capability to formulate an overall self-description (Kugle \& Clements, 1980).

\section{Self-Attributes}

In an effort to reach some closure for what seems to be an endless proliferation of terms, let us conclude with Kaplan's (1980) definition for self-attributes or selffeelings. Self-attributes or feelings are "...the affective or emotional responses of individuals to themselves upon perceiving and evaluating their own attributes and behaviors" (Kaplan, p. 3). Simply defined, self-concept is the way one talks about oneself to oneself.

With the terms defined, it is possible to move on to self-concept theory. A historical overview of selfconcept theory's evolution since 1890 can now be discussed.

\section{Self-Concept Theoretical Foundations}

\section{Aistorical Overview}

The twentieth century has witnessed considerable gains in the exploration of self-concept theory. In spite of the preponderance of writings during this era, it would 
be a grave oversight io review the literature wichout the consideration of one nineteenth century thinker.

James' (1890) writings are the primary forerunner to modern self-concept theory. He suggests that we are continually involved in the process of self seeking and self estimating cur material, social and spiritual selves. "One may say, however, that the normal provocative of self-feeling is one's actual success or failure, and the good or bad actual position one holds in the world" (James, p. 306).

Dividing the global $==i r$ into two portions, James calls the empirical person "Me", and the judging thought "I". While "I" is the pure experience of self as a subject, "Me" is the content of an experience and self as an object. Thus, the self is both "Me" and "In.

Elaborating upon James' "Me", Burns (1979) describes it as a "...spiritual self, material self, social self and bodily self" (Burns, p. 7). Burns states that all selfconcept aspects of feelings, attitudes, evaluations, descriptive categories and future anticipation are included in "Me".

Mead (1934) equates self-concept with social experiences. According to Mead, language is the connector between oneself and society. The self-concept is a social product which emerges as a result of social communications. Individuals can internalize the actions of others 
and treat themselves as others treat them. This is how people become objects of themselves.

Modifying James' "I-Me" definitions, Mead describes "I" similarly to Freud's "id". Our behaviors, he tells us, begin as "In behaviors. They are impulsive and disorganized. "Me" incorporates societal interventions into the resulting behavior. Mead bases the emergence of "Me" upon the foundation of childhood experiences and modeling. To Mead, childhood role playing marks the beginning of personal role explorations through uninhibited actions. Role dabbling on the game level becomes more of an internalization of significant others' (persons of importance) roles. Herein the child learns societal rules and procedures.

It is through Mead's writings that the "I" and "Me" of James become tied to the two main threads of self definitions prevailing in the literature today, the self as a process and the self as an object. James' "I" is equivalent to the self as a process, while "Me" is akin to the self as an object.

The self as a process is comprised of the ongoing conscious interpretations which according to zuercher (i977) include: conscious thought, perceptions, planning, making choices, evaluating and introspection (zuercher, p. 25-6). On the other hand, the self as an object qives rise to a conceptual framework upon which are anchored the 
senses of identity and self-esteem. Identity and self esteem are a result of both interactions with other people and the individual's proqressing through space and time (Zuercher, 1977).

Self-concept theory's increased credibility evolved after early behaviorist investigations of stimulusresponse events using variable manipulations (skinner, 1938). Once observable behavioral findings were acknowledged, some theorists went further than the strictly observable behavioral philosophy and claimed the existence of internal, nonobservable states which can induce behaviors. Herein, self-concept theory was born.

From neo-Freudian writings, the self can be interpreted as a learned response to social interactions. Neither Freud nor neo-Freudians center much attention on self-concept theory. Although, self-attitudes are credited with considerable importance. A neo-Freudian, Adler (1927) considers the center of personality to be motivated consciously. This train of thought represents a sharp divergence from Freud's emphasis on unconscious influence. Alder asserts that the self is consciously developed via the person's strivings for feelings of superiority.

Horney (1945) proposes that self systerns are a product of anxiety avoidance. Childhood experiences are attributed with much of the responsibility for establishing anxiety as a basic personality trait. A recurrent theme 
in her writings is the child's pleasure seeking through attempts to meet significant others' expectations. Proposing that idealized self-images are developed within each individual, Horney defines life as a continuous struggle towards self-realization. Self-realization is not always realistic in light of idealized personal goals. Inner conflict is a result of this discrepancy. Problems arise when the idealized self and the actual self are not very much alike.

Another neo-Freudian, Sullivan (1953), agrees with Horney that self systems are the result of personal striving to reduce or avoid anxiety. A self system is "... an organization of educative experience called into being by the necessity to avoid or minimize incidents of anxiety" (Sullivan, p. 165). The core of Sullivan's self system investigations are the interpersonal relationships between child and mother. During attempts to elicit positive reinforcements from mother, the child internalizes descriptive value systems (i.e., good me, bad me, not me).

Lewin (1948) believes that the self is relatively permanent and provides consistency to the entire personality. Lecky (1934) goes a step further by insisting that self-consistency is the central motivation for human behavior. A theory of self-consistency is formulated by Lecky. He believes that this theory can be used to describe the central motivation for all human behavior. 
Through anticipating that an individual will react to situations in accordance with internalized concepts which stem from behaviors consistent with self perception, Lecky theorizes that people strive to preserve existing selfimages.

Lecky (1934) and Jersild (1952) feel that individuals accept experiences which support the self picture that is already in place. When conflicting experiences arise and recur, a struggle and resistence to self-image modifications takes place. It is thus that the self-consistency motive is set into operation.

Essential to any serious considerations of self theories are the writings of Maslow (1954). Maslow ascribes to the belief that every person has basic needs and meta needs. Basic needs are necessary for survival and include: food, clothing and shelter, safety, security, self-esteem and love.

Meta needs are those needs aside from basic needs. They assist people in their striving for self actualization. Meta needs include: order, unity, goodness, justice and beauty. When basic needs are not met, Maslow tells us that the individual's efforts to meet meta needs are impaired. Reaching a level of self-acualization then encompasses the inherent necessity for having met basic needs and also attaining a considerable degree of success in meeting meta needs. To Maslow, people are self actual- 
ized when they are: self accepting, psychologically unified, anà integrated, self determining, fully functioning and are realizing their full potentials.

Traveling into territory beyond that touched by Maslow's theory, Rogers $(1951,1959)$ sets forth a theory of organismic actualization. Rogers (1959) tells us that the self is phenomenological. Phenomenology refers to each individual living within his or her own world (Rogers, 1959, p. 191). Every person struggles to reach an envisoned ideal self. Self actualization, or becoming the idealized self, is a primary motivating force for everyone.

The theoretical contention for organismic actualization assures that self actualization must occur on two planes in order to be successfully reached. It is therefore necessary to attain both psychological and physical potential before self actualization can occur. Rogers insists that there must be a congruence between phenomenal experiences (the world as it is seen and experienced) and the person's self-concept. Without this essential congruence, an individual will exhibit anxiety, rigidity and defensiveress. The-self concept cannot help but be negatively impacted when congruence is absent.

To Rogers (1951) the self-concept has four essential characteristics: (1) the self endeavors to be consistent, (2) self perceptions cause the individual to conduct her- 
self consistently with her perceived ideal self, (3) experiences which are threatening or deviate from the perceived self are initially denied or distorted to allow for the preservation of the existing perceived self, (4) changes in self perception can occur over a period of time when recurring experiences overwhelm the perceived selfimage with incongruent images.

Relating personalized aspects of life to the self, Allport (1955) entitles the entire personal life realm the "proprium." The proprium has seven component elements: bodily sense, cognitive self identity as manifested over time, self enhancement, self extension to other people and things, rationality, self-image, and working to enhance one's self-image. Only at middle age does the self reach full development. Life prior to middle age is directed towards the exploration of the seven proprium components. upon reaching maturity, the individual has greater self acceptance, insight, and a philosophy of life.

Cattell (1950) goes even further than Allport by suggesting that selective perceptions are important to self-concept. To the dual role of the self (as both process and object) is added the dimension of selectivity. Cattell sees self in three interrelated forms: Felt self, Structural self and Contemplated self. "Felt Self" concerns itself with internal questioning; while "Contemplated Self" blends the actual and the desired ideal model. 
Both are examined through personal behaviors and self introspection. The "Structural self" enables the interpretation and explanation of the self by way of an integrated framework.

Of the neo-Freudians, Erikson (1968) attaches the highest importance to interpretation of the self as a process and an object. In his writings he revisits freud via a heavy emphasis upon experiential influences, and goes even further by examining cultural influences on the self as an obiect.

Within a given culture, Erikson tells us that identity is birthed in an eight leveled process of development. He finds certain varieties of conflicts and their resolution to be distinct aspects of particular stages. A series of conflicts or crises motivate personal reflection and result in the development of individual qualities. To Erickson, perceptions of self are continually changing. Being aware of where one is directed and feeling confident about this direction represents Erickson's ideal personal state. Identity evolves through exploration of personal power and weakness. Erikson believes that identity entails self recognition and recognition by others. Purkey (1970) describes the self as "...a complex and dynamic system of beliefs which an individual holds true about himself, each belief with a corresponding 
value" (Purkey, p. 7). Therefore, Purkey concludes that the self is both dynamic and organized.

The self is dynamic because every person actively tries to perpetuate, protect and augment self perceived images. "...Everything is comprehended from the personal self-referent vantage point; the world exists for the individual only as he is conscious of it" (Purkey, p. 10). New self-images, which are consistent and relevant to the already existing self perceptions are readily assimilated. Inconsistent self-images are rejected or distorted.

An organized view of the self is also supported by Purkey. The self is organized into categories of self beliefs. Some of the self beliefs are central to the individual. These central beliefs are highly cherished, resistent to change, and will be fought over. Less central beliefs are more easily modified and changed. Fvery self category has both a positive and negative value. Successes reinforce the positive value while failures strengthen the negative evaluations.

Silvernail (1981) writes that the self-concept evolves. Initially the self becomes recognized and differentiated from others. Once role, ability and attribute parameters are explored, a self-concept resultingly emerges. 
This emerging self-concept has many dimensions such as: body self, social self, cognitive self and selfesteem (Silvernail 1981, p. 9). Some dimensions are of greater importance to the individual and are consequently hierarchically ranked in the order of their proximity to individually valued self-images.

\footnotetext{
"The self-concept, at least the general self-concept, is fairly stable. Our core perceptions develop early and change little through time. A long history of inconsistent perceptions is needed before these 'selfs' change. However, as we descend the self-concept hierarchy -- that is move away from the core images -- the selfconcept becomes less stable" (Silvernail, p. 10). Loss of stability is attributed to the self-esteem
} element which has an ongoing evaluative function. Core self evaluations are developed at an early age. They tend to remain constant. It is the evaluations of lesser import which are continually reassessed. Reassessment of less important evaluations can result in their being replaced by new images.

Rosenberg and Kaplan (1982) explain self-concept on the basis of psychological centrality. The principle of psychological centrality describes the self-concept as being comprised of many parts. Some components are considered to have more bearing on feelings of self worth, while others are of considerably lesser importance. Rosenberg and Kaplan list four dimensions of selfconcept. These dimensions are integral parts of the 
self-concept as a whole and include: self-esteem, self confidence, self crystalization, and self-concept stability.

of the four dimensions, self-esteem represents feelings of self worth. Self-esteem is said to be the level of acceptance and respect held for oneself.

Self confidence is the presence of an internal locus of control over oneself. Locus of control is achieved through willfull manipulation of qoals and successes. Self confidence can sometimes be generalized across situations, at other times it is restricted to a single realm of operation.

Highly important is the influence of self confidence upon the components of the self (i.e., student, worker, age, sex) which comprise the parts of the whole person. Rosenberg and Raplan (1982) tell us that components are the nouns and adjectives which when summed together are the whole self-concept. Components can vary greatly in their levels of importance. In addition to the importance attributed to the components, their salience must also be considered. Salience is the dearee to which components are at the forefront of the individual's thoughts. The structure of the self-concept emerges as a result of how components are grouped and related.

Self crystalization is the internal cognitive processing of incoming information that bears upon the 
individual's perceptions of self. This is the mechanism which can be activated or remodeled to the extent that self perceptions are maintained or changed. It is derived from past experiences and exerts an influence upon how information pertaining to the self is organized and stored.

Self-concept stability is the last dimension of the self-concept as defined by the principle of psychological centrality. By self-concept stability, Rosenberg et. al. are referring to the degree of constancy which the selfconcept maintains over time. They believe that the selfconcept is constantly being reassessed. Reassessment is on the basis of environmental and significant others' influences.

Self-concept can be different and distinct at a number of levels. These levels are described as planes. An individual can favor a plane of thought so that it becomes a dominant means for interpreting incoming messages. "The self-concept, then, includes a plane of reality, a plane of possibility, a plane of fantasy, a plane of morality, and a plane of performance" (Rosenberg and Raplan, 1982, p. 7).

\section{A Synthesis of Self-Concept Theory}

While this historical overview provides a perspective of the evolution of self-concept theory, it fails to 
synthesize prevailing thought into related theoretical classifications. Any effort to integrate these conceptualizations requires a brief discussion of the primary self-concept schools of thought. It must be understood that these schools of thought are not unique unto themselves and contain many common characteristics. Lack of mutually exclusive theoretical categories precludes considerable difficulty in efforts to neatly fit theorists into these enumerated groupings: social comparison theory, reflected appraisal theory, social interaction theory, anxiety avoidance theory, idealized self theory, self-esteem theory, and self-consistency theory, The following represents an attempt to describe the essence of key self-concept theories as well as their proponents. Social comparison theory. The earliest writings pertaining to self-concept are represented by social comparison theory. Social comparison theory presumes that people judge and model themselves through ongoing comparisons of themselves to others (Calhoun \& Morse, 1977; Coleman, Campbell, Hobson, McPartland and others, 1966; James, 1890 ; and Merton, 1948 ).

\section{Reflected appraisal theory. Slightly varied from} social comparison theory is reflected appraisal theory. The nuance of difference centers upon the degree of influence exerted by others. According to reflected appraisal theory, we respond to ourselves as we believe 
others see us. Cooley's (1912) looking-glass self fits within this theoretical assemblage. Highly influential are other's perceived judgements of ourselves. These judgements are attributed with the responsibility for shaping self perceptions and actions (Brookover, Thomas \& Patterson, 1965; Cooley, 1912, Mead, 1934; and Sullivan, 1953).

Social interaction theory. Combining the tenets of social comparison and reflected appraisal theories is social interaction theory. It describes the reciprocal effect of shaping influences exerted by others and self comparisons to others as a dynamic interactive process (Lemert, 1972; and Schur, 1971).

Anxiety avoidance theory. In anxiety avoidance theory, self systems result from attempts to avoid experiences evidencing high levels of anxiety. A heavy emphasis upon extrinsic motivation initiated by significant others (persons of importance to the individual) is central to this theory. (Horney, 1945; and Sullivan, 1953). Idealized self theory. This theory (or its derivative organismic actualization) emphasizes the intrinsic desire of all individuals to become self actualized. Reaching self actualization requires that the person be: self accepting, self determining, and actually realizing full potential. A congruence between perceived self and actual life experiences is essential if self actualization 
is to be achieved. There is a solid self-consistency element to idealized self theory (Maslow, 1954; Rogers, 1951, 1959).

Two theoretical avenues of thought attempt to explain motivational factors related to self-esteem. One school espouses a self-esteem theory, while the second supports a theory of self-consistency.

Self-esteem theory. Proponents of self-esteem theory hold that an individual's motivations are directly tied to an internal need for fostering feelings of importance, productivity and self satisfaction. The level of this need can vary from person to person. What is consistent here is the motivation to increase self valuation through the raising of self-esteem. Low self-esteem individuals are more dependent upon others for approval than those with high self-esteem. (Dittes, 1959; Jordan, 1953; and Rosenberq, 1965).

Self-consistency theory. According to self-consistency theory, the way a person receives information, acts, and feels are directly related to an active, yet internally motivated, attempt to retain a self-image which is consistent with the mental picture already in place. All relationships with others and self evaluations have a common measuring stick...they are compared to the mental self picture and evaluated on the basis of their congruence to this image. (Engel, 1959; Festinger, 1957; Jersild, 1952; Lecky, 1934).1

10ther self-consistency theorists are: Maracek \& Mettee, 1972; Rogers, 1951, 1959; Secord \& Bachman, 1965. 
Consistency theory suggests that persons having high self-esteem will actively work to perpetuate successful experiences; while individuals exhibiting low self-esteem will avoid success experiences. Those who evidence unclear self-appraisals will strive for success-filled experiences (Marecek \& Mettee, 1972).

Jones (1982) states that both self-esteem and selfconsistency theories support the contention that "...the major sources of change in thought or action involve the individual's evaluation of himself, his choice of activities or social roles, and his relationships with others" (Jones, p. 155). Where both theories differ is in their interpretation of which motivational factors can be considered primarily responsible for changes in self perception. Self-esteem proponents argue that the principal impetus responsible for change is each individual's inherent need to preserve feelings of high self-worth. Selfconsistency advocates insist that the chief motivational force is one which perpetuates consistency with the already established self picture.

\section{Self-Concept Characteristics}

Some additional characteristics of self-concept have been the topic of considerable debate and require discussion: stability or crystalization over time, social identity elements, and dissonance effects. 
Stability and crystalization. Stability of selfconcept has been a topic for heated discussions over a long period of time. Supporters of a stable and crystalized self-concept tell us that self images become clearly defined in early childhood and are continued into adulthood (Carlson, 1965; Engel, 1959; Mead, 1934; Rogers, 1951; Silvernail, 1981).

Supporting a diametrically opposite point of view, other theorists assert that the self-concept is continualIy the object of reassessment. Environmental and significant others' influences are responsible for this continuous reappraisal (Erikson, 1968; Festinger, 1954; Morse and Gergin, 1982; Purkey, 1970).

Finding a middle group, purkey (1970), Silvernail (1981), and stryker (1982) maintain that some self-concept components are crystalized while others have not assumed clarity and consistency. Depending upon their centrality to or distance from personally valued self images, components will or will not be crystalized.

Social identity and dissonance. Stryker (1982) speaks to the relationship between social identity elements and dissonance effects. Social identity elements (i.e., minority group membership, sex, socioeconomic status, age, etc.) are considerably influencd by interactions which occur in social contexts. "Although social contexts impinge on the individual in many ways, their 
impact on individual self-concepts are likely to be strong if these contexts are dissonant, that is, if the qualities of the individual diverge from those prevailing in his or her envirunment" (stryker, 1982, p. 211). Dissonance enters the scene when various social identities, which the individual may hold, are different from the social identities for the majority of those around her.

\section{Self-concept developmental stages. There are those} who believe that self-concept characteristics have developmental stages. Dickstein (1977) claims that the selfconcept varies according to a person's passages through five self-concept developmental stages: (1) the dynamic self, (2) the self as an object, (3) the self as knower, (4) the self as an integrated whole, and (5) the selfless self. She further explains that an individial's selfconcept development can become arrested at a particular stage, thereby preventing her passing through all five stages.

The dynamic self stage is one of environmental exploration. Here the child gradually extends selfindependence through increasing personal skills in selfcare and environmental exploration. Chronologically this developmental stage ranges from toddler to five years of age.

Encompassing the child's first through latter elementary grades, the self as an object develops. A central 
focus to this stage is that of self evaluation. Self evaluations, Dickstein postulates, are based upon observations of others' behaviors. The feelings of self-worth which evolved in the dynamic self stage are thus compared to the new input representing judgements of others.

Active striving to reach self-created ideals is particular to the self as a knower stage. Into adolescence, the chiid seeks to attain ideals pertaining to individually valued personality and life style characteristics. This is a highly introspective phase which has considerable basis in its two preceding developmental stages. It must be noted that the self as a knower step also has the capability of striking a new dimension in the evolving self-concept.

The self as an integrated whole entails awareness and acceptance of oneself as a unique individual. It also presumes some level of understanding as to one's own place within the total order of the universe.

Lastly, the fifth stage is that of the selfless self. This final level of self-concept can be totally independent of the previous stages. A person who has not previously achieved high self-esteem can still succeed in reaching it at this stage. The selfless self is marked by highly consistent self perceptions, self knowledge and self appreciation. It is the most difficult level to measure. 
Self-concent developmental crises. Others claim that self-concept characteristics are shaped by crisis experiences. Erikson (1968) insists that a child's development is a series of successive crises. A crisis is described as "...a turning point, a crucial period of increased vulnerability and heightened potential, and therefore, the ontogenetic source of generational strength and maladjustment" (Erikson, p. 96). Crises occur in response to the child's need to manage new situations. Depending upon how the child reacts and grows as a result of these crises/turning points, the personality takes form and matures.

At the end of the child's adolescent process a firm sense of identity should be present. This sense of identity is an essertial condition which must be met if additional maturation is to occur.

\section{Interactive self-concept influences. By far the} most theorists insist that an interactive effect of many influences shapes self-concept (Burns, 1979; Erikson, 1968; James, 1890; Jersild, 1952; Mead, 1934; Rosenberg \& Kaplan, 1982). Burns (1979) speaks to self-concept development as a result of the interactive effects of many variables. During the child's first five years, the child's personality and self-concept are shaped into a framework that serves as the structure upon which the more complete personality and self-concept will be built 
(Burns, 1979). A young child explores experiences via sensory and motor investigations. Self gradually becomes understood as a separate entity from the surroundings only after "body" and "not-body" boundaries have been defined. "Self awareness emerges slowly as the infant uses and acts upon his own environment" (Burns, p. 149). According to Burns, self-concept gradually is formed and continues to develop throughout life. Initially, self-concept is solely body image, but once control over personal environment is mastered, self-concept takes on added dimensions. Burns lists five sources of self-concept modification and growth: body image, langliage, environmental feedback, sex role model identification and child rearing (Burns, p. 150). An elaboration of studies investigating the influences upon a child's self-concept by these and other variables will be carried out in Chapter II.

\section{Self-Valuation}

As the self evolves into a more clearly defined form, differentiation occurs" ... Once the child has achieved the ability to attribute purpose and intention to the acts of others, this ability will have profound and pervasive influence on the development of the self system" (Jersild, 1952, p. 17). Each person works to achieve positive evaluations. A climate which nurtures positive 
self-concept can be developed or ignored. Samuels (1977) emphasizes the need for fostering trust, autonomy, and initiative if positive self-concept is to be actualized. School impacts on self-concept. Our schools entail a process of continuous evaluations relating to student proficiences and limitations. Minimal student choice for the areas of school work which must be comoleted, and even less flexibility in choosing how the work will be evaluated, anchors students into a highly rigid system where there are two choices...do it or fail. The responsibility for either choice rests with the child. Burns (1979) tells us that we set our children up for sink or swim decisions far too early in their lives. "The role of the school, moreover, is not only incidental but direct. It dispenses praise and reproof, acceptance and rejection, on a colossal scalen (Jersild, 1952, p. 90).

speaking to the relationship between school and self-esteem, Faust (1980) strongly emphasizes the important role of the school. "Nothing is so critical to effective learning as a sense of self-esteem; nothing is so certain to diminish or destroy self-esteem as the use of "right" and "good," "wrong" and "bad" as evaluations of what the learner has produced" (Faust, p. 83).

As self-esteem developes in the child, both cognitive and affective brain domains exert an influence upon one another. Self-esteem is not emotional although it has 
an impact on emotions. Instead, it is a thinking experience which is affected by feelings. Self respect and feedback from significant others collect and formulate an accumulation of self perceptions. This collection of self perceptions has the capability of setting off emotional reactions.

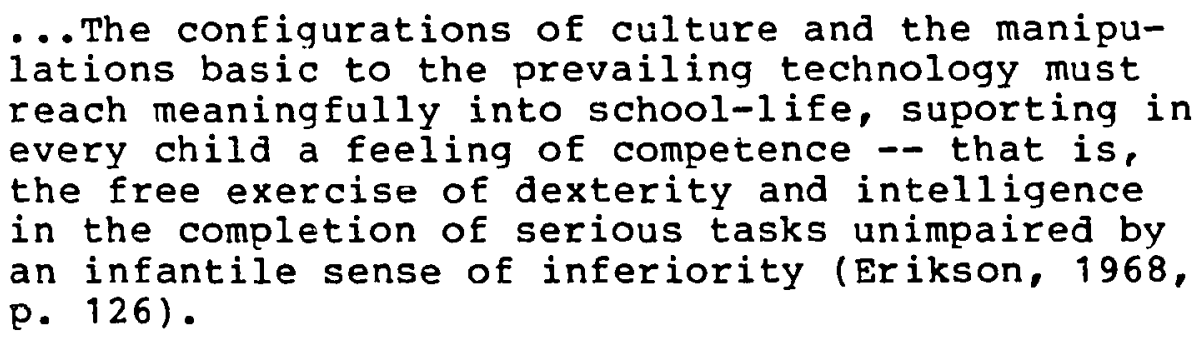

Grading in the schools is product-centered. While grades are intended to motivate students extrinsically, grades often result in attaching labels of "good" or "bad." "Grades become product symbols not only of students' personal worth in the present, but also their potential worth estimated by society. Students who produce the 'right' products are identified as 'good' persons" (Faust, 1980, p. 100).

Physical, social and emotional development are equally within the aegis of the school. This widening of purpose injects self-concept development as a central theme in non-cognitive development, and this is also linked with the all too recent awareness that academic development and progress cannot be considered in isolation from other aspects of human development (Burns,1979, p. 275).

Low self-valuation. Individuals evidencing low selfvaluation perceive themselves as objects of rejection. 
Through avoidance mechanisms, they elude rejection and anxiety by first attacking or isolating themselves from others (Sullivan, 1953).

"Feelings of worthlessness and other negative selfimages grow by accretion-like a snowball as it rolls down a slope" (Hyatt, 1977, p. 75). A cycle of events gives rise to and solidify low self-esteem. Inaccurate perception can result in unreasonable reactions to others. Those who believe that they have been treated unreasonably react through negative feedback. This feedback reinforces low self-esteem so the cycle perpetuates and feeds upon itself (Hyatt, 1977).

... Uncertain or unstable self-esteem is associated with attempts to resolve discrepancies betwen self-image and self-conceptions in favor of self-conception, i.e., attempts at self enhancement. Once an equilibrium between selfimage and self-conception is reached, efforts will be made to maintain that state -- thus consistency tendencies are associated with certain, or stable, self evaluations" (Rugle and Clements, 1980 , p. 5)

Kaplan (1973) attributes negative self-attitude causality to three factors:

1. The individual perceives a personal lack of self valued attributes and behaviors.

2. The individual fosters feelings of personal failure based on self perceived voids in being the object of positive attitudes from significant others. 
3. The individual either does not have or use defense mechanisms whict downplay self-devaluing effects (Kaplan, P. 9).

Horney (1945) submits that persons experiencing rejection at an early age must have greater strength in dealing with conflict than others who herald from more secure backgrounds. This contention is echoed by Jersild $(1952)$.

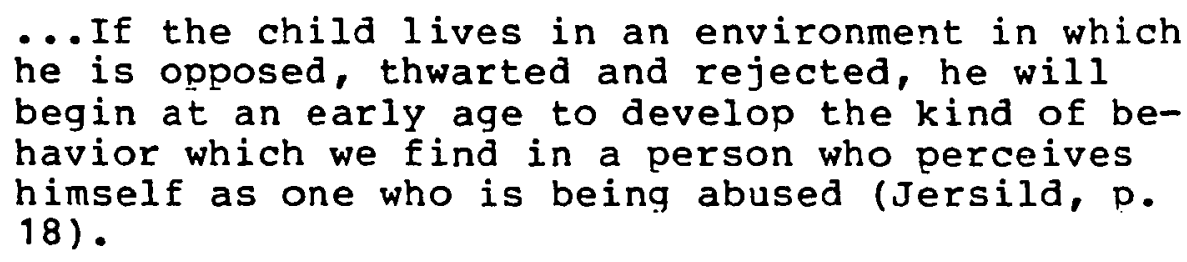

Ascribing the desire for feelings of self worth to all individuals, Raplan (1973) insists that we are continually motivated to attain, keep or restore high levels of self-esteem. He is concerned that environmental conditions can be highly limiting factors to self-esteem.

So long as the same conditions that led to self rejecting attitudes continue to hold, limits will be placed on the extent to which the subjects will be able to gain self-acceotance within the context of the normative environment (Kaplan, p. 224).

Low self-esteem can have many ramifications. A study by Marecek and Mettee (1972) found some interesting self-esteem effects on student performance. These effects indicate that "...only subjects certain of their low self-esteem failed to show any improvement in their subsequent performace, subjects uncertain of their low self- 
esteem improved significantly following a self-produced success" (Marecek et. al p. 98).

According to Rosenberg (1965) children evidencing low self-esteem are: less trusting of people, less assertive, and less likely to be the initiators of conversation. Burns (1979) provides some additional charcteristics to this list. Individuals with low self-esteem often display sensitivity to criticism, project blame, are overly critical of others; have little interest in competition, tend to be timid, and prefer to be left to themselves (Burns, p. 219).

Many studies have found significant relationships between low self-esteem, self-concept and anxiety. Prior to embarking upon this terrain, it must be understood that self-esteem and self-concept have been used as interchangeable terms in the majority of these studies.

Horowitz (1962) reports high anxiety scores for upper elementary students who evidence low self-concept scores. A study by Bledsoe (1964) describes a significantly negative correlation between manifest anxiety and self-concept scores for fourth and sixth grade girls and boys.

Stanwyck and Felker (1973) also found a significant negative correlation between student self-concept scores and anxiety levels. Low self-concept students were high in anxiety, while the reverse was true for high self- 
concept students. Rosenberg (1965) tells of similar findings supporting strong associations between anxiety and self-esteem for juniors and seniors in high school. Feldhusen and Thurston (1964) describe children with lower levels of anxiety as being more self-accepting. Numerous studies, in addition to those already cited, concur in their findings that there is a strong negative relationship between self-concept and anxiety. These studies provide substantial evidence that there is a strong connection between high levels of anxiety and low self-concept as well as a conversely low anxiety, high self-concept relationship (Ausubel \& Robinson, 1969; Coopersmith, 1967; Many \& Many, 1975). Stress resulting from academic failure is found to impair the performance of able children and to lower their reported self-concepts (Gabbler \& Gibby, 1967).

Psychosomatic illnesses are a major result of the inability of a person to cope, and adjust his self-concept to experience and behavior... Sickness provides a temporary respite from pitting the self-concept against situations in which it cannot stand judgement (Burns, 1979, p., 270).

High self-valuation. Scholars assert that an individual's total existence eminates from the central concept of self (Cheong, 1974).

The self-concept, then, is an arena of passionate involvement, not detached neutrality. It motivates behavior, interaction, perception, attention, valuation, or virtually anything else that enters the human experience (Rosenberg, Kaplan, 1982, D. 9). 
Further emphasizing the import of high selfvaluation, Clemes and Bean (1981) declare, "at every stage of our life our self-esteem determines how we act, how we learn, how we relate, how we feel, and how we work" (Clemes \& Bean, p. 11). Clemes and Bean claim that four conditions must be present in high levels for sound selfesteem to exist. These essential conditions are a sense of connectiveness, uniqueness, power and models. The absence or diminution of one or more of these conditions will result in lowered self-esteem.

Before the conditions for high self-esteem can be discussed, a clarification of the terminology must occur. Clemes and Bean distinguish between the terms self-esteem" and "self-concept." They treat self-esteem as a feeling and self-concept as a theory or set of ideas about oneself. "Self-concept inclines children toward behavior that is consistent with their personal beliefs; selfesteem influences how these beliefs are carried into action, and whether they are at all "(Clemes and Bean, 1981, p. 24).

Therefore, they postulate that if self-esteem is low, confusion and stress impact the manner in which the child's self-concept is brought forth. This results in poor school performance and loss of motivation. Low self-esteem is seen as begetting anxiety which in turn interferes with learning. 
The first of Clemes and Bean's conditions is that of connectiveness. Connectiveness refers to the feelings of satisfaction which are derived from relating to others. Uniqueness pertains to understanding and valuing those aspects of yourself which make you different from others. Power relates to the way that you rally resources, skills and opportunities to change your life's directionality. Locus of control can be considered synonymous to power since it means that you have things in control rather than allowing yourself to be a victim of circumstances. Models are those whom you choose to emulate.

Absence of one or more of the four conditions needer for high self-esteem is called a "critical condition". Children exhibit symptoms of: repetition, intensity, and amount when a critical condition exists.

Repetition means that the behavior will persist in spite of problem response indicators. The behavior will be reused in many inappropriate situations, often resulting in unhappiness or distress for the child.

Intensity symptoms are evidenced by strong negative emotional reactions. When intensity symptomology arises, it should be easy to determine which critical condition is being overstressed through a careful analysis of the situation at hand.

The last symptom of a critical condition is one of amount. Amount refers to the number of behavioral recur- 
rences. While clemes and Bean caution against concern over the presence of any one symptom, they do recomnend careful consideration of behaviors from all symptomatic areas.

High self-valuations have been linked with many cherished and worthy personal characteristics. Sheerer (1949) says that "... One's attitudes towards others are related to a decidely significant degree to the attitudes one holds towards one's self" (Sheerer, p. 174).

Performance in the schools has a strong relationship with student self-perceptions. Burns (1979) asserts that superior student performance is directly related to more positive self-concept.

...Children who possess positive self concepts are able to make more positive and clearer appraisals of their ability to perform in the school milieu and actually produce results which are superior to those turned in by pupils with more uncertain and negative feelings about themselves (Burns, p. 279).

Erikson (1968) also decries the importance of positive self-valuations in early childhood and throughout life. He insists that a positive self view acts as an insulation against irrational low self-valuations.

In counterbalancing the inner remnants of the original inequalities of childhood, and thus weakening the dominance of the superego, a positive sense of identity permits the individual to forego irrational self-repudiation, the total prejudice against themselves which characterizes neurotics and psychotics, as well as fanatic hate of others (Erikson, p. 89). 
As this is a study designed to examine school

practices the next chapter will enlarge upon self-concept relationships with school achievement. Before an in depth discussion of the influences upon self-concept, the means for assessing levels of self-concept should be understood. The following section will summarize measurement tools which are used in self-concept research.

\section{Related Measurement Tool Research}

Writings about the self have proliferated throughout the twentieth century. The collection of empirical data pertaining to the self has not come unto itself until rather recently. At the head of the pack in the area of self-concept research were Ruhn and McPartland (1954). Their important work coordinated empirical research methodology with Mead's (1934) theory of symbolic interactionism. Quickly the floodgates were opened to a torrent of self-concept studies in both sociology and psychology. Gradually a merger between the two distinct fields of study formulated the currently predominant social psychology approach to self-concept investigation. This investigation, social psychology of the self, is possible because the self-concept is seen as a product of social experiences as well as being an actively influential social force (Rosenberg and Kaplan, 1982). 
Empirically, zeroing in on self-concept is not an easy task. One major difficulty in cross-comparing research findings within this area is the profusion of tools used in its measurement. In spite of the multitude of self-concept measures, there has been considerable difficulty predicting future behaviors using self-concept theories and state-of-the-art measures.

Self-concept research evidences a trend towards differentiation of subdivisions in the phenomenal self. Scholars distinguish between the conscious and the unconscious self. "Phenomenology" is used to describe the direct awareness of the conscious self; while "non-phenominal" is synonymous with the unconscious self perceptions, attitudes and motivations (Wylie, 1974).

Phenominal dimension theorists collect data on the self-concept through a number of different means. Measures of self-concept usually probe from one to three core areas which include the physical self, social self, and academic self. These central dimensions to self-concept measurement have evolved into the forefront of selfconcept description as a result of empirical research findings (McIntire \& Drummond, 1977; Purkey, 1970; Samuels, 1977; Wylie, 1979).

Four types of self-concept measures, or combinations thereof, have gained varying degrees of use: direct observations, behavioral trace reports, projective techni- 
ques, and self reports. Any measure must be scrutinized on the basis of validity and reliablity selecticn factors. An instrument is valid when it measures what it claims to measure, and is reliable when findings are consistent over a number of administrations (Compton, 1980).

\section{Direct Observation Report}

Direct observation reports are derived from researchers' inferences about the high or low levels of self-esteem which a person might exhibit. This form of measurement is dependent upon expressive and body langauge messages which are interpreted by the observer. As could readily be deduced, this method entails considerable guesswork and subjectivity.

\section{Behavioral Trace Reports}

Behavioral trace reports can be ex-post-facto or current. Data are collected from student files. Profiles of reported behaviors are drawn from the files. This form of measurement can readily become invalid if consistent updating of the records with objective positive and negative information should flounder. When all of the data are not reported, a skewed and nonrepresentative profile emerges.

\section{Projective Techniques}

Projective techniques use ink blots or pictures to reveal latent or covert aspects of the self-concept. Ex- 
pressed sentences (heralding from the conscious or unconscicus) are used to make inferences about the level of esteem. Possible introduction of subjectivity in the scoring of these measures should be considered and controlled for (Knapp, 1973).

\section{Self Reports}

Self reports can be the most reliable means for measuring self-concept (Knapp, 1973). Through answering questions about oneself, an overall measure of self-concept evolves.

Self reporting can give rise to the tendency for someone to withhold important information or to provide responses which are deemed to be socially acceptable. For these reasons, honest feedback and checks for consistent responses are generally built into the measure. Knapp (1973) assures testers that weaknesses in self report measures of self-concept can be dealt with in such a manner that contaminating effects on the responses are minimized. Social-desirability responses, where the respondent answers questions according to what would be considered socially acceptable answers rather than truly felt responses, can be reduced through the use of equal numbers of positive and negatively worded statements. Assuring anonymity, establishing rapport and providing a nonthreatening climate are all cited by knapp as means for bolstering the strength of self report measurement. 
Tools for self report can take four forms: $Q$ sort, Likert scales, check lists, free responses and forced choice responses (Kerlinger, 1982). Q sort self-reporting involves the sorting of cards or statements into piles or classes which best or least describe self feelings.

Likert scales list personality traits, which should have equal attitude values, expressed over a continuum of possible response choices. The respondent chooses the response which comes closest to describing personal perceptions about presence or absence of the trait from five gradually varying response options. Each choice option holds a point value. A total self-concept score is derived through summing each of the selected point values. Respondents have been known to tend towards median response options, thereby impacting the reliability of the research findings. Caution on the part of the developer in the areas of choice options and instructions can diminish the likelihood for this possibility. Check lists require the subject to mark self descriptive words or statements. Variations in the reliability of this method are dependent upon the degree of liberal descriptiveness which the respondent is willing to allow. Some respondents choose words or phrases which exactly fit self perceptions while others allow considerable latitude in their choice descriptors. 
Free responses can be projective answers to questions or open ended sentence completions. The researcher interprets or infers from the person's responses. Inferences and interpretations result in considerable subjectivity for free response measures. Cross individual comparisons are also made more difficult as responses can go off on many tangents.

Forced choice responses provide the subject with a statement and then limit response options to "yes"/"non or multiple choice answer selections. Questionnaires have gained in credibility and are increasingly used for gauging self-concept (Edwards, 1957; Rerlinger, 1982).

When utilizing the techniques advocated by Rnapp (1973), forced choice responses become a superior means for self-concept data collection. Controls for social desirability responses and equal numbers of positive and negative statements serve to tighten and refine response reliability. Using forced choice measures, data analysis across a sizeable sample can be readily carried out.

\section{Summary}

Self-concept investigations are steadily gaining in their frequency and continualiy refining the theoretical universs. A recurrent theme in the self-concept literature is the far reaching impacts of self feelings. While numerous theories have arisen in an attempt to explain 
self-concept, there is a commonality of agreement as to its importance. Influencing an individual's entire existence, self-concept is recognized as influencing interpersonal relationships, behavior, ferception, valuation and all human experiences (Cheong, 1974; Clemes \& Bean, 1981; Rosenberg, and Kaplan, 1982).

Schools have an impact upon a student's self-concept through evaluations of successes and failures. These school imposed evaluations influence self judgements of personal worth. Academic development is an integral part of the entire student's being. It is for this reason that school infuences upon a student's self-concept must not be underemphasized.

Characteristics exhibited by a child with a low self-concept have considerable implications for that student's capability to successfully interact among and benefit from school offerings. Children evidencing low selfconcepts are attributed with: poor school performance and loss of motivation (Clemes \& Bean, 1981); higher levels of anxiety which can interfere with learning (Áusubel \& Robin son, 1969; Bledsoe, 1964; Clemens \& Bean, 1981);2 feelings of confusion and stress (Clemes \& Bean, 1981); avoiding

20thers contending that high anxiety interfers with learning are: Coopersmith, 1967; Feldhusen \& Thurston, 1964; Horowitz, 1962; Many \& Many, 1975, Rosenberg, 1965; stanwyck \& Felker, 1973 all agree that high anxiety can impede learning. 
success experiences and failing to improve (Marecek \& Mettee, 1972); believing themselves to be worthless and personal failures (Kaplan, 1973); having less adeptness in dealing with conflict (Horney, 1945; Jersild, 1952); sensitivity to criticism, projecting blame, being overly critical, acting timidly and disliking competition (Burns, 1979).

Most educators readily accept the premise that the role of the schools is to perpetuate successful experiences. Low self-concepts appear to impede this process, while high self-concepts may well facilitate it. Extensive discussion of the link between self-concept and academic achievement will occur in the next chapter. It may be concluded that high self-concepts exhibit the following student attributes: self appraisals of school experiences which are more positive and clearer (Burns, 1979): feelings of power or locus of control over one's life are present and bolstered by high levels of self satisfaction (Clemes \& Bean, 1981). It is not difficult to conclude that fostering positive student self-concepts is an important concern for all educators.

Recent innovations in self-concept research measures provide a ready means for assessing the self-concepts of our students. Four varieties of self-concept measurement tools are in use today, they include: direct observations, behavioral trace reports, projective techniques and 
self reports. Self reports have some inherent weaknesses which, when dealt with properly, can be minimized. Of the types of self-concept measures, self reports lend themselves best to empirical research which addresses a population of some breadth.

Professional educators, have the self-concept theoretical rationale and empirical measurement technology at their fingertips. Too many children are not succeeding in the schools. The high drop out rates are indicative of some form of school failure. Administrators must do more than talk about concerns over the system's shortcomings in meeting the needs of all students. Further exploration of school-initiated influences upon our students' selfconcepts is essential. Having provided a literature supported rationale detailing the importance of self-concept, the next chapter will provide some intriguing evidence pertaining to the variables which research has found to exert significant influence upon a student's selfconcept. Attention to these influential variables makes possible the conceptualization of a research design which can probe the relationships between special education labeling of learning disabled students, and levels of student self-concept. 
CHAPTER II

\section{Literature Review of Self-Concept and}

\section{Labeling in the Schools}

"Self-concept inclines children toward behavior that is consistent with their personal beliefs; self esteem influences how these beliefs are carried into action and whether they are at all" (Clemes \& Bean, 1981, p. 24). Self-concept is not emotional, although it has an impact on emotions. Instead it is a thinking experience which is affected by values. Self respect and feedback from significant others collect and formulate an accumulation of ideas (Burns, 1979). This collection of ideas has the capability of setting off emotional reactions. "Reduced self-esteem leaves students feeling vulnerable and unsafe, resulting in anxiety and fear" (Faust, 1980, p. 55). Manifest anxiety has been significantly tied to negative self-concept (Âusubel \& Robinson, 1969; Bledsoe, 1964; Clemes \& Bean, 1981). In turn, mental stress and confusion have been described as inhibitors to learning. (Bledsoe and Garrison, 1962). Resultingly, children perform poorly in school and suffer a loss of motivation if self esteem is low (Clemes and Bean, 1981). 
Apart from humanistic concerns over student feelings of self-worth are research findings which significantly link students evidencing lower self-concepts with low school achievement levels (Burns, 1979; Covington \& Beery, 1976; Silvernail, 1981). "At every stage of our life our self-esteem determines how we act, how we learn, how we relate, how we feel, and how we work" (Clemes \& Bean, 1981, p. 11). As a student's self-concept influences learning, behavior, interpersonal relationships, and feelings, imposing a label which could possibly affect selfconcept is a critical administrative concern. Labeling theory has considerable base in G. H. Mead's concept of symbolic interactionism. Mead and subsequent theorists describe the self as a process. Dynamic social interaction processes are held responsible for shaping and reshaping identity and behavior. According to this school of thought, sources of labels which hold credibility, power and attractiveness are credited with having a greater potential to effect change in a person's self attitudes. "Theoretically, once children have been ... labeled, significant others will react to them as deviant individuals and they, in turn will adopt that view of themselves." (Chassim 1979, p. 1).

Positive and negative labels can vary in their impact on behaviors related to identity. Recent research 
focusing on positive and negative labels indicates that a positive label will be accepted as a part of personal identity, but does not result in behavior change. Conversely, negative labels can produce both identity and behavior changes (Moeller, 1981).

Scholars supporting a labeling theory of deviance claim that actually violating a norm in itself does not result in identity and behavior changes. Responsibility for self-concept and future behavior changes is attributed to the labeling process (Burkhead \& others, 1979; Ullman \& Krasner, 1975).

Children with low self-concepts are ascribed with characteristics such as easily frustrated, giving up early, evading responsibility, becoming wrapped up in thernselves, exhibiting high levels of anxiety, less assertive, less faith in people, more conforming and more sensitive to criticism (Burns, 1979; Coopersmith, 1967; Many \& Many, 1975 McIntyre \& Drummond 1977; Rosenberg, 1965). Low self-concept implications for successful learning experiences are tremendous. "Nothing is so critical to effective learning as a sense of self-esteem..." (Faust, 1980, p. 83). Educators need to be cognizant of whether an administrative intervention, such as special education labeling, can be significantly tied to low student selfconcept. If labeling and self-concept relationships are to be explored, the other major variables which have been 
found to exert influence upon self-concept must also be considered.

\section{Variables Exerting Influence Upon Self-Concept}

Educators who support a self-esteem theory of selfconcept assert that there is a direct and causal relationship between self-concept and academic achievement. The self-esteem theory ascribes all of a person's actions to that individual's striving for acceptance and recognition. A person's primary motivation is based upon attempts at self-enhancement. Self-est.eem advocates insist that the schools must provide educational experiences which foster and nurture positive student self-concept (Caslyn \& Kenny, 1977).

Another noteworthy perspective, that of developmental theorists, insists that self-concept variables are modified as a result of academic achievement successes or failures. Their attention is focused at the development of curriculum which meets the needs of the student and brings about successful academic achievement. These, they tell us, result in raised self-concept.

Attempting to determine "which comes first, the chicken or the egg?" Caslyn and Kenny (1977) conducted an interesting study. Using a cross-lagged panel correlation, which provides a statistical means for deriving causal inferences, they examined longitudinal self-concept 
and achievement data. Due to the lengtin of the study, previous statistical state-of-the-art limitations and self-concept variations over time, few researchers nave undertaken longitudinal studies. Caslyn and Renney interpret their findings as supporting the skill development frame of thought.

Apparently zdolescents' performance in school more often affects their self-concept of ability and their perception of others' assessment of that ability than others' perception of ability leads to changes in self-concept of ability. which in turn leads to changes in academic performance (Caslyn and Kenney, 1977, p. 142).

Brookover, Shailer and Patterson (1964) probe the interrelationships between general self-concept, academic ability self-concept and academic achievement. They conclude that a student's self-concept is a central factor in how the student performs in school. The study accredits self-concept changes with being responsible for causing performance changes. This supports the self-esteem theory. Further findings also support the contention that there is a considerable impact by significant others. Student perceptions of what significant others think are positively and significantly tied to that student's global (overall) self-concept. Global self-concept and achievement, as determined by academic grade point average, are both found to be significantly and positively related (Brookover et. al, 1964). 
A later study by Brookover, Patterson and another colleague Thomas (1965) finds student self-concept gains to affect academic performance. Through attempts to determine the causal factors found in the relationship between self-concept and academic achievement, Brookover et. al (1965) conclude that self-concept is a threshold variable which cannot be lowered below a certain point if successful learning is to occur.

Surveying research findings, Burns (1979) assumes another position regarding the argument over self-esteem or developmental theory advocacy. He takes a new middleof-the-road stance.

At the present state of knowledge it seems reasonable to assume that the relationship between self-concept and academic attainment is reciprocal, not unidirectional (Burns, p. 283).

Self-concept and Academic Achievement

Intelligence and self-concept have not proven to be highly influential upon one another. Representing but a few of many studies reporting similar findings, Coopersmith (1967) and simon and simon (1975) find no significant and positive relationship between IQ and selfconcept. Moving on to some areas where there have been findings of a substantial relationship with self-concept, academic achievement is a variable of considerable proportion. 
Academic achievement and self-concept are shown to be significantly related in a profusion of studies (Black, 1974; Bledsoe, 1964 ; Brookover, Thomas \& Patterson, 1965; Busby, Fillmer \& Smittle, 1974).3 Several aspects of self-concept and academic achievement are examined in the Iiterature. Vereen $(1980)$ reports a highly significant relationship between reading achievement and self-concept for one hundred and seventeen fifth grade students. Her sample population is comprised of low socioeconomic status subjects who are predominantly of minority group membership. Reading achievement scores are derived from the Metropolitan Achievement Test, while self-concept is measured by the Piers-Harris Children's Self-Concept Scale. In a study of fourth and fifth grade students of middle to low socioeconomic status, of whom one half were Chicano, zimmerman and Allebrand (1965) are able to significantly link poor reading ability and low feelings of self-worth. In this and numerous other studies students evidencing both low self reports and low reading achievement are described as actually avoiding achievement.

3other studies also examine the relationship between academic achievement and self-concept: Caplin, 1969; Cole, 1974; Combs, 1964; Coopersmith, 1959; Fink 1962; Gordon, 1977; Leviton, 1975; McIntyre \& Drummond, 1977; Primávera, Simon \& Primavera, 1974; Purkey, 1970; Rogers, Smith \& Coleman, 1978; Roth, 1959; Samuels, 1977; Sears, 1970; Simon \& Simon, 1975; Smith, Zingale \& Coleman, 1978; Strong, Smith, \& Rogers, 1978; Vereen, 1980; Williams \& Cole, 1968; Zimmerman \& Allebrand, 1965. 
In the investigation of the self-concepts of underachieving students as compared to the self-concepts of students achieving at or above grade level, repeatedly low self-concept and underachievement are significantly related (Combs, 1964; Fink, 1962; Simon and Simon, 1975; Zimmerman \& Allebrand, 1965).

Attempting to explain the intricate relationship between low self-concept and academic underachievement, $\mathrm{Z}$ immerman and Allebrand (1965) attribute student underachievement to success avoidance tactics. Students evidencing low levels of reading success are described as not feeling positively ahout themselves. Zimmerman and Allebrand propose that in order to avoid failure, low achievers will refuse to even try. They explain that the student's refusal to perform a task is less threatening than trying to perform the task and not succeeding. Going further, zimmerman and Allebrand tell us that their sample of fourth and fifth grade poor readers described feelings of anxiety, inadequacy and discouragement. Good readers of the same age recounted feelings of adjustment and motivation to successfully achieve.

Examining the effects of failure produced stress on the self-concepts and intellectual productivity of seventh grade students, Gibby and Gibby (1967) set forth some thought provoking findings. When a group of sixty students, who were academically superior, were given 
falsified test results indicating that they had failed the test, these capable students became less effective in their subsequent performance. As a part of this study, student perceptions of failure are documented in the areas of self perception, perceptions of relationships with significant others, and academic productivity. Through the lowering of reading expectation levels for low achieving readers, Cohn and Rornelly (1970) report improvement in student self-concept scores. Justifiable concerns arise over the lowering of expectancies. It is not an easy task for a pedagogue to retain that crucial element of challenge so that a student will be motivated to work to potential and yet rot pass beys. into that realm of frustration which begets lowered self perceptions of academic capability. Achievement's essential cornerstone is an individual's self perception that successful achievement is readily possible (Van Koughnett \& Smith, $1969)$.

In a study designed to probe self-concept and school achievement interrelationships, Brookover, Shailer and Patterson (1964) find significant correlations between student responses about their self perceptions of ability and use of these self-concept scores to predict grade point averages. Other studies also utilize measures of self-concept ability to effectively predict student grade point average. Studies of high school and college 
students by Jones and Strowic (1968) and Jones and

Grieneeks (1970) found self perception measures, when compared to the predictability of aptitude and intelligence measures, to be superior predictors of grade point average.

Brookover, Erikson and Joiner (1967) propose that A positive self concept of ability is only a necessary, but not sufficient condition for achievement... Although a significant proportion of students with high self-concepts of ability achieved at a relatively lower level, practically none of the students with lower (less positive) self-concepts of ability achieved at a high level (Brookover, Erikson \& Joiner, p. 142-3).

While an overwhelming preponderance of research findings support the conclusion that a strong and significant relationship exists between self-concept and achievement, there are a few studies which have been unable to reach a similar conclusion (Leviton \& Kiraly, 1975; Marx \& Winne, 1975; Wattenberg \& Clifford, 1964; and Williams, 1973).

Some research findings do not support contentions of significant correlations between self-concept and academic achievement. Williams (1973) investigates reading and self-concept interrelationships for one hundred thirtythree first grade students. Using an adapted form of the Coopersmith SEI (Self-Esteem Inventory), Williams was 
unable to find significant correlations between selfconcept and reading achievement on the California Achievement Test. He surmises that two possible variables might serve as confounding influences upon the study's results: (1) stable self-concepts might only occur in children older than those found in the first grade, therefore self-concept fluctuations for these younger children could be responsible for the nonsignificant research findings; (2) as the SEI was adapted for use with younger subjects, its sensitivity to self-concept variations for the sample could be impaired.

Studying a group of primarily Black fifth and sixth grade students of low socioeconomic status, Marx and Winne (1975) compare self-concept and academic achievement scores. For the ninety-eight subjects studied, the sears Self-Concept Inventory and Stanford Achievement Test score comparisons do not net significant correlations.

Attempting to untangle the causal relationships for high or low student self-concepts, a number of important variables have been addressed and readdressed by the existant research. While some studies explore two and three variable interactions, others embark upon highly sophisticated analyses of multivariable combinations and interactions. A review of the literature relating to the variables which might exert an influence upon a regular 
student's self-concept appears to yield a sizeable number of variables. Whether studied singularly or as part of a multiple variable analysis which is examined in combination with self-concept, the following variables are cited as exerting the most influence upon the self-concept of a regular student: achievement, age/grade, sex, minority group membership, socioeconomic status, place in family, and significant others. As achievement interactions with self-concept have already been explored, the task remains to overview the six remaining variables' representation in the literature.

\section{Grade/Age}

It is appropriate to begin a consideration of variables which might exert an influence upon self-concept by looking at age. Widespread theoretical arguments pertaining to self-concept crystalization (or lack of $i t$ ) over time preclude the necessity to consider age (Erikson, 1968; Rosenberg, 1979; Rosenberg \& Raplan; 1982; Silvernail, 1981).

A number of studies and theoretical writings recount age influences upon self-concept and achievement (Bledsoe, 1962; Bohan, 1973; Coleman et. al, 1966).4 It must be re-

\footnotetext{
A Age has also been cited as influencing self-concept by: Grant, 1969; Long, Henderson \& Ziller, 1967; Piers \& Harris, 1964; Rosenberg, 1979; and Trowbridge, 1972.
} 
marked that not all of these research findings are positive and highly significant, but they do tend to be significant to varying degrees.

Piers and Harris $(1964)$ report significantly lower mean self-concept scores for sixth grade students as compared to scores for fourth grade students. Coleman et. al (1966) describe a widening achievement and self-concept gap between low and high achievers as they pass through school.

other studies imply minimal age influences upon self-concept (Burns 1979; Chang, 1975; Coleman, 1974). A study by coleman (1974) finds adolescents to have steady self-concepts. He suggests that in spite of the identity problems which some adolescents experience, this is not the case for all young people. Coleman concludes that identity is comprised of two dimensions (1) the present and (2) the future. Identity conflicts which increase with age are related to future identity. This becomes an explanation for self-concept shifts which might occur in some youth. "Most general self-concept studies tend to suggest that the self-concept is stable from pre-adolescence onwards" (Burns, 1979, p. 284).

As can be readily seen, concensus as to age influences is not reached in the literature. Therefore, this is an important variable for consideration. 
Sex

Sex role identity is central to self-concept development. This concept is not challenged. What is questioned is whether self-concept scores vary between the sexes. Purkey (1970) suggests that "sex differences do seem to influence the relationshp between the self and achievement, primarily in the area of underachievement" (Purkey, p. 15). He found low achieving male students to have lower self-concepts than underachieving female students.

Many studies mirror Purkey's findings of sex variations in self-concept (Bohan, 1973; Connell, Stroobant, Sinclair, Connell \& Rogers, 1975; Coopersmith, 1967).5 Only two studies were found which refute the sex differences for self-concept scores that are repeatedly described in the literature (Chang, 1975; and Primavera, Simon \& Primavera, 1974).

Investigating the influence of sex differences upon the ties between self-esteem and academic achievement, Primavera, Simon and Primavera (1974) studied one hundred and eighty students having a mean age of eleven years old. They report significant correlations between overall

${ }^{5}$ Sex impacts upon self-concept are also described by: Erdwins, Small \& Gross, 1980; Maccoby \& Jacklin, 1974; Purkey, 1970; Stryker, (1982). 
academic achievement and self-concept for their female sample, but findings for the males are considerably less conclusive. Boys have significant correlations for cnly math achievement scores and self-esteem scores. Though their findings support significant self-esteem and math achievement correlations for both sexes, overall academic achievement for boys is missing. In spite of the sex differences described, between group sex correlational comparisons are not at significant levels.

As but two of the surveyed studies are resistent to the position that sex does play a part in self-concept measurement, the obvious implication is that it must be considered an important variable. Any study hoping to determine variable relationships should contend with the sex variable.

\section{Minority Group Membership}

Minority status and low self-concept have been paired in the literature as far back as Lewin's (1948) writings. Supported by the landmark supreme court case decision set forth in Brown vs the Topeka Board of Education (1954), the notion that separate is not equal education has served as a springboard to extensive race related research. In an effort to determine segregation effects on the self-concepts of black children, many research studies have mushroomed on the scene. A number of 
researchers report that olack and other minority children have lower self-concepts than their same-aged white peers (Āsher \& Allen, 1969; Chang, 1975; Gabbler \& Gibby, 1967),6 Burns (1979) and Silvernail's (1981) writings reassert the contention that self-concept scores do show across racial group variations.

In an attempt to explain self-concept variations across racial groups, Erickson (1968) declared that everyone has a psychosocial identity which includes both positive and negative components.

The individual belonging to an oppressed and exploited minority, which is aware of the dominant cultural ideals, but prevented from emulating them is apt to fuse the negative images held up to him by the dominant majority with the negative identity cultivated in his own group (Erikson, p. 303).

Evidence in two studies seems to indicate that a black pupil's self-esteem increases as the ratio of black to white students rises within the school (Coleman et. al, 1966, Soares \& Soares, 1971). Both educationally and politically, "the Coleman Report" (1966) is responsible for initiating many changes. In a far-reaching national study, Coleman et. al. report finding that as the ratio of white to black students increases, there is a substantial

6 Race and self-concept interactions are further examined by: Goodman, 1952; Hawk, 1957; Lewin, 1948; Marx \& Winne, 1975; Peterson \& Ramirez, 1971; Porter, 1971; Proshansky \& Newton, 1968; Rosenberg \& Simmons, 1973; Soars \& Soars, 1971; Stryker, 1982. 
decrease in the academic self-concepts of black students. These findings are particularly noteworthy in view of the fact that black students attending predominantly white schools have higher achievement scores than those of black students in predominantly black schools. What we find here are black students from predominantly black schools who have lower achievement scores but higher self-concept scores than their black counterparts in primarily white schools. Thus, "the Coleman Report" targets a raciallybased discrepancy in achievement predictions related to self-concept. Self-concept, used as a means for predicting student achievement, has proven to be a weak predictor for black children and a strong predictor for white children.

A study conducted by Soares and Soares (1971) reports higher self-esteem for disadvantaged boys who are black. White boys with low socioeconomic status have significantly lower self-esteem than their black peers. Overall, disadvantaged boys have significantly higher self perceptions than those of disadvantaged girls. Contrary findings are evidenced for advantaged students. In this study, advantaged girls have significantly more positive self perceptions than their advantaged male counterparts. Some more recent studies seem to indicate that the self-concepts of minority children are presently not so 
low as previous research would have us believe (Caplin, 1969; Carpenter \& Busse, 1969, Cicirelli, 1977). 7 Capiin's (i969) study of low socioeconomic black and white intermediate grade students is one such study. Probing selfconcept via student completions of unfinished sentences, no significant between race differences are found for personal/social item responses.

A review of the literature suggests enough variations in research findings to justify researchers' attempts to control for the minority group membership variable. When attempting to examine important self-concept interrelationships, as many potentially confounding variables as possible must be controlled.

It is probably indisputable that race and socioeconomic level are variables that can affect self-esteem when mediated by negative social attitudes (Morse \& Piers, 1973, p. 7).

5 Minority children's self-concept findings are also explored by: Fox \& Barnes, 1971; Hurstfeld, 1978; Linton, 1972; McAdoo, 1976; Morse \& Piers, 1973; Rosenberg \& Simmons, 1971; Siswein, 1970; and Ward \& Braun, 1972. 


\section{$\underline{\text { Socioeconomic Status }}$}

Any theory of self-concept which recognizes an effect on self perceptions resulting from social interactions should consider the possible ramifications of social group membership. Tying self-concept to the levels of respect attributed by society is not theoretically difficult. It seems sensible to go one step further and inquire into whether different socioeconomic status does have the capability of exerting a significant influence upon self-concept.

In an analysis of the interrelationship effects of socioeconomic status and self-esteem, Clements, Peck and Green (1978) recount a direct tie between high pupil socioeconomic status and high self-esteem. Their results show self-esteem to be a significant predictor of school achievement. Students with high self-esteem indicated gains in school achievement. A reciprocal relationship is evidenced wherein students experiencing high achievement levels show increased self-esteem.

Another study by Linton (1972) describes similar self-concept and socioeconomic interactions. Anglo and Mexican American sixth grade students of both sexes are examined for differences on academic and global selfconcept. While ethnic background and sex do not significantly correlate with self-concept, socioeconomic status 
is found to be a significant variable. High socioeconomic status is shown to be closely associated with high selfconcept, while low socioeconomic status is linked with low self-concept for both ethnic groups. Mexican-American students with middle socioeconomic status have similar self-concept scores to those of low socioeconomic status Mexican-American and Anglo students.

A significant number of studies probing socioeconomic status (SES) and self-concept describe a strong relationship between high self-concept and high SES (Clements, Peck \& Green, 1978; Linton, 1972; Proshansky \& Newton, 1968; Rosenberg, 1979).8 Only one source surveyed in this review minimizes the importance of socioeconomic status in younger children (Rosenberg \& Pearlin, 1982). Rosenberg and Pearlin distinguish between children and adults in their work on socioeconomic status (SES) and self-concept. They assure us that children are not so vulnerable to ses influences since most of the child's elementary school peers come from similar social and economic backgrounds. Rather, Rosenberg and Pearlin detail compelling arguments for the rise of SES influences

${ }^{8}$ Socioeconomic status and varying levels of selfconcept can be further researched through examination of the following authors' works: Samuels, 1977; Silvernail, 1981; Stryker in Rosenberg \& Kaplan (Ed.), 1982; Trowbridge, 1972). 
in middle and high schools. Here a more heterogeneous SES sampling is probably due to serving larger geographical areas than the traditional neighborhood elementary schools.

If SES is not a psychologically central trait which is valued by the student, then it should not have an impact upon self-esteem. Rosenberg and Pearlin (1982) argue that high SES is probably more important to adults since adults have a locus of control over the presence or lack of economic successes and are exposed to people from high SES groups through their jobs. Even if SES influences upon students' self perceptions might not be psychologically central, this variable's potential influences should not be dismissed without examination.

\section{Place in Family}

of the literature surveyed for this study, the child's place in the birth order of siblings does not receive extensive attention. This is not to say that more scholars do not speak to this subject in other writings in the more than four thousand sources on self-concept. It merely means that in this substantial review of the literature, place in family is only occasionally mentioned (Coopersmith, 1967; McDaniel, Ball \& Fortunato, 1978; and McIntire \& Drummond, 1977; and Sears, 1970). Generally, place in family is credited with being a confounding vari- 
able which has not been addressed in studies that result in statistically nonsignificant self-concept findings. Coopersmith (1967) Patterson and Sechrest (1970) describe a significant relationship between self-concept and the child's place in the family with oldest children exhibiting higher self-concepts.

\section{Significant Others}

Repeatedly, the self-concept literature emphasizes the influence of significant others upon an individual's selfconcept. Significant others are persons of importance whose opinions and actions exert some influence upon another individual's self perceptions. The role of significant others in the child's immediate environment is to provide reinforcements to behaviors (Soares \& Soares, 1972).

Envirommental feedback has its largest impact when it is from significant others (Soares \& Soares, 1972). The infant seeks acceptance and love from significant others. Security and satisfaction are by products of relationships with significant others. The role of these significant persons continues in spite of social environment expansions. Significant others shape self-concept through conveying their impressions by means of expressive and body lanquaqe (Gordon, 1958; Wylie, 1961; and Yamamoto, 1972). Three subgroups of a child's significant others include: parents, peers and teachers. 
Parents. Numerous studies confirm claims that parents exercise a highly important influence upon their child's self-concept (Silvernail, 1981). As early childhood years are primarily spent with family in the home, parental influences are indeed highly important to the child's self-concept.

studies which are the most successful in isolating statistically significant child-rearing influences on self-concept are those probing parental accepting and rejecting practices in the home. Stott (1939) and Behrens (1954) both find children from homes with accepting parents to have higher self-concepts.

Coopersmith (1967) demonstrates that children with lower self-ratings herald from home environments having low levels of warmth, supportiveness, encouragement and love. Warm accepting parental practices are significantly related to higher level self-esteem for their children. It is also interesting to note that the same study shows parental insistence upon well defined behavior standards and rules as resulting in higher child self-esteem. Highly controling mothers exhibit low levels of nurturing and supportivness which often results in children who are less capable of dealing with situational school demands. It appears that a parent should be nurturing and supportive, as well as actively striving to enforce clearly defined 
parameters of performance expectation for the child. Parents using positive feedback to convey approval and guidance should also make clear their expectations for success.

Pulling a conside:able body of data together, Coopersmith (1967) lists three family conditions which must be present for a child to develop feelings of self worth: parental warmth, respectful treatment and clearly defined limits. Parental warmth is necessary to foster feelings of being loved and valued. The child's views and feelings must be considered if respectful parental treatment is to occur. Finally, parental expectations for success should be clearly defined and consistently enforced, thereby enabling the child to understand what is expected. A study of eleven year olds by sears (1970) reaffirms the positive relationship between a child's self-concept, parental warmth and acceptance.

Samuels (1977), Dickstein and Posner (1978) agree in their findings that high self-concept correlates positiveIy with good parental relationships. Dickstein and Posner emphasize the importance of role modeling. They report that boys having close father-son relationships and girls who have close mother-daughter relationsios generally have high levels of self-esteem. Studying a small sample of forty-two children ranging in age from eight to eleven years old, Dickstein and Posner stress the importance 
of parent/child closeness in determining levels of child self-esteem.

Peers. Proposing a theory of social comparison, Festinger (1954) describes the tendency to utilize feedback from significant others as a means for shaping self perceptions. Coopersmith (1967) sets forth the proposition that self evaluations are more highly influenced by group norms than personal norms. A school classroom has group norms which can quickly come to bear considerable pressure upon the student.

"The child compares his/her own level of achievement to the achievement levels of others in the classroom, and to the extent that the results of such a comparison are favorable, his or her self-concept is enhanced, but if the comparison is unfavorable, his or her selfconcept may be diminished" (Rogers, Smith \& Coleman, 1978, p. 56).

Mannarino (1976) examines preadolescent peer relationships and their influence upon self-concept. Controlling for $I Q$, he finds students having a special chum or buddy to have higher self-concept scores on the Piers-Harris Self-Concept Scale. While these are interesting findings, too many variables which might influence self-concept go unaddressed in this study. Teachers. As a result of their heavily evaluative component, schools become one of a child's primary sources for attaining approval. School influences upon self-concepts can rival home influences. 


\begin{abstract}
"It is reasonable to assume that for many young people school is second only to the home as an institution which determines the growing individual's concept of himself and his attitudes of self acceptance or self rejection" (Jersild, i952, p. 90).
\end{abstract}

The student strives for success in the school setting and receives extrinsic approval when the teacher evaluates those efforts favorably. Once student dependence upon outside means such as teacher praise and high grades is established, those ties between school evaluated student ability and student perceptions of self worth become stronger. When the student must conform to standards set by both teachers and classroom peer groups, there is a loss of control over that student's own learnina. This loss of control can erode feelings of self regard when the extrinsically set standards for success are not achieved by the student. "All too often, schools are places where students face failure, rejection, and daily reminders of their limitations" (Purkey, 1970, p. 40). It is not surprising when a repeated message of school failure is tied to a modified self-esteem.

"From eight years of age confidence wanes as
school ceases to be a secure supporting place. A
sense of personal failure is constantly communi-
cated to many youngsters; self-esteem is dis-
couraged rather than enhanced" (Burns, p. 184).

Jersild (1952) echos the thoughts of purkey and Burns. "The learner's life at school is heavily invested with success and failure, pride and shame" (Jersild, 1952, p. 7). 
Those sentiments presented above are repeatedly

found within th: 1iterature. There is indeed the poten-

tial for redeeming the educational experience in terms of fostering positive self-concepts within our students.

"The development of a sense of inferiority, the feeling that one will never be "any good," is a danger which can be minimized by a teacher who knows how to emphasize what a child can do..." (Erikson, 1968, p. 125).

Burns (1979) agrees with Erikson over the degree of influence which a teacher can exert. He attributes increasing levels of significant others' importance to teachers.

Teachers and peer groups begin to replace parents as a major source of self information. With their aura of expertise, authority and evaluation, teachers are 'significant others' who feed the pupils' self-concepts with a menu of positive, neutral and negative reinforcement, and create an ethos in the relationship which may enhance or debase academic Derformance" (Burns, 1979, p. 276).

Looking into the relationsip between student selfconcept scores, teacher self-concept ratings of the student, and student achievement levels, Chang (1975) studied a sample of almost two hundred students from the fourth through the sixth grades. Her findings show a significant relationship between student reports of self-concept and teacher self-concept ratings of the stuo'ent. In this study, teacher ratings of their student's self-concepts are also significantly correlated to the students' academic achievement. 
Another study where teachers rated students tells us that second grade students whose teachers describe as disruptive in the classroom are found to have lower selfesteem. Level and stability of student self-esteem are positively related to both achievement and accuracy in self ranking of reading ability (Kugle and clements, $1980)$

In a study providing further information in the area of teacher influences upon their student's self perceptions, Davidson and Lang (1960) recount findings of positive correlations between student discerned feelings about themselves and self-esteem levels. A significant relationship between positive student perceptions of teacher feelings, higher academic achievement, and teacher desired classroom behaviors is also statistically evidenced. Similar findings are reported by Brookover, Erikson and Joiner $(1967)$.

Primary student perceptions of their teachers' feelings towards them are found to be positively tied to student self perceptions and academic achievement by Davidson and Lang (1960). Students describing their teachers as being supportive show higher self-concept scores and higher levels of academic achievement. Davidson and Lang believe that these younger students are quite skilled in evaluating how their teachers feel about them. 
Kleinfeld (1972) reports some interesting findings in her research pertaining to significant others' impacts on self-concept. Racial group membership and sex tend to mark a distinction between group findings. Black female students, who are in high school, report significant selfconcept influences resulting from teacher perceived evaluations. This finding is not the case for white high school students. For white students, parentally perceived evaluations are more closely linked to academic self-concept than teacher perceived evaluations. The Brookover studies (1965\&1967) describe similar correlations for white students. Contradicting the previously described studies, O'Connor (1978) finds no significant correlation between student perceptions of how their teachers feel about them and the student's self perceptions. In this group of fourth through sixth grade students, an exception is noted relative to the recurrent theme represented within the literature. Some additional studies examining teacher/ self-concept interactions are of interest. Confident, well-adjusted teachers with high self-concepts tend to have students who exhibit high self-concepts $10^{\prime}$ Connor, 1978 ; and Samuels, 1977).

"... Children who lack positive self-concepts to begin with undoubtedly can be damaged by destructive teacher behaviors since already-existent negative self-feelings would be reinforced" (Samuels, p. 103). 
The literature does not yield a clear statement, which is also data based, regarding whether teachers or parents should be considered the most important significant other for school-aged children. Smith (1980) tells us that "The clear implication is that how children feel about themselves is a function not simply of how well they perform, but of how well they perform relative to significant others" (Smith, p. 21). What is obvious to a researcher without much serious investigation is the highly important role that significant others play in the shaping of self feelings. Any self-concept research should consider significant others as an important variable. ... The individual comes to respond to himself and develop self attitudes consistent with those expressed by others in his world. He values himself as they value him; he demeans himself to the extent that they reject, ignore or demean him (Burns, 1979, p. 16).

Self-fulfilling prophecy. Once some concensus has been reached as to whether teachers can be considered significant others to their students the next natural step is to examine whether teachers' attitudes do indeed exert some influence upon their students. Self-fulfillinq prophecy is a term which describes the belief that teacher expectations for student behaviors can influence how well that student will perform in school.

Of course the classic study of self-fulfilling prophecy is the study by Rosenthal and Jacobson (1968). 
This piece of research marks the onset of a myriad of studies probing student performance responses to teacher expectations. In the Rosenthal and Jacobson study, teachers were told that their students would experience intellectual growth spurts. No concrete facts supported these researcher claims that IQ (intelligence quotient) gains would occur. The fact of the matter is that the study sample of students was in reality randomly chosen from the school population at large. Therefore, the researchers' introduced claims of IQ spurt expectations were totally unfounded. What does become fact are the findings of this study. The researcher-introduced claims actually do occur. Rosenthal and Jacobson attribute this IQ growth spurt effect to teacher initiated selffulfilling prophecy. Student IQ performance gains are credited to teacher introduced behavior expectations for their students. "... reacher's favorable expectations can be responsible for gains in their pupils' IQs and grades..." (Rosenthal and Jacobson, 1968, p. 98). The technical quality of the Rosenthal and Jacobson self-fulfilling prophecy research has not gone unchallenged (Elashoff \& Snow, 1971; MacMillan, Jones and Aloia, 1974; Thorndyke, 1968). These concerns are based upon the widespread unquestioning acceptance of the self-fulfilling prophecy theory when there have been some contradictory research findings (Claiborn, 1969; Evans \& Rosenthal, 1969; and Jose, 1971). 
Elashoff and Snow (1971) tell us that the Rosenthal and Jacobson reporting of design, data, and data analysis are lacking in detail and abounding in over-simplification. They claim that IQ charges are not significant since the P-value doesn't tell hor close the true difference is to the observed difference. Significance in the Rosenthal and Jacobson study is thus written off as a result of interactions between sample size and statistical treatment effects.

Rosenthal and Rubin (1971) are quick to rebut the Elashoff and snow allegations. They retort that an "imbalance in sample size has nothing to do with randomization or the ability to obtain unbiased estimates..." (Rosenthal \& Rubin, p. 4). Additionally, they question the validity of the Claiborn (1969) study as an argument against self-fulfilling prophecy. Rosenthal and Rubin call attention to the fact that Elaihoff and snow (1971) do not clearly present the fact that two thirds of the Claiborn (1969) study's teachers were aware of the experiment's intent and thus could bias its rindings. Fressing their arguments further, Rosenthal and Rubin refer the serious scholar to the many studies which indeed show significant teacher expectancy effects which confirm their self-fulfilling prophecy contention. A few of these studies are cited here (Beez, 1968; Meichenbaum, Bowers \& Ross, 1969; Palardy, 1969; Samuels, 1977). 
Agreement that teacher expectations do influence study achievement outcomes is voiced by Palardy (1969). Investigating sex related teacher expectations for their students, Palardy reports that teachers who hold no preconceived notions of higher achievement for boys or girls, at the end of the year have no differences between sexes on reading achievement scores. Teachers having prejudged expectations that boys will have lower levels of reading success than girls, actually find year-end reading results which show boys to have lower reading achievement levels. Purkey $(1970)$ is resolute in his position that a self-fulfilling prophecy effect does actively exist within the schools. Self-fulfilling prophecy is credited with influencing both student achievement and self-concept. "...The teacher's attitudes and opinions regarding his students have a significant influence on their success in school" (Purkey, p. 47). "Frevention of negative selfconcepts is a vital first step in teaching" (Purkey, D. 43).

If as the literature suggests, significant others do considerably impact self-concept, and self-concept interacts with school achievement, then teachers' attitudes and feedback are capable of influencing how a student does and feels in school. Brophy and Good (1975) are concerned over the variations in the levels of teacher feedback to their students. Through examination of the numbers of 
teacher feedback responses to students, Brophy and Good found low achieving students to be the recipients of significantly less teacher feedback than high achieving students. The same findings are announced by Rerman (1979).

Rowe (in Samuels, 1977) reports that the time which teachers wait for student responses varies between groups of high and low achieving students. Teachers wait significantly longer for high achieving student responses than for their low achieving peers. Following a teacher training intervention, Rowe tells us that when teachers increased their waiting time for student responses, low achieving students responded more often. It becomes a rather frightening thought to consider what effects conscious and unconscious teacher messages and expectations can bring about.

Myers and Ridle (1981) believe that teacher preconceptions are self-perpetuating and resist ciear cut evidence that they are mistaken. Describing labeling influences upon gifted students and their teachers, Myers and Ridle subscribe to the self-fulfilling prophecy theory. They claim that social labeling assumptions cause individuals to assume roles which are thrust upon them by others. "...social labels can create their own reality" (Myers \& Ridle, p. 30). 


\section{Labeling Theory and Research}

A natural extension from preconceived teacher expectations is the concern over stereotypical treatment of students on the basis of their group membership. If teachers have already established expectations for persons who are members of certain groups (i.e., boys/girls, high achievers/low achievers; minority student/white students, special education students/regular students) then they are guilty of stereotyping. As we are now aware of what preconceived teacher notions can bring about, an investigation of stereotypical treatment due to group labeling seems highly important.

\section{Labeling Theory}

The term "stereotyping" has long been used in the literature to emphasize discriminatory practices against racial/ethnic minorities and women (Allport, 1955). stereotyping is a pervasive reaction to (and ireatment of) others on the basis of their group membership. Mental pictures of what people from a particular group are like become more important than what the labeled individual is really like. Treating others on the basis of stereotypical views is a continuous, everyday occurance. A theory of social interrelationships, "symbolic inter- 
actionism," has arisen in the wake of daily stereotyping. Symbolic interactionism describes the continual social typing of oneself and others (Schur, 1971). Both labeling and stereotyping fall within the parameters of symbolic interactionism.

Stereotyping equips others with a comfortable means for dealing with persons who have been labeled. "Stereotyping can serve at all levels, to instigate or propel mechanisms of self-fulfilling prophecy..." (Schur, p. 52). "Labeling automatically implies a discrimination process" (Porter, 1971, p. 231).

Social labeling is one aspect of the social identity component found within the self-concept (Rosenberg, 1979). Labels which are imposed by society can give rise to modified self-concept.

"When the language of verbs becomes the language of nouns, either through formal certification procedures or general social recognition, the labeling process occurs, and produces additional elements of social identity" (Rosenberg, p. 10).

ullman and Krasner (1975) contend that labels influence the behaviors of those who are labeled as well as reactions to these individuals by others. When a label is used, others narrow their perceptions of that person to the parameters encompassed by the label. They explain that rather than seeing and responding to a whole person, others stereotype and respond in terms of the label. 
Stryker (1982) shares in the concern that social identity.labels are more than merely classifying someone. "People so labeled are treated differently by others, are subjected to different social expectations, are socialized in different ways and have different opportunities -- in short, undergo different life experiences" (stryker, 1982, p. 210). How can all of these levels of personal influence possibly be tossed aside as potentially impacting self-concept? Stryker as.erts that they do indeed take part in shaping the self-concept.

Bem (1972) and Toner (1979) agree that individuals do modify behaviors to conform with imposed labels. "The labeler often brings about compliance with the label by altering his/her interactions with the labeled person" (Toner, 1979, p. 2).

\section{Labeling Theory of Deviance}

Considerable artention in the Iiterature is addressed to the labeling theory of deviance. As the literature on labeling is not terribly extensive, deviance labeling provides more issues requiring careful scrutiny. This portion of labeling theory is a response to legal and medical profession attempts at discerning deviance causalities. "The labeling school asserts that deviance outcomes reflect complex processes of action and reaction, of response and counter responsen (Schur, 1971, p. 11). 
Jones (1972) is concerned that labels have been used too indiscriminantly.

Insufficient attention has been given to the fact that some of the labels used to imply deficiencies and shortcomings...generate attendant problems of lowered self-concept and expectations which interfere with children's optimum growth and development (Jones, 1972, p. 553).

Others are also concerned over labeling impacts which can intrude upon the self. "Theoretically, once children have been so labeled, significant others in their environment will react to them as deviant individuals and they, in turn, will adopt that view of themselves" (Chassim, et. al, 1979, p. 1). Deviancy theorists attribute considerable credence to the power exercised by significant others as compared to the power held by the deviantly labeled individual. Persons or groups with power impose their expectations upon low power individual or group targets. As those in power are the ones who set the rules and issue the labels, what is left is the low power labeling target's need to conform and be "normal". This need is accompanied by considerable internal turmoil over the shaping and reshaping of the labeling target's identity (Becker, 1963).

Power groups or individuals can represent a broad range of relationships. Parents, teachers, doctors, judges etc. can be authority figures of power. Another form of power is societal power. Societal power based on racial, sexual and age difference favoritism is derived from current social norms (Scheff, 1975). 
Processes of social definition, or labeling, that contribute to deviance outcomes are actually found on at least three levels of social action... collective rule making, interpersonal reactions, and organizational processing...' (Schur, 1971, p. 11 ).

When someone violates a socially defined norm, "the group responds by setting in motion rule enforcing machanisms, essential to which is labeling the individual" (Moeller, 1981, p. 3). This thought is expanded upon by Lemert $(1972)$.

Normalization, or conversely, assigning deviant meaning to actions, takes place in informal interaction or through formal agencies of social control. Agencies and agents of social control, actively seeking to advance or defend their values, define deviation and also assign deviant acts to individuals (Lemert, 1972, p. 61).

A social-psychological theory of delinquent behavior proposes that antisocial behaviors are initiated as eqo defense mechanisms (Matza, 1969). "Delinquent behavior, particularly disruptive behavior in school, is a defense against self-derogation" (Gold, 1982, p. 441).

Disruptive school behaviors are carried out by the student in an effort to entertain peers and to earn their approval. Additionally, disruptive behavior provides a tool for conveying a message. "It defies the exercise of authority over both deportment and standards for scholastic achievement, devalues the devaluations, and rejects the devaluators" (Cohen, 1982, p. \$42). 
Mahoney (1974) maintains that current studies which examine deviant labeling effects on juvenile delinquents' behaviors are not as empirically defendable as would be desired. Rather, they evidence many methodological weaknesses. She acknowledges that a number of studies are consistent in showing that "..official labeling leads to a change in the self-image of some adolescents." (Mahoney, p. 608).

\section{Labeling Research}

Labeling research within the regular school arena is limited. Moeller (1981) investigates the effects of labeling on self-esteem for sixty-six college students. Subjects completed the Tennessee Self-concept Scale and an Adjective Checklist before and after the intervention of a randomly assigned "dependable" or "undependable" label. His findings indicated a significant difference in subject self-description between those who were labeled positively as opposed to those who were negatively labeled. No significant self-esteem and behavior effects were found as a result of this labeling activity. It should be mentioned that the intent of Moeller's study was to look at the immediate impacts of labeling. Long term labeling effects which might evolve over a year or longer cannot be accounted for in this research. 
Chassim et. al, (1979) point out that a central component to labeling theory is whether or not the stereotypical role of the label is assumed by the subject or not. Role engulfment occurs when an individual accepts and internalizes other's definitions.

The fact that individuals may reject their labels or identify with relatively positive versions of their labels suggests that the impact of deviant labeling processes on self-concept and behavior may not be as negative as previously hypothesized (Chassim, et. al, p. 3 ).

A principal of psychological centrality for labeling theory is set forth by Rosenberg and Raplan (1982). Central self-concept components are highly important to the individual, therefore if a component such as doing well in school is psychologically central to a student, then labels affecting his self views about this self-concept component have considerable importance to him. Dependent upon the centrality or peripherality of the self-concept component which the label influences, the individual's feelings of self worth respectively may or may not be affected. (Rosenberg and Raplan, p. 177). According to the self consistency theory of self-concept, low self evaluators should more readily assume a negative label as this would reinforce central self images. The degree of label acceptance or rejection can influence the extent of selfconcept intervention resulting from the labeling process (MacMillan \& Jones, 1972). 
Suzanne Faust (in V. Faust, 1980) conducted a labeling study which describes findings that lend further credibility to the school of thought supporting self-fulfilling prophecy. A control and experimental group of sixth grade students were administered the same reading comprehension test. Scores for both groups should have been almost perfect.

Test instructions were the same for both groups. The experimental group had some additional information before the test. They were told that excellent students rarely miss any questions, while average students usually miss two questions, and poor students generally miss three or four questions.

Research results show nine out of every ten control students to have scores of 808 or higher. The experimental group seems to have held preconceived self images as to whether they were excellent, average, or poor students since the labels which they gave themselves before the testing actually do hold true in the score levels which they earn.

The majority of the few labeling studies using regular class students were conducted to examine teacher attitudes. Looking into the influence of labeling upon teacher attitudes, Smith and Greenberg (1975) reported some interesting findings. In their study, nine student profiles were presented to 288 teachers. These student 
profiles included information on school performance, social class and outside school behavior. Every sketch was about a male student and had identical IQ and achievement data. Through the use of a questionnaire to elicit teacher responses, Smith and Greenberg found that social class membership does indeed influence teachers' views of student behaviors occuring outside of the school.

In addition to social class labeling infuences upon teacher expectations, racial and ethnic labels are also shown to impact teacher expectancies (Jackson \& Cosca, 1974; Leacock, 1969; and Zucker \& Prieto, 1977). Schrank (1970) assures us that labeling does influence both teacher and student role expectations. According to Schrank, not only are role expectations influenced, teachers and students react on the basis of these stereotypical label expectations.

For those children whose educability is in doubt there is a label... they appear not to be able to learn as do those who are more advantaged... Quite inseparable from these differences between the advantaged and disadvantaged are the differences in their teacher's expecations for what they can achieve in school (Rosenthal \& Jacobson, 1968, p. 181 ).

Faust (1980) percentively depicts an irony found within our schools. "The major purpose of schools is to change people; the basic purpose of people is to remain the samen (Faust, p. 27). Obviously espousing a selfconsistency theory of the self, Faust has great concern 
over the impact which teacher role expectations can exert upon a child's self-concept. Preconceived opinions can influence teacher interactions with their students. Describing our school setting as one which precludes assaults upon a student's self esteem, Faust emphasizes the important role of the teacher in setting the classroom standards of "right" and "wrong". He seriously ponders whether educators, in their efforts to evaluate students, are consciously or unconsciously developing control measures which "...annihilate self esteem, breeding resentment, anger, hate and raqe that more than anything else, limit human potential" (Faust, 1980, p. 28).

"Reduced self-esteem leaves students feeling vulnerable and unsafe, resulting in anxiety and fear" (Faust, 1980, p. 55). Student resentment over the loss of self-esteem can be externalized in explosive behaviors or resistence to learning. Faust describes an experiment by Seligman which he believes is analogous to what occurs to students in the labeling process.

Seligman (in Faust, 1980) conducted a study with dogs to investigate "learned helplessness". Using a warning signal followed by a painful electric shock, he discovered that dogs who had been strapped in a hammock during the signal: shock situation, were likely to endure the shock pain rather than run and jump a barrier to freedom (even when they were not strapped in and free to 
run). Seligman concludes that in essence these dogs were taught/conditioned to accept a hopeless situation rather than seek readily open avenues of respite from the pain. Faust (1980) juxtaposes this learned helplessness concept into the school arena by drawing an analogy between the constricting physical hammock for the dogs and the teacher-imposed mental hammock of "right" and "wrong" in the classroom. According to Faust, the same acceptance and internalization principle that is described by seligman, is set into operation when a school imposed label is affixed to a child.

We do not know how far-reaching labeling effects can be over the years. Labeling effects which might be carried through to adulthood are not clearly demonstrated in the literature (Guskin \& Spicker, 1968; MacMillan, Jones and Aloia, 1974). "The negative effects of the label, if they exist and persist into adulthood, probably reside in the self and peer perceptions during childhood and the lifelong memory of these, and that is difficult to demonstrate" (Macmillan et. al, p. 251).

Admittedly, labeling provides a means for communicating a child's learning problems and also serves as a way to determine levels of funding and delivery service needs. What becomes the essence of this issue is whether we are being Machiavellian in our rationale for the use of labels in our schools. While labels do undisputedly 
create greater ease in administration and funding of labeled students' programs, does the possible end of lowered self-concept justify these administrative means?

"Children who are categorized and labeled as different may be permanently stigmatized, rejected by adults and other children and excluded from opportunities essential for their full and healthy development" (Hobbs, Egerton, \& Matheny, 1975, p. 21).

\section{Concern In Special Education Over Self-Concept}

Concerns evidenced in regular education certainly

call attention to the possibility that special education students' self-concepts may also be in jeopardy. The importance of self-concept must not be ignored.

Self-concept, then, whether used as an outcome itself or as a moderator variable that helps explain achievement outcomes, is a critical variable in education and in educational evaluation and research (Shavelson, Hubner \& Stanton, 1976, p. $408)$.

The rendering of special education services in the schools, since the 1975 Education of Handicapped Children Act (PL 94-142) has presumed that an essential entrance requirement be met. This requirement insists that the child is unable to succeed in a regular educational environment without some form of special services intervention. Educational intervention can assume many forms on a continuum which ranges from remaining in the regular class and having a special education person provide information and support for the regular teacher, to the other extreme 
where the child might be placed in a self-contained special education classroom which only serves special education students. However the child might be placed, the essential concern over a child being served for special education purposes is that performance limitation, which initially earmarked the child as a potential candidate for special education, may be responsible for a lowered self-concept in that child.

It seems reasonable to assume that unsuccessful students, whether underachievers, nonachievers, or poor readers, are likely to hold attitudes about themselves and their abilities which are pervasively negative... Students with negative selfimages of ability rarely perform well in school... (Purkey, 1970, p. 22).

As children with speoific learning disabilities are the focus for this investigation, special education concerns over the self-concepts of exceptional students will be limited to the learning disabled population. The descriptor "specific learning disability" might easily be called a wastebasket term. Over the years this term has managed to be consistent only in the fact that its definition means a variety of things to a variety of people (Bryan \& Pearl; 1982; Cheong, 1974; Cruickshank, 1972; Johnson, Johnson, Olson \& Newman, 1981; Myers \& Hammill, 1976). Most definitions refer to deficit skills in the three R's and spelling. Therefore, the center of attention has become one of determining strategies used in 
dealing with specific learning disability symptoms rather than its causality.

Instead of focusing upon one definition of specific learning disability as it compared to another, it seems far more sensible to refer to the two legal definitions of import here in the state of Oregon. While they have similar wording, inclusion of both gives the federal and state perspective to specific learning disabiities.

The Education of Handicapped Children Act, PL 94-142 defines "specific learning disability" as: ...a disorder in one or more of the basic psychological processes involved in understanding or using language, spoken or written, which may manifest itself in an imperfect ability to listen, think, speak, read, write, spell, or to do mathematical calculations. The term includes such conditions as perceptual handicaps, brain injury, minimal brain dysfunction, dyslexia, and developmental aphasia. The term does not include children who have learning problems which are primarily the result of visual, hearing, or motor handicaps, of mental retardation, or of environmental, cultural or economic disadvantage. (PL 94-142, 1975, D. 42478 section 121a. 5.9)

Oregon's efforts to clarify the intent of PL 94-142 have lead to series of Technical Assistance Papers. One such paper is solely devoted to specific learnina àisabilities. The Specific Learning Disabilities Technical Assistance Paper 4 (1982) draws its definition of specific learning disabilities from OAR 581-15-051.

One category of children who are handicapped; a disorder of one or more of the basic psychological processes involved in understanding or using langauge, spoken or written, which may manifest itself in an 
imperfect ability to listen, think, speak, read,write, spell, or to do mathematical calculations. Children with specific learning disabilities are unable to profit from regular classroom methods and materials without special educational help, and are, or will become, extreme underachievers. These deficiencies may be exhibited in mild to severe difficulties with perception (the ability to attach meaning to sensory stimuli), conceptualization, language, memory, motor skilis, or control of attention. Specific learning disabilities include such conditions as perceptual handicaps, brain injury, minimal brain dysfunction, dyslexia, and developmental aphasia. The term does not include children who have learing problems which are primariy the result of visual, hearing, or motor handicaps, mental retardation, emotional disturbance, or are due to environmental, cultural, or economic disadvantage (Oregon Administrative Rules 581-15051).

\section{LD Self-Concept Research}

Bryan and Pearl (1982) feel that attempts to define "specific learning disability" (LD) are centered upon academic retardation and cognitive processes. They are concerned over the lack of attention to motivational and personality influences which can be highly important to specific learning disability research and school delivery systems. In a series of studies designed to explore third through eighth grade regular and LD parochial and public school students' perceptions regarding control over their school successes and failures, Bryan and Pearl report consistent findings. LD students regularly attribute school successes to luck and easy task requirements. Regular students explain school successes as a resul'c of hard work and ability. Students who are LD do not equate trying harder 
with doing better in school. Instead LD students evidence a lack of a locus of control over their school successes and failures. Since academic self perception is an important part of the entire self-concept, these recurrent findings by Bryan and Pearl, are of concern to educators desiring to effectively work with LD students.

\section{Academic Achievement and LD Self-Concept}

The majority of school successes are based upon academic achievement. Simply by the characteristics used to identify LD students, it is obvious that a major delay in grade level achievement must be present in at least one academic area, or the child would not be receiving special education services on the basis of having a learning disability. Lacking success in a subject area to the extent that a substantial delay in grade level achievement is evidenced, gives rise to concerns over the ramifications of these failures upon the LD student's self perceptions. Approaching this from Rosenberg and Kaplan's (1982) psychological centrality principle of self-concept, if the LD student has a high academic self-concept component, school failures might easily perpetuate lowered academic self-concept. Therefore, if the child values doing well in the failed subject areas, the lack of academic success could be all the more devastating to the child's seli-concept. A child's future school aspirations have 
their roots in whatever feelings are held about current levels of performance (Florio-Forslund, 1978).

Rather than assuming that research findings of significant relationships between self-concept and academic achievement are universally applicable, Black (1974), Houck and Houck (1976), and Leviton and Rirally (1975) probe these interactions for LD students. Black (1974) uses the Piers-Harris Children's Self-Concept Scale and the wide Range Achievement Test (WRAT) to investigate self-concept and achievement linkages for a group of fifty regular and LD students. For both groups, student selfconcept score levels are found to be closely related to the extent of the student's underachievement level. Thus, self-concept and academic achievement are found to exert an influence upon one another. Self-concept and academic achievement are not found to be closely linked in the following two studies. Houck and Houck (1976) also use the WRAT to measure academic achievement, but differ from the Black study by using the Erimary self-Concept Inventory. Their study entails the use of thirty-seven LD students who are aged eight through fourteen. Nineteen of the students received special education instruction in a self-contained classroom (of all LD students). Eighteen were in regular classes and received special education services in a resource room (where they had a special education teacher for varying 
periods of time and returned to the regular class the rest of the day). Age and sex between groups were comparable. Low nonsignificant correlations between self-concept and achievement lead Houck and Houck to conclude that selfconcept and achievement are not closely correlated for LD students.

It must be noted that the age range of eight through fourteen does indeed raise a red flag of concern when considering the arguments for and against self-concept crystalization over various age groupings (Erikson, 1968; Festinger, 1981; Rosenberg, 1979; Rosenberg \& Kaplan, 1982; Silvernail, 1981). Too many studies report age influences upon self-concept and achievement to readily discount this limitation in the Houck and Houck (1976) study (Bledsoe, 1962; Bohan, 1973; Coleman et. al, 1966).9 Houck and Houck also raise another possibility which might impact their findings. They question whether the Primary Self-Concept Inventory should be used in a correlational study. It is possible that their findings might be contaminated by an inappropriate statistical manipulaton.

A second study reports no significant correlations between self-concept and academic achievement. Leviton and Kirally (i975) conducted a study of sixty-four LD stu-

${ }^{9}$ Age impacts upon self-concept are further probed by: Grant, 1969; Long, Anderson \& Ziller, 1967; Piers \& Harris, 1964; and Trowbridge, 1972. 
dents from the first through third grades. Having eliminated any subjects who might have additional handicapping conditions, Leviton and Kirally administered the Self-Concept Self-Appraisal Inventory and the Metropolitan Achievement Test to their subjects. No direct positive relationship is found between self-concept and academic achievement for these LD students. To a somewhat lesser extent (since their sample ranged in age from about six through eight) the age concern described for the Houck and Houck study should also be considered here as these children were rather young to have cystalized self-concepts.

\section{Placement}

When conducting an investigation of self-concept for LD students, a profusion of arguments is encountered. The point of the two opposing postures is simple, each claims that placement affects the student's self-concept. One group asserts that special education placement for LD students should be in classrooms where the primary reference group includes significant others with similar handicapping conditions (Drews and Goldberg, Passow \& Justman (in MacMillan et. al, 1974); Kaplowitz, 1981; Olavarri, 1966; Schurr et. al, 1972; Smith, 1980). These arguments have their roots in social comparison theory wherein the individual is continually involved in self judgements which are derived through self comparisons to significant 
others (Calhoun \& Morse, 1977; Coleman, Campbeil, Fobson, McPartland and others, 1966; James, 1890; Merton, 1948; strang, Smith \& Rogers, 1978). Here positive social comparisons and high self-concept are thought to be encouraged when significant others have homogeneous characteristics with the subject.

Social comparison theory can also be used to defend the opposing posture that the LD student's placement should be with significant others who are regular students. As no labeling and special class placement stigma are borne by regular students, social comparisons with this group are not believed to lower the LD student's self-concept. Supporters of least restrictive environment placement believe that other than being set apart by special class placement, the LD student can interact with students in regular classes and feel equal to these school peers (Bacher, 1965; Borg, 1966; Carroll, 1967).10

Drawing from the group of writers and researchers advocating the student's spending considerable time in both self-contained special classes and resource rooms, the more recent research supports the contention that the placement can foster higher LD student self-concepts. Smith (1980) tells us that at the onset of his study, he

\footnotetext{
10 These authors also support least restrictive environment placement for exceptional students: Dunn, 1968; Johnson \& Kirk, 1950; Mann, 1960; Meyerowitz, 1962.
} 
was concerned that placement in a special class would preclude negative self valuations for LD students. He remarks that his findings were indeed a surprise. The length of LD student enrollment in special classes was found to be correlated positively with higher self-concept scores. The longer the student remained in the special education class, the higher the student's self-concept. LD students attending special classes for some length of time are found to have almost identical mean Piers-Harris Self Concept scale scores to the regular student norming sample for the self-concept measure.

The clear implication is that how children feel about themselves is a function not simply of how well they perform, but of how well they perform relative to significant others (Smith, 1980, p. 21).

In Smith's study, special class placement over time does yield higher self-concept scores. LD labeled students in regular classes are shown to have lower self-concepts than their LD peers who are in the resource room for all or part of the day.

Raplowitz (1981) describes mainstreamed LD students as having self-concepts which vary between the resource room and regular classroom environments. In an ex-postfacto study of thirty-four mainstreamed LD students, she compared subjects who ranged in age from nine through thirteen years old. Teachers assessed the self-concepts of their students. Within their resource rooms, LD stu- 
dents had significantly higher self-concepts than in their reqular classrooms.

Problems inherent to ex-post-facto studies can be manifold; but rather than addressing possible hypothetical problems, it seems more valuable to Doint out some glaring points of concern in Raplowitz's study. The study had a small population which ranged in subject age over a four year span. Age infuences upon self-concept were not controlled for in this sample. Another issue of import is the use of teacher reports to determine self-concept levels for the students in the sample. Third party reports of self-concept are difficult, at best, to justify.

The crux of the arguments for those advocates of more special education direct services and less least restrictive environment placement rests upon the self-concept influences which are believed to be exerted. Removing peer models with similar handicapping conditions is seen by this group as being detrimental.

... When similar others are removed as a source of comparison, self-concept declines if those remaining are superior on the relevant ability or selfconcept dimension (Smith, Dokecki \& Davis, 1977, p. 194).

Representing the faction of supporters for least restrictive environment placement are many writers and researchers from the 1960's (Bacher, 1965; Borg, 1966; Cârroll, 1967; Dunn, 1968). Dunn (1968) is concerned that 
self contained special education placement could have a significant impact on the student's "...feelings of inferiority and problems of acceptance" (Dunn, p. 9). Arguments between these two factions have been raging back anj forth for some time. Both groups wish to bring about student placements which best foster higher self-concept. Since the implementation of PL 94-142, there have not been any studies supporting higher selfconcepts for total least restrictive environmment placement.

Strang, Smith and Rogers (1978) do report that onehalf day of special education and one half day of regular class placement, for academically handicapped students, does give rise to significantly higher self-concepts than for a control group of special education self contained students who remain in the special class all day. Using the Piers-Harris Self-Concept Scale, twenty-seven experimental students and twenty-five control group comparison students with ages of six to ten were studied. Strang et. al are concerned that total least restrictive environment placement would remove the special education classroom peer reference group which enhances self-concept through social comparisons.

A study by Ribner (1978) also examines the relationship between special class placement and the self-concepts of LD students. The overall results suggest placement in- 
fuences upon different dimensions of the self-concept. LD students with least restrictive environment regular class and resource room placement are shown to have lower selfconcepts of general competence. Both groups of LD students (self contained special class and regular class/resource room) report lower adequacy self-concepts than their regular classroom peers. To say the least, the potential for deleterious placement effects upon self-concept has been researched with mixed findings. Since the more recent studies lean heavily towards indicating that the daily length of time spent in special education classes impacts the level of the student's self-concept, it would seem that this is an important variable to address in research studies pertaining to LD students.

\section{Juvenile Delinquency and the Learning Disabled}

Special education concerns over the self-concept of LD students do not end with placement issues. Special educators are concerned over what might be a link between juvenile delinquency and students who have learning disabilities (Comptroller General of the United States, 1977; Mauser, 1974; Reckless \& Dinitz, 1967)。

n...The self-concept might be one of the important self-factors in determining the 'drift' toward or away from delinquency and crime" (Reckless \& Dinitz, p. 522). 
Classroom failures over time can result in negative attitudes towards school and lowered self-concept (Rnaus \& McKeever, 1977; Mauser, 1974). Delinquent behavior patterns can provide a means for school failure avoidance. The Comptroller General (1977) suggests that pride over behavioral successes as a juvenile delinquent can become a substitute for socially accepted behavior patterns which the LD student has previously been unable to generate in the school setting. When the LD student's self-concept suffers, it is not difficult for that student to reject the institutional standards which might be in a great part responsible for the lowered self valuations, and instead turn to delinquent behaviors.

... Learning disabiities and problems in selfconcept are associated in a circular fashion... Problems in the remediation of learning disabilities in older children and the commonly reported high dropout rate of learning disabled adolescents are undoubtedly related to this process (Black, 1974, p. 1139).

From this information, it is not difficult to surmise why many educators are deeply concerned. Not only are LD students dropping out of school, but there are close similarities between the characteristics of LD and delinquent youth.

Both learning disabled and juvenile delinquent individuals have many behavioral similarities, and following a learning disability model is necessary when assessing, monitoring, and remediating the educational deficits found in the majority of our delinquent youth (Mauser, p. 392). 
Mauser (1974) goes on to cite a number of characteristics common to juvenile delinquents. A few of these commonalities are of particular concern to special educators: (1) there is a high incidence of LD students found within the total population of juvenile delinquent: youths, (2) both LD students and juvenile delinquents tend to have negative self-concepts, (3) both LD and delinquent students have histories of primary grade problems in school.

Berman and Siegal (1977) present an overview of psychometric studies which bring to the forefront some very interesting points. Once again, strong linkages between LD and delinquent students are evident:

(1) Many children who are labeled delinquent show an ability constellation which differs from that of normal, nondelinquent children. (2) Apparently the more gross differences which were observed in earlier studies reflect the presence of more basic psychological deficits -e.g., reading disorder etc.... It can therefore be surmised that the psychological deficits which characterize juvenile delinquents resemble those of neurologically impaired children and...may be an indicator of more subtle disabilities which appear as sequella of cerebral mysfunction (Berman \& Siegal, 1977, p. 583).

It should also be remarked that when analyzing the degree of influence exerted by the variables of "skill impairment" and "social class," Berman and Siegal find a much clearer relationship between skill impairment and juvenile delinquency. Ties between social class and delinquency are not nearly so obvious. 
As these writings make evident, many LD children do have problems in the area of accepted socialization behaviors. While causality for juvenile delinquency can neither be pinned to having a learning disability nor to exhibiting a low self-concept, both are indeed important factors to be considered. Special education concerns over the school serving as a catalyst to heighten the possibility for the student to have a lowered self-concept or become a juvenile delinquent are highly critical. Proactive administrative and teaching strategies addressing the nurturing of positive self-concepts for LD students certainly appear to be in order.

\section{Self-Concept and Special Education}

\section{Labeling Research}

Earlier discussions in this dissertation have addressed the fact that labeling abounds in misperceptions and stereotypical expectations. When labeling is used in special education, an additional concept of "spread" arises. Spread refers to the belief that when a person has a handicapping condition, the total individual is impaired (Burkhead, 1979). "...The term 'handicapped' implies the limitations may be due to psychological, social and/or environmental factors the disorder itself" (Burkhead, 1979, p. 4). Therefore, a special education label may be more debilitating than other types of labels. 
Labeling and the Mentally Retarded

The assumption here is that a label, if denigrating, suppresses performance measures of a labeled child below the level at which he would score despite the behavioral limitations that led to his being labeled mentally retarded (Macmillan et. al, 1974, p. 242).

A number of educators explore the possibility of detrimental labeling effects upon mentally retarded students (Budoff \& Siperstein, 1978; Chassim, Presson, Young \& Light, 1979).11 studies examining the effects of the "mentally retarded" (MR) label are heavily invested in the perceptions held by significant others who fall within peer and teacher groupings.

In a study looking into low income peer acceptance of educable mentally retarded (EMR) labeled and nonlabeled students, Budoff and siperstein (1978) used adjective checklists and activity preference lists to fathom the confused waters of labeling. Budoff and siperstein report that their findings from this study of ninety-six white, sixth grade students indicate that regular students have different levels of acceptance for MR students. The study had reqular class peers describe their attitudes towards

${ }^{11}$ Labeling effects are also discussed by: Dunn, 1968; Gottlieb, 1974; Guskin, 1974; Haywood, 1971; Jones, 1972; MacMillan et. al, 1974; Mercer, 1971; Miller, 1956; Potter, 1971; Rist, 1970. 
low achievers. These low achievers were actually performing at the same skill levels. The only difference being that some low achievers were labeled MR, while others were not labeled at all. Regular class student responses indicate that these low income sixth graders have more positive attitudes towards special education labeled "EMR" low achievers than nonlabeled low achievers.

Children may be more tolerant and accepting of incompetent behavior from a peer who is not expected to perform well than from a child for whom there is no obvious explanation for poor performance (Budoff and Siperstein, 1978, p. 478)

Gottlieb (1974) holds that lower academic achievement, not labeling and special placement, is responsible for negatively stigmatizing children who are mentally retarded. Studying middle class students who were in the fourth grade, Gottlieb finds that academic ability more greatly influences regular student attitudes than mental retardation labels. From his findings he concludes that low academic achievement results in peer attitudes of less esteem regardless of whether or not the child is labeled. Labeling effects on peer attitudes do not prove to be statistically significant in this study.

Speaking to "retarded" labels, Gottlieb proposes that labels can assume two roles. The function of the label may well be contingent upon the child's behaviors. Thereby, the label can in effect both stigmatize and pro- 
tect the child labeled MR (Gottlieb, 1974; Macmillan et. al, 1974). Gottlieb concedes that special education labels might possibly be responsible for deleterious effects upon self-concept and teacher expectations. He suggests that it would be worthwhile to examine the labeled student's feelings about peer treatment. Moving to the upper end of the mental retardation continuum, Rist (1970) presents an interesting argument that "fast" and "slow learner" labeling, at the kindergarten level, can become an oppressive shadow hanging over children from one grade to the next. In a longitudinal study which observed a class of children as they passed from kindergarten through the second grade, Rist tells us that by the eighth day of kindergarten, the teacher had already grouped the children. Grouping, Rist claims was based upon the degree of conformity or deviance from middle class dress, language useage and manners. The teacher used no test to categorize the students, and yet labeled them "fast" and "slow learners". The reading groupings to which this first teacher assigned the children remained relatively unchanged through the second grade when the study was completed.

This is, in a sense, another manifestation of the self-fulfilling prophecy in that a 'slow learner' had no option but to continue to be a slow learner, regardless of performance or potential (Rist, 1970, p. 435). 
Children enter the schools with valuing systems and feelings of self worth which have been fostered in the home. These values can be perpetuated or modified by feedback in the school. "In the school setting, the teacher, through communication, strategies, is primarily responsible for enhancing the child's feeling of worth both as a person and as a student" (Florio-Forslund, 1978, p. 11). Reactions and feelings which consciously, or unconsciously are weighted with stereotypical expectations can communicate many messages to a labeled child. These messages can set this child apart from other peers as well as convey to the child that somehow he or she is not the same as the other children. It is because of the compeling influence which teachers can bear that Guskin (1974) recommends the use of conscious strategies geared towards the removal of labeling effects through training. Teachers must recognize that...

the label retarded includes a wide range of children-including those who are mislabeled because of instrument inadequacies or language problems -and to understand that most of the children... labeled retarded will live 'normal' adult lives and are deemed adequate by their nonretarded peers outside of school, we might expect that these teachers would interact in a more positive way with the 'retarded' children with whom they come in contact (Guskin, 1974, p. 263). 
Labeling and the Learning Disabled

Labels lend themselves to responses by others which are stereotypical and often negative. Individual differences and positive means for coping with handicapping conditions are overlooked. "If persons with handicaps internalize societal norms, they face rejection of the self and feelings of shame and embarrassment" (Burkhead, 1979, p. 9). Societal norms are capable of exerting considerable influence.

Once the child has been labeled, he no longer is considered as one who can behave, learn, and achieve with ease. He now is in the class 'dummy', 'retard', and 'spas', and must suffer the resuitant shame... Learning disabilities, being poorly understood by the public, are assumed to be some form of mental retardation or emotional disturbance (Kronick, 1976, p. 116).

Shame and embarrassment are not the only dangers which labeling may elicit. "...The individual may also respond according to the dictates of that label which influence self-concept and self confidence" (Burkhead, p. 7). When this occurs the behaviors which were stereotypically attached to the label often actually become the behaviors of the person with the handicapping condition (Burkhead, 1979; Scheff, 1975; Ullman \& Krasner, 1975). Therefore, labeling influences upon learning disabled (LD) students can be twofold. Should the student become aware that she has been labeled LD, she might have a lowered self-concept as a result of being "different". 
Secondly, when others are aware of the handicap label, they may consciously or subconsciously treat that student differently from students who are not labeled (Dexter, $1964)$

According to Kronick (1976), LD students have modified interactions with significant others. Significant others, such as teachers and peers, interact differently with LD children because many of the learning disabled are unable to successfully manage the established role expectations for social behaviors. A LD child may often use unacceptable behaviors in many social situations (in spite of receiving negative feedback every time that the behavior occurs). When a pattern of inappropriate behaviors emerges, Kronick believes that stereotypical treatments based upon labels are then reinforced. The results of these modified social reactions to LD students can include:

(1) Reduced and distorted information to the ego. Thus, the learning disabled person who has an unclear image of self receives less truthful or confirming feedback.

(2) The learning disabled person who may have difficulty perceiving distorted information between affect and ideas.

(3) The learning disabled person has trouble perceiving the situational gestalt, individual, group images, is too concrete to reconcile ambiguity, receives an ambiguous message concerning the situation or group image.

(4) The learning disabled person lacks the perception to perceive this as a pseudocommunication so that he patterns his own communication from it. Consequently, this may be one of the reasons $h$ is communication is unclear, shallow and lacks appropriate affect (Kronick, p. 118). 
As has been previously mentioned, the stereotypical

treatment of labeled children has close ties to teacher self-fulfilling prophecy expectations. "...An individual's expectations may be defined as subjective probabilities assigned to the occurrence of a future event" (Stoller, Algozzine \& Ysseldyke, 1981, P. 53). These expectations can prove dangerous.

The trouble is that since most of us tend to use individual incidents to support generalizations, the seemingly innocent banter of the lounge is converted to expectations that have a profound impact on the success of children... It is common for negative expectation not only to color the view adults hold of the child but to influence teaching techniques and alternatives as well (Dworkin \& Dworkin, 1979, pp. 712-713).

A variety of studies have resulted in findings that clinically labeled LD students are seen by teachers in a less positive manner than other students who are not labeled (Foster, 1976; Good \& Dembo, 1973; Jones, 1974).12 "...The negative halo of the label still results in more negative perceptions of uenavior than when the child is labeled normal" (Foster, Ysseldyke \& Reese, 1975, p. 469).

12 Teacher perceptions of LD labeled students have been studied by these additional researchers: Mayer, 1971; Panda \& Bartel, 1972; Prieto \& McCoy, 1979; Salvia, Clark \& Yseldyke, 1973; Ysseldyke \& Foster, 1978. 
Investigating teacher expectations tied to the use of the label "learning disabled" (LD), Foster (1976) had two groups of elementary teachers view a video tape. One group was told that the child in the tape was normal, while the experimentai group received information that the child was learning disabled. Foster found the experimental group's zatings to be significantly more negative than those of the control group where the child was not labeled. These findings lead Foster to conclude that a LD label does generate teacher expectations which can be responsible for coloring objectivity to the extent that student behaviors are observed in a more negative light. Ysseldyke and Foster (1978) conducted a spin-off study to the Foster (1976) research. It was designed to examine whether special education labels of "LD" and "EH" (emotionally handicapped) influence teacher observations and expectancies. They had all teachers view the same video tape. Before seeing the tape, teachers were given information that the child in the tape was LD, EH or a regular student. The labeling information was found to exert considerable influence upon how the teachers perceived the child in the video tape.

Deviancy labels do result in an alteration of teacher expectancy toward the child so labeled, and this change of expectancy can result in an alteration of a teacher's objective evaluation of a child's behavior" (Ysseldyke \& Foster, p. 615). 
Another clinical study which utilized videotapes, achievement test information, and a case study was conducted by Stoller, Algozzine \& Ysseldyke (1981). Special education teacher expectations were gauged in terms of labeled "LD" and "EY" students' performance levels. It was found that special education teachers based their future performance expectations for their students upon the present levels of student classroom performance. Variance from expected student outcomes was interpreted by teachers as being attributed to luck for low achieving students who performed higher than would be expected. High competence students who performed lower than was expected were seen by the special education teachers as having lower scores due to increased task difficulty. "This outcome suggests that perceived competence may have a profound effect on teacher expectations for a child" (stoller et. al, p. 58).

Prieto and McCoy (1979) describe the heavy infuence which special education labels can exert. When teachers were asked questions about children from different racial and ethnic groups, the perceptions of the minority children were the same as for other children. When a handicapping condition label was added, then teacher perceptions of the minority students were indeed impacted. Not only are teacher perceptions modified, but also their expectations and interactions with LD students are 
effected. Bryan's (1978) study notes that LD students experienced more teacher contacts than regular students. Teacher contacts in the form of positive reinforcements were the same for $L D$ and regular students. Interestingly, what caused the variation which served to push teacher interactions with LD students well. ahead of those for regular students was the number of negative reinforcement forms of teacher contacts. LD students received twice as many negative criticisms from their teachers as did regular students. Of these negative teacher/student interactions, the majority were related to student behaviors and procedural interactions which are often connected with the characteristics found within the learning disability handicapping condition (i.e. student problems in following directions).

Examining LD (learning disabled) and EH (emotionally handicapped) labeling impacts, Algozzine, Mercer and Countermine (197?) report some engaging findings. They describe lower levels of teacher tolerance for aggressive and disruptive LD labeled student behaviors than for $E H$ labeled student behaviors.

As has been demonstrated, labeling can effect changes in teacher expectations. Special education labels may be more heavily laden with stereotypical images and expectations than minority group labels (Prieto \& McCoy, 1979). "Where negative expectation already exists, 
neither awareness nor positive labeling is a sufficient safeguard against differential teaching behaviors" (Dworkin \& Dworkin, 1979, p. 713).

\section{Statement of the Problem}

Formal student labels which are assigned by the schools can be responsible for evoking a myriad of stereotypical images, reactions and misunderstandings (Mercer, 1973; Robbins, Mercer \& Meyers, 1967). The "learning disability" label is substantiated by test results and therefore has considerable credibility to educators. When paired with stereotypical misconceptions about the learning disabled, the credibility lent by test results can serve to reinforce social labeling assumptions. If teachers hold conscious or subconscious stereotypical expectations for students who are labeled, then labeling the child as ID could readily bring about discriminatory interpersonal interactions (Bem, 1972; Dworkin \& Dworkin, 1979; Foster, 1976; Florio-Forslund, 1978).13 There is a possibility that special education labels might carry a more negative stigma than other labels (Prieto \& McCoy, 1979).

13 Teacher expectations, as tied to students who have been labeled are further spoken to by: Good \& Dembo, 1973; Guskin, 1974; Jones, 1974; Rronick, 1976; Mayer, 1971; Panda \& Bartel, 1972; Porter, 1971; Prieto \& McCoy, 1979; Salvia, Clark \& Ysseldyke, 1973; Shur, 1971; Stryker, Toner, 1979; Ullman \& Rrasner, 1975; Ysseldyke \& Foster, 1978. 
Numerous studies describe modified expectations and treatment of formally labeled individuals (Budoff \& Siperstein, 1978; Faust, 1980; Gottlieb, 1974).14 Speaking specifically to the labeling of learning disabled students, there are compelling research findings which assert that LD students are viewed less positively than other students (Good \& Dembo, 1973; Jones, 1974).15

Whether the LD student comes to conclude that he is "different" as a result of being treated discriminatorily by significant others, or because the stereotypical role model of the label has been personally accepted and internalized, the label can result in modified self perceptions and social interactions (Burkhead, 1979; Rronick, 1976; Scheff, 1975; Ullman \& Krasner, 1975). Negative labels can produce identity and behavior changes (Moeller, 1981).

In the schools, special education labels are assigned only after the child has been carefuly screened and tested. Referral for special education testing occurs when the child has exhibited a pattern of academic problems. For a child to be labeled "learning disabled", there must be a significant difference between the child's intellectual potential

\footnotetext{
${ }^{14}$ These authors also report that labeling can cause modified expectations: Jackson \& Cosca, 1974; Relly, Bullock \& Dykes, 1977; Leacock, 1969; Moeller, 1981; Rist, 1970; Smith \& Greenberg, 1975; Zucker \& Prieto, 1977.

15 Less positive perceptions of LD students are reported by: Mayer, 1971; Panda \& Bartel; 1972; Prieto \& McCoy, 1979; Salvia, Clark \& Ysseldyke, 1973; Ysseldyke \& Foster, 1978.
} 
and the actual achievement level. When a child has

repeatedly evidenced academic problems in school, there is a substantial possibility that there might be resulting neqative self-concept impacts (Black, 1974; Bledsoe, 1964;

Brookover: Thomas \& Patterson, 1964; Burns, 1979).16

The addition of a negative LD label could be responsible for rendering the child's self perceptions a heavy blow. Brookover, Patterson and Thomas (1965) assert that when self-concept is lowered below a minimum threshold level, learning can not occur. A sense of self worth is essential to a successful learning experience (Faust, 1980). The critical factor to how a child performs in school is the level of that child's self-concept (Brookover, Shailer \& Patterson, 1964).

The relationship between self-concept and academic achievement is a reciprocal interaction (Burns, 1979). It is persistent and continuously on going.

The best evidence now available suggests that it is a two-way street, that there is a continuous interaction between the self and academic achievement, and that each directly infuences the other (Purkey, 1970 , p. 23).

16 The relationsip between self-concept and academic achievement is explored by: Busby, Fillmer \& Smittle, 1974; Caplin, 1969; Cole, 1974; Combs, 1964; Coopersmith, 1959; Covington \& Beery, 1976; Fink, 1962; Gordon, 1977; LaBenne \& Greene, 1965; Leviton, 1975; McIntyre \& Drummond, 1977; Primavera, Simon \& Primavera, 1974; Purkey, 1970; Rogers, Smith \& Coleman, 1978; Roth, 1959; Samuels, 1977; Sears, 1970; Silvernail, 1981; Simon \& Simon, 1975; Smith, Zingale \& Coleman, 1978, Strang, Smith \& Rogers, 1978; Williams \& Cole, 1968; Vereen, 1980; Zimmerman \& Allebrand, 1965. 
An understanding of the variables which exert an influence upon the child's self-concept is highy important to educators. Linkages between low self-concept and low academic achievement can not be ignored (Burns, 1979; Covington \& Berry, 1976; Silvernail, 1981). Additionally, a number of personality characteristics attributed to children with low self-concept must be considered to be possible inhibitors to successful learning experiences. A child with a low self-concept may have some or all of the following characteristics: sensitivity to criticism, projection of blame, overly critical of others, prefer to be left alone, less trusting of people, less assertive, less likely to initiate conversations, less adept in dealing with conflict, high levels of anxiety and stress, and easily frustrated (Ausubel \& Robinson, 1969; Burns, 1979; Coopersmith, 1967).17 "When a child is overwhelmed by anxiety about his performance, whether at school or home, he cannot focus on a task" (Frostig \& Maslow, 1973, P. $84)$.

There is a considerable likelihood that pedagogues are going awry somewhere in the process of serving $\mathrm{LD}$ children. Large numbers of LD children have been shown to be juvenile delinquents (Berman \& Siegal, 1976; Comptrol-

17 Characteristics of children with low self-concepts are further described by: Feldhusen \& Thurston, 1964; Gabbler \& Gibby, 1967; Horowitz, 1962; Many \& Many, 1975; Rosenberg, 1965; Stanwyk \& Felker, 1973. 
ler General of the United States, 1977; Mauser, 1974; Reckless \& Dinitz, 1967). Chronic classroom failures over the years can result in a lowered self-concent and negative attitudes towards school (Knaus \& McKeever, 1977; Mauser, 1974). While the causality for juvenile delinguency cannot be clearly tied to the schools, concerns that the schools may serve as catalyst in the process of lowering self-concepts and fostering delinquency are of the utmost importance to administrators and teachers. Should the special education labeling of learning disabled students be responsible for heightening the likelihood that a child's self-concept will be lowered, an active intervention into this downward spiral of events must occur immediately.

Most of the studies which have actually succeeded in isolating the variable of a special education label have done so in the area of teacher and peer expectations and perceptions. "Studies simply have not been designed in such a way as to provide ciear support for the hypothesized effects of labeling, although this is not to say that no such effect exists" (MacMillan, et. al, 1974, p. $242)$.

\section{Purpose of the study}

The intent of this research was to explore special education labeling relationships with measured student 
self-concept. By way of a survey of related literature, the researcher has presented arguments supporting the underlying theoretical bases of special education labeling impacts on student self-concepts. The literature review has encompassed an examination of: research supported ties between self-concept and low achievement, labeling theory, as well as self-concept and labeling theory concerns particular to special education students. Through conducting this research, the investigator hoped to determine whether special education LD labels negatively influence self-concept. Findings from this research will be utilized, by the three participating school districts in determining whether existing administrative labeling practices should be modified to better foster positive student self-concepts.

\section{Content and/or Methodological Limitations of} Previous Studies Leading to this study

According to MacMillan et. al (1974) labeling issues have been clouded to a great extent by additional issues of considerable concern such as self contained classrooms and other unaddressed variables (i.e., achievement, age, sex, minority group membership, socioeconomic status, birth order and significant others). Studies relative to special education labeling effects are heavily invested in the probing of perceptions held by significant others, 
rather than looking into the feelings of the person who is the object of the label (Algozzine et. al, 1977; Buddoff \& Siperstein, 1978; Foster, 1976).18

The lack of attention to the interactions of labeling with student self-concept has probably been due to the manifold variables which must be controlled for if self-concept and labeling relationships are to be validly measured. Studies have used matching and statistical manipulations to control for some of these potentially confounding variables in self-concept research, but none have gone so far as to address all of the variables which this research will consider. (Boersma, Chapman \& Battle, 1979; Legette, 1979; McIntyre \& Drummond, 1977; Ottenbacher, 1981).19

\section{These researchers also examined significant} others' perceptions: Good \& Dembo, 1973; Gottlieb, 1974; Jones, 1972; Mayer, 1965; Prieto \& McCoy, 1979; Ysseldyke \& Foster, 1978.

19 Additional studies in self-concept addressing a number of variables have been carried out by: Rosenberg, 1979; Trowbridge, 1972. 
CHAPTER III

\section{METHODS AND PROCEDURES}

The intent of this investigation is to explore special education labeling interactions as measured by student self-concept. An important question addressing whether learning disabled students' self-concepts are negatively influenced by special education 1 abeling has been explored.

\section{Research question}

Will students who are labeled learning disabled exhibit lower global self-concepts than regular students when achievement and other variables are controlled for?

\section{Hypothesis}

Special education students labeled "learning disabled" (LD) and regular education students, with scores within a band range of equivalent reading and mathematics achievement levels on the Portland Achievement Test and controlled on independent variables, statistically will show no significance between group differences $(p<.05)$ on the piersHarris Children's Self-Concept scale total scores. 


\section{Design of the Investigation}

As self-concept is impacted by a variety of outside factors, this study was designed to examine the relationships of the following major self-concept variables which have been found through research to have an important influence upon self-concept: achievement, age of the subject, sex, socioeconomic status (SES), ethnic origin, place in the family, significant others, and special class placement. Achievement served as the selection variable; and the entire population for the study had equivalent achievement scores on the Portland Achievement Test's spring testing. Age, sex, sEs, ethnic origin, place in family, significant others, and special class placement were independent variables.

Most labels are derived from diagnostic procedures which are deficit oriented and closely tied to whether the student is achieving according to grade level norms. The first confounding variable which had to be accounted for was that of achievement. Achievement, not $I Q$, is repeatedly cited in the literature as significantly correlating with measured student self-concept (Black, 1974; Bledsoe, 1964; 
Brookover, Thomas, \& Patterson, 1965; Brookover, Shailer, \& Patterson, 1964; Burns, 1979).20

For this reason, all students' scores in this study

fell within a predetermined equivalent achievement test

band range on the Portland Achievement Test.

After controlling for achievement influences upon self-concept, the study proceeded to focus on additional

influences of externai independent variables. Selfconcept literature describes seven major external variables which to some degree are believed to have an impact upon overall self-concept. This study needed to ascertain that the between-group differences in self-concept were due to labeling and not confounded by these seven independent variables. These external variables could prove a threat to the study's validity by interacting with the student's global self-concept and thus causing between-group differences which prevented a clear view of labeling relationships with the student's self-concept.

20 Further individuals who support this correlation between achievement and self-concept are: Busby, Fillmer, \& Smittle, 1974; Caplin, 1969; Caslyn Kenny, 1977; Cole, 1974; Combs, 1964; Coopersmith, 1959; Covington \& Beery, 1976; Fink, 1962; Gordon, 1977; LaBenne \& Green, 1965; Leviton, 1975; McIntire \& Drummond, 1977; Primavera, Simon, \& Primavera, 1974; Purkey, 1970; Rogers, Smith \& Coleman, 1978, Roth, 1959; Samuels, 1977; Sears, 1970, Silvernail, 1981; Simon \& Simon, 1975; Smith, Zingale, \& Coleman, 1978; Strang, Smith, \& Rogers, 1978; Vereen, 1980; Williams \& Cole, 1968; Zimmerman \& Allebrand, 1965. 
While the literature's findings for these seven external independent variables are sometimes mixed, enough studies have found them to exert a significant influence upon a child's self-concept that ignoring the potential for their contaminating this study's self-concept findings would have been unscholarly. Consensus as to age influences upon a child's self-concept is not reached within the literature. Theoretical arguments over self-concept crystalization with age (or lack of it) are set forth by Erikson (1968), Rosenberg (1979), Rosenberg and Raplan (1982), and Silvernail (1981). A number of research studies and writings recount the presence of age influences upon a child's self-concept (Bledsoe, 1962; Bohan, 1973; Coleman, Campbell, Hobson, \& Others, 1966; Grant, 1969; Long, Henderson, \& Ziller, 1967; Piers \& Harris, 1964; Trowbridge, 1972). Sex variations in children's self-concept are particularly evident in low-achieving students. AS LD students have low achievement in one or more school areas, sex should be considered an important external variable which must be examined. A number of studies agree that self-concept can vary on the basis of sex (Bohan, 1973; Connell, stroobant, Sinclair, Connell, \& Rogers, 1975).21

21 others evidencing work in this area are: Coopersmith, Erdwins, Small, \& Gross, 1980; Maccoby \& Jacklin, 1974; Purkey, 1970; Rosenberg \& Simmons in Rosenberg \& Kaplan (Ed.), 1982; Stryker in Rosenberg \& Kaplan (Ed.), 1982 . 
Ethnic origin refers to whether or not the child is a member of a minority group. For many years, minority group membership has been shown to be a significant factor in self-concept research (Asher \& Allen, 1969; Chang, 1975).22 Socioeconomic status (SES) is considered an important part of self-concept research because of its interactive social group ties with social group membership.

Self-concept is theoretically based upon social interactions (Burns, 1979).23 Many of the writings which examine the relationship between self-concept and SES describe significant ties between high self-concept and high SES (Clemerits, Peck, \& Green, 1978; Linton, 1972; Proshansky \& Newton, 1968; Rosenberg, 1979; Samuels, 1977; Silvernail, 1981; Stryker in Rosenberg \& Raplan (Ed.), 1982; Trowbridge, 1972) .

Place in family refers to the child's place in the birth order of siblings. From the literature which was

22 Others examining self-concept and minority group membership are: Gabbler \& Gibby, 1967; Goodman, 1952; Hawk, 1967; Lewin, 1948; Marx \& Winne, 1975; Peterson \& Ramirez, 1971; Porter, 1971; Proshansky \& Newton, 1968; Rosenberq \& Simmons, 1971; Soars \& Soars, 1971; Stryker in Rosenberg \& Kaplan (Ed.), 1982.

23 Numerous scholars believe that self-concept has its basis in social interaction: Adler, 1927; Allport, 1955; Brookover, Thomas, \& Patterson, 1965; Calhoun \& Morse, 1977; Cattel, 1950; Coleman, Campbel1, Hobson, \& Others, 1966; Cooley, 1912; Erikson, 1968; Horney, 1945; James, 1890; Jersild, 1952; Lecky, 1934; Lemert, 1972; Maslow; 1954; Mead, 1934; Merton, 1948; Rogers, 1951, 1959; Schur, 1971; Sullivan, 1953; Zuercher, 1977. 
reviewed, this independent variable receives the least attention in empirical research (Coopersmith, 1967; Sechris, 1970). Generally, place in family is described as a possibly confounding variable within studies which resulted in nonsignificant research findings (McDaniel, Ball, \& Fortunato, 1978; McIntire \& Drummond, 1977; Sears, 1970). Significant others are persons of importance to the child. These important persons reinforce behaviors and influence self perceptions (Soars \& Soars, 1971). The most highly significant others to school children are parents, peers and teachers. It is unknown as to which of these significant others had more influence upon the child's self-concept (Smith, 1980). Research studies confirm that significant others do influence a child's self-concept (Behrens, 1954; Brookover, Erikson, \& Joiner, 1967; Chang, 1975; Coopersmith, 1967; Davidson \& Lang, 1960; Kleinfeld, 1972; Mannarino, 1976; Rogers, Smith, \& Coleman, 1978; Stott, 1939).

Special class placement pertains to the type of services which the LD child receives in the school. These services can range on a continuum between total service in a regular classroom to total service in a special education class. Two factions differ in their view of which type of placement best fosters positive self feelings for LD students. They are in agreement that placement does influence 
self-concept (Drews \& Goldberg in MacMillan, Jones, \& Aloia, 1974; Kaplowitz, 1981).24

In order to examine these external variables' influences upon self-concept each distribution was analyzed for statistical differences between regular and special education labeled LD student groups. Any of the external variable scores found to be significantly different (at $p<$ .05) between regular and LD labeled student groups, were to be statistically analyzed to determine whether they could be responsible for between-group differences on student self-concept scores. Through these variable controls, the study was able to determine whether these independent variables significantly increased the variance between LD labeled and regular student groups on their Piers-Harris Self-Concept Scale. Variable data were analyzed as shown in the following Figure 1.

\footnotetext{
24 Others contending that placement can impact self-concept are: Bacher, 1965; Borg, 1966; Carroll, 1967; Jones \& Aloia, 1974; Dunn, 1968; Johnson \& Kirk, 1950; Jones in MacMillan et al., 1974; Mann, 1960; Meyerowitz, 1962; Olavarri, 1966; Ribner, 1978; Schurr, Towne, \& Joiner, 1972; Smith, 1980; Strang, Smith, \& Rogers, 1978.
} 
ACHIEVEMENT

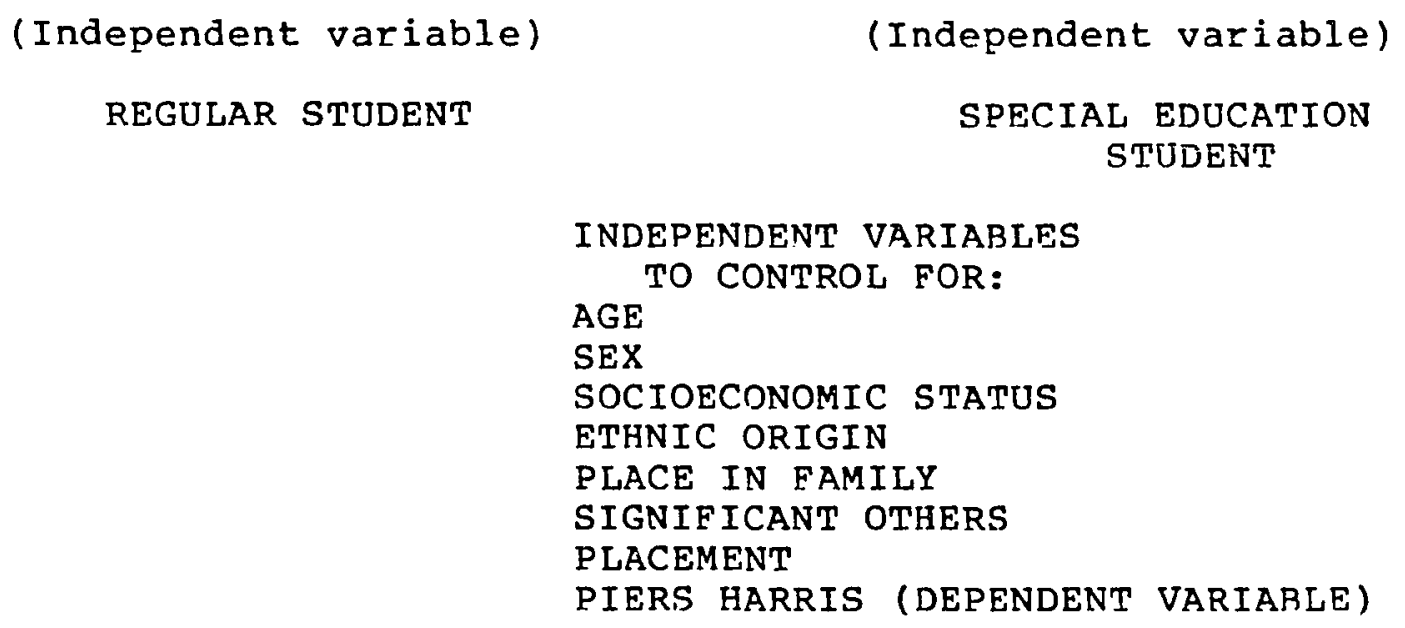

Figure 1. Variable Labels (Selection Variable). 
Initially the study was designed to use statistical controls for significant external variables. Due to the limited number of participants, analysis through varied statistical manipulations took the place of the planned "statistical controls for external variables" as shown in Figure 2 . These analyses were used to form a data profile where conclusions were drawn as a result of a variety of statistical manipulations. Analysis of the statistical findings

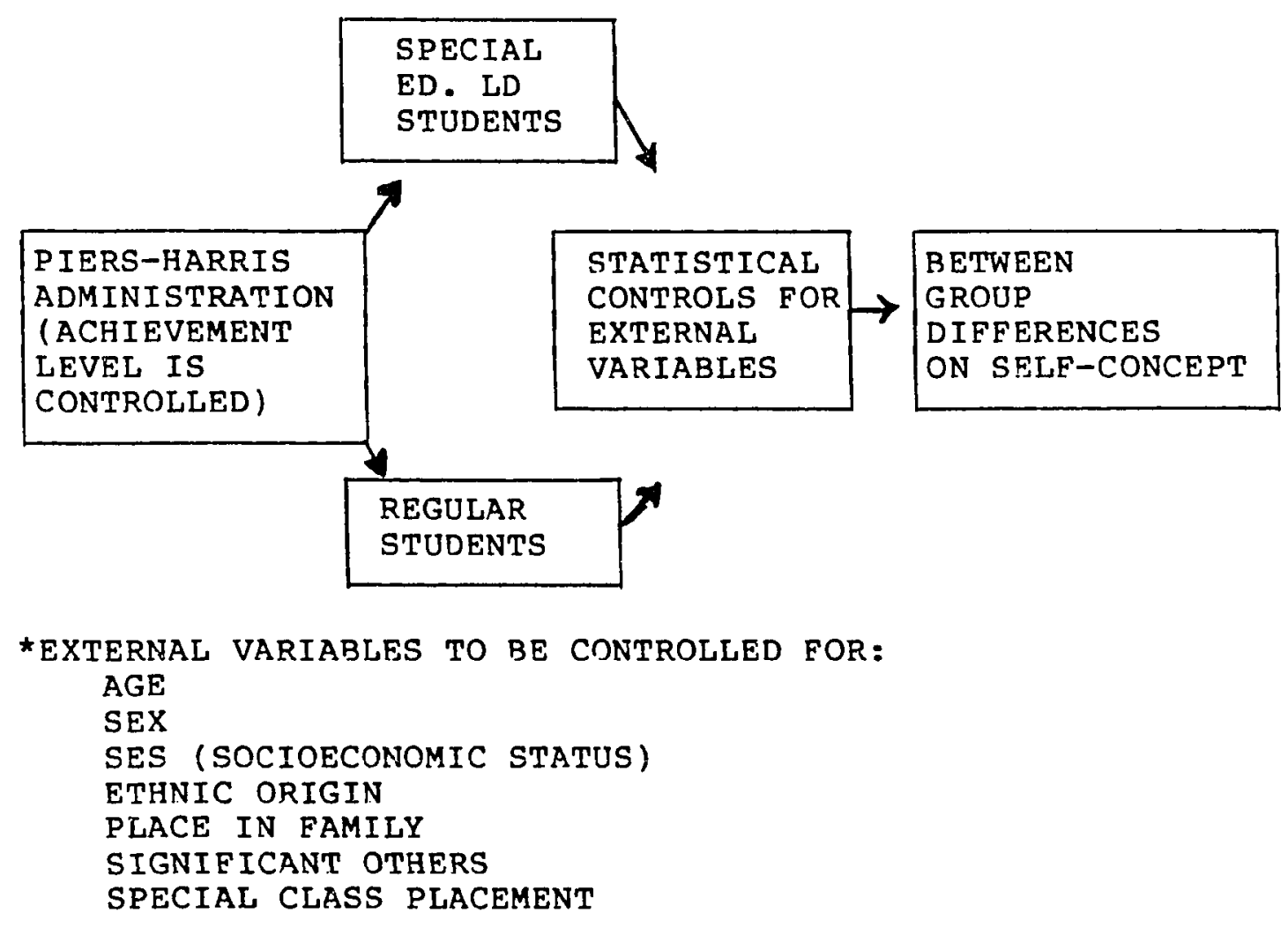

Figure 2. Design for the study. 
resulted in the building of a case to substantiate the study's hypothesis.

\section{subjects}

Description of Subjects

Subjects were drawn from the Fall 1983 fifth grade student population of. three suburban Portland, Oregon school districts. These districts include: Centennial School District, David Douglas School District, and Reynolds School District. Participants for this study were choser according to fifth grade placement due to reading and comprehension skill levels which LD students needed to complete the Piers-Harris Self-Concept Scale.

The specific study group was further defined by the predetermined selection criterion of spring Portland Achievement Test composite Math and Reading RIT (Rasch achievement equal interval units) scores ranging from 354 to 386. RIT achievement score ranges were determined through statistical analyses of all learning disabled LD students' achievement scores, $\bar{A}$ mean and a standard deviation of the entire three district LD population's achievement scores, were used to set the equivalent band range for the achievement score. All LD students having combined reading and math RIT scores which fell within the band range of 1 SD below the mean and .5 SD above the mean were asked to participate in the study. 
Subjects were randomly selected to comprise a control group. Students who were not labeled for special education service purposes (regular students), and who had RIT scores falling within the established achievement score band range, became the control group. From a total of 127 subjects who were requested to participate in the study, 44 subjects and their families consented to participate. Research results for all study populations were evaluated when 44 subjects were generated to meet the minimum requirements of the data analysis section. The final study sample included 18 learning disabled and 26 regular class students with equivalent reading and math achievement scores.

\section{Sampling Procedures}

Selection of students to participate in the study was through the use of stratified random sampling. Names of students meeting the criteria on the portland Achievement Test were retrieved from the computer bank. Retrieved subjects were grouped on the basis of whether they had or did not have special education LD labels. Those subjects with LD special education labels comprised one group, while subjects who had not been labeled for any type of special education service comprised the control group. All LD labeled students falling within the selection criterion band range were requested to participate in 
the study. The examiner randomly selected names of students from the regular student group population whose scores fell within the predetermined achievement band range. A total of 127 subjects were mailed consent and family information forms.

A breakdown of sex, age, and ethnic origin was essential to allow for an analysis of the variable interrelationships which can impact self-concept. Boys were more heavily represented (26 participants) than girls (18 participants). Subjects ranged in age from 10 to 12 years of age. Minority group members accounted for only two students.

Subjects with LD special education labels comprised one group. Those subjects who had not been labeled for any type of special education services comprised the control group.

\section{Data Gathering}

Collection of data for use in this research occurred on two levels. Parents completed consent and demographic information sheets (see Appendices $A$ and $B$ ). The demographic information sheets provided information to assist in controlling for external variables as well as for probing parental perceptions of subject association with and internalization of handicapping condition labels.

Once forty-four parents and subjects consented to participate in the study, subjects from both groups were 
taken from their respective classrooms and administered the Fiers-Harris Self-Concept Scale: "The Way I Feel About Myself." Subjects, at the same time, completed a researcher developed student Information Sheet (SIS). The researcher gave instructions which encouraged subjects to answer how they felt, not how they believed others expected them to respond. Subjects were assured that their responses would be held confidential and would not in any way affect their school report cards. This was necessary to encourage frank student responses which were not motivated by concerns over socially desirable answers. Students were asked to mark one answer per question on both the dichotomous Piers-Harris Self-Concept Scale and the multiple choice portion of the SIS (Student Information sheet).

The entire subject response period ran about twenty minutes. Subject removal from classroom activities did not exceed thirty minutes. An overview of the data collection procedures is shown in rigure 3 . 
Informed Consent and Demographic Information forms mailed to parents of subjects.

Parent and student signatures on the Informed Consent Forms.

Parental response to demographic information questions.

Forms mailed to the PSU Special Education Department. Special Education secretaries separated signed consent forms from numbered demographic forms. Researcher and Special Education Directors mailed reminder cards/made phone calls to parents who had not responded to the initial mailing.

Building level testing dates, times, and room locations were set.

Students were administered the Piers-Harris by the researcher.

Self-Concept Scale and Student Information Sheets were analyzed by the researcher.

Figure 3. Data collection procedures. 
Apparatus

Parents filled out a family information sheet. Students completed the Piers-Harris Self-Concept scale: The Way I Feel About Myself, and a single page researcher developed sIs (student Information sheet).

Family Information. The family information sheet is a ten question survey which was designed to provide information pertaining to subject association with and internalization of the LD label. Information to be used in the examination of external variables which have been shown by research to impact self-concept was also collected. Questions were primarily multiple choice with one short answer completion. Data which were collected on this form were combined with student response data and analyzed in total. Piers-Harris Self-Concept Scale. Students answered questions on the Piers-Harris Self-Concept Scale as the researcher read them aloud. The Piers-Harris Self-Concept Scale is an eighty question dichotomous, forced choice measure (see Appendix C). Items on this scale are designed to elicit global self-concept information from student respondents. Geared for students with an approximate third grade reading level, the Piers-Harris was readily completed in some fifteen to twenty minutes. (Administration and scoring of this scale did not require a psychometrist or special training). 
Items on the Piers-Harris are presented in a simple declarative statement format where students circle either a "yes" or "no" response. There are equivalent numbers of positively and negatively worded response items. The sequence of expected "yes" and "no" responses is varied in order to more readily zero in on student inappropriate guesses or peseveration patterns.

Originally a pool of 164 Piers-Harris items were drawn from a Jesild (1952) study's findings. This study was related to children's personal concerns regaráing themselves. Item statistical analysis and judge recommendations have resulted in a reduction to eighty items.

Multiple factor analysis was used by Piers-Harris, and six primary content area factors resulted from this analysis: behavior, intellectual and school status, physical appearance, anxiety, popularity, happiness and satisfaction. A verificational analysis of these six areas was not a part of this study. Weighting for each factor has not been standardized and was therefore avoided.

Reliability. The Piers-Harris Self-Concept Scale is one of the most reliable self-concept instruments with alpha coefficients ranging from .88 to .95 (Smith \& Rogers, 1978). Smith and Rogers amassed reliability information on the Piers-Harris for LD subjects. Using 
data from a variety of geographical areas they report strong and consistent short and long term lover six months) test-retest reliability (Smith \& Rogers, 1977). Smith and Rogers' respect for the reliability of the Piers-Harris Self-Concept scale is echoed by Shavelson, Hubner, and stanton (1976), as well as Robinson and Shaver (1973)

Stewart, Crump, and Mclean (1979) conducted a testretest reliability study with the Piers-Harris. Over three test completions, they found LD junior high and elementary student item responses to be unstable.

Test-retest reliability information is available for the initial 164 items and the revised form (being used in this study) with 80 irems. Both forms evidence significant test-retest correlations, with the shorter revised version having a higher significant retest correlation of .77 after a four month interim period (Piers \& Harris, 1969). Coefficients of internal consistency for student total score rank orderings are stable (Shavelson, et al., 1976; Wing in Piers \& Harris, 1969). Inter-scorer reliability on the Piers-Harris should be very high as a result of both simple instructions and dichotomous forced choice responses. Respondents simply mark the "yes" or "no" answer beside the statement which the researcher reads to them. 
Validity. Construct validity is confirmed by the findings of a number of studies. A study by Cox (Piers \& Harris, 1969) found subject self-concepts to substantiate existing theories of child rearing practices. Millen (Piers \& Harris, 1969) described findings of significant correlations between the Piers-Harris, the Children's Social Desirability Scale, and the Children's Manifest Anxiety Scale. Piers and Harris (1964) report confirmation of theoretically predicted lower self-concept for 88 MR (Mentally Retarded) subjects who were institutionalized. Smith (1980) also claims that the Piers-Harris Self-Concept scale does have construct validity as a result of student scores which confirm self-concept predictions made by social comparison theory.

Concurrent validity was found by Mayer to be significant at $p<.01$ between the Piers-Harris Self-Concept Scale and the Lipsitt Children's Self-concept Scale (Mayer, 1965). Piers (in Piers-Harris, 1969) found $p<$ .05 to $p<.01$ significant correlations between PiersHarris total scores and peer ratings for three fourths of their sample groups of fourth and sixth grade students. In the same study only one of four groups of fourth and sixth graders had positive correlations between teacher ratings and Piers-Harris total scores. Cox found highly significant correlations $(p<.01)$ for sixth through ninth grade teacher and peer ratings as compared to Piers-Harris 
total scores for the areas of socially effective behavior and superego strength (Piers \& Harris, 1969).

While phenomenological measures generally have limited predictive powers, Guardo (1969) did find a correlation between Piers-Harris Self-Concept Scale total score predictions and popularity nominations. Therefore, when considering "state of the art" self-concept: measures, Smith and Rogers tell us that the Piers-Harris is;, "One of the best instruments for assessing a child's self-concept" (Smith \& Rogers, 1977, p. 558). Robinson and Shaver (1973); Shavelson; Huber, and Stanton (1976); and Wylie (1974) agree that the Piers-Harris is one of the more valuable self-concept assessment instruments.

The Piers-Harris . . is superior to most self report, paper and pencil procedures for self-concept in that psychometric data are available, and its use in ongoing research adds evidence to its validity (Knapp, 1973, p. 22).

Repeatedly, the Piers-Harris has been used with learning disabled (LD) students (Smith, 1980; Smith \& Rogers, 1978; Stephans, 1977; Wanat, 1983). Wylie's (1974) primary concern over the use of the Piers-Harris with children evidencing learning disabilities is focused on the possible confounding of low scores by unreliable responses. This issue of response unreliability was determined not to be a concern in a study by Smith and Rogers (1977). 
It may be concluded that the Piers-Harris selfConcept scale is an appropriate and reliable instrument for the measurement of self-concept in elementary aged children at least as early as the third grade, and for children representing somewhat different populations in terms of geographical location and urban or rural setting (Stanwyck \& Felker, 1971, p.5).

\section{Student Information Sheet}

A researcher designed SIS (Student Information

Sheet) was administered with the Piers-Harris Self-Concept scale. Student instructions for both measures were provided by the researcher before the testing began. Subjects answered questions as the researcher read them. The SIS was comprised of seven multiple choice questions designed to probe student identification with: success in school, student perceptions of teacher support/or lack of it, and awareness of personally applied special education labels.

One short written definition response is geared towards ascertaining whether the subjects attribute positive or negative definitions to the LD handicapping condition which they may have. Answers to this question were used to draw some conclusions regarding the subjects' images of themselves in accordance with whether they defined the handicapping condition in a positive or negative fashion. 


\section{Data Analysis}

Data were gathered and analyzed to determine how much explained variance could be attributed to special education labeled students as compared to regular education students. Analysis of Variance (ANOVA) and Chi Square were used to examine whether: age, sex, socioeconomic status, ethnic origin, place in family, significant others, or special placement were significantly different between groups.

Further ANOVA manipulations of data were used to examine the main effects of the Piers-Harris total scores by special education learning disabled students and regular students with the variables: age, socioeconomic status other children, significant others, and special class placement.

Conclusions regarding labeling relationships with self-concept were generated through the analysis of findings which indicated significance $(p<.05)$. Piers-Harris Self-Concept Scale total score analysis of variance with a $p<.05$. region of rejection.

\section{Limitations}

A variety of research limitations resulted from the small number of participants in this study. Appropriate statistical analyses were severely limited by the small sample number. ANOVA was used as a research tool to 
comprise one component in a case building approach. Use of this statistic with a sample of 44 subjects necessitated the examination of data through the use of a number of statistical manipulations. With the numerous inaependent variables which this study needed to address, statistical controls for significant between group differences could not be exercised. Rather, case building through a variety of statistical analyses was necessary.

It had also been hoped that the effects of interactive variables could be analyzed. Individual attention to the potentially confounding external variables of self-concept is not sufficient unto itself when considered in accordance with self-concept theory. Unfortunately, interactive variable effects could not be analyzed due to this small sample. Therefore, the seven variables, which research has targeted as potential influences upon selfconcept, could not be examined in this study to the extent initially planned to determine whether together they exerted a significant influence upon self-concept.

Two other possible limitations could pertain to the assessment tools used for the determination of achievement and self-concept levels. This study made the assumption, based upon careful research, that these two measures were valid indicators of achievement and self-concept for both LD and regular class students. 
Statistically significant findings from this study are generalizable to fifth grade elementary populations with composite, spring testing, math and reading achievement scores ranging from 354 to 386 on the Portland Achievement Test. These findings are further limited in generalizability to Pacific Northwest suburban regular and learning disabled students. 


\section{CHAPTER IV}

\section{FINDINGS}

The intent of this study was to examine whether students labeled (learning disabled) for special education delivery services exhibit lower global self-concepts than regular non-labeled students when achievement and other variables, ascribed with the capacity to impact self-concept, have been controlled. This chapter examines data which were collected and analyzed via a variety of statistical procedures. A case-building approach was used due to the statistical limitations created by the small number of subjects who chose to participate in this study. Two major areas of findings are described. The first section of this chapter focuses upon data and?yses which pertain to the seven variables described by the literature to have significant impact upon self-concept. The following section carried out data analyses supporting or rejecting this study's hypothesis. Last, some interesting incidental findings are shared.

\section{Crosstab Analysis of Respondent Representation}

The following tables depict respondent represeníation by frequency and group percentage. of those partici- 
pants in this study, 18 (418) were learning disabled while 26 (598) were regular students. A total of 44 subjects participated in this research.

TABLE I

RESPONDENT REPRESENTATION ON SELF-CONCEPT VARIABLES

\begin{tabular}{|c|c|c|c|c|c|c|}
\hline \multirow[b]{2}{*}{ Variable } & \multicolumn{2}{|c|}{$\begin{array}{l}\text { Learning } \\
\text { Disabled } \\
\text { Students }\end{array}$} & \multicolumn{2}{|c|}{$\begin{array}{l}\text { Regular } \\
\text { Students }\end{array}$} & \multicolumn{2}{|c|}{$\begin{array}{l}\text { Total } \\
\text { Group }\end{array}$} \\
\hline & $\mathrm{N}$ & 8 & $\mathrm{~N}$ & 8 & $\mathrm{~N}$ & 8 \\
\hline $\begin{array}{l}\text { Age: } \\
10 \text { years old } \\
11 \text { years olds } \\
12 \text { years old }\end{array}$ & $\begin{array}{l}4 \\
9 \\
5\end{array}$ & $\begin{array}{l}9 \\
20.5 \\
11.4\end{array}$ & $\begin{array}{r}15 \\
9 \\
2\end{array}$ & $\begin{array}{r}34.2 \\
20.5 \\
4.5\end{array}$ & $\begin{array}{r}19 \\
18 \\
7\end{array}$ & $\begin{array}{l}43.2 \\
40.9 \\
15.9\end{array}$ \\
\hline Column Total & 18 & 40.9 & 26 & 59.1 & 44 & 100 \\
\hline $\begin{array}{l}\text { Sex: } \\
\text { Female } \\
\text { Male }\end{array}$ & $\begin{array}{r}4 \\
14\end{array}$ & $\begin{array}{r}9.1 \\
31.8\end{array}$ & $\begin{array}{l}14 \\
12\end{array}$ & $\begin{array}{l}31.8 \\
27.3\end{array}$ & $\begin{array}{l}18 \\
26\end{array}$ & $\begin{array}{l}41.0 \\
59.0\end{array}$ \\
\hline Column Total & 18 & 40.9 & 26 & 59.1 & 44 & 100 \\
\hline $\begin{array}{l}\text { Socioeconomic Sta } \\
\text { Missing Data } \\
\$ 100-\$ 9,999 \\
\$ 10,000-\$ 14,999 \\
\$ 15,000-\$ 19,999 \\
\$ 20,000-\$ 29,999 \\
\$ 30,000-\$ 44,999\end{array}$ & $\begin{array}{l}\text { tus: } \\
1 \\
2 \\
2 \\
1 \\
6 \\
6\end{array}$ & $\begin{array}{r}2.3 \\
4.5 \\
4.5 \\
2.3 \\
13.6 \\
13.6\end{array}$ & $\begin{array}{l}0 \\
4 \\
4 \\
3 \\
7 \\
8\end{array}$ & $\begin{array}{r}0 \\
9.1 \\
9.1 \\
6.8 \\
15.9 \\
18.2\end{array}$ & $\begin{array}{r}1 \\
6 \\
6 \\
4 \\
13 \\
14\end{array}$ & $\begin{array}{r}2.3 \\
13.6 \\
13.6 \\
9.1 \\
29.5 \\
31.8\end{array}$ \\
\hline Column Total & 18 & 40.9 & 26 & 59.1 & 44 & 100 \\
\hline $\begin{array}{l}\text { Ethnic Origin: } \\
\text { Black } \\
\text { White } \\
\text { Native American }\end{array}$ & $\begin{array}{r}1 \\
17 \\
0\end{array}$ & $\begin{array}{c}2.3 \\
38.6 \\
0\end{array}$ & $\begin{array}{r}0 \\
25 \\
1\end{array}$ & $\begin{array}{c}0 \\
56.8 \\
2.3\end{array}$ & $\begin{array}{r}1 \\
42 \\
1\end{array}$ & $\begin{array}{r}2.3 \\
95.4 \\
2.3\end{array}$ \\
\hline Column Total & 18 & 40.9 & 26 & 59.1 & 44 & 100 \\
\hline
\end{tabular}


TABLE I (Continued)

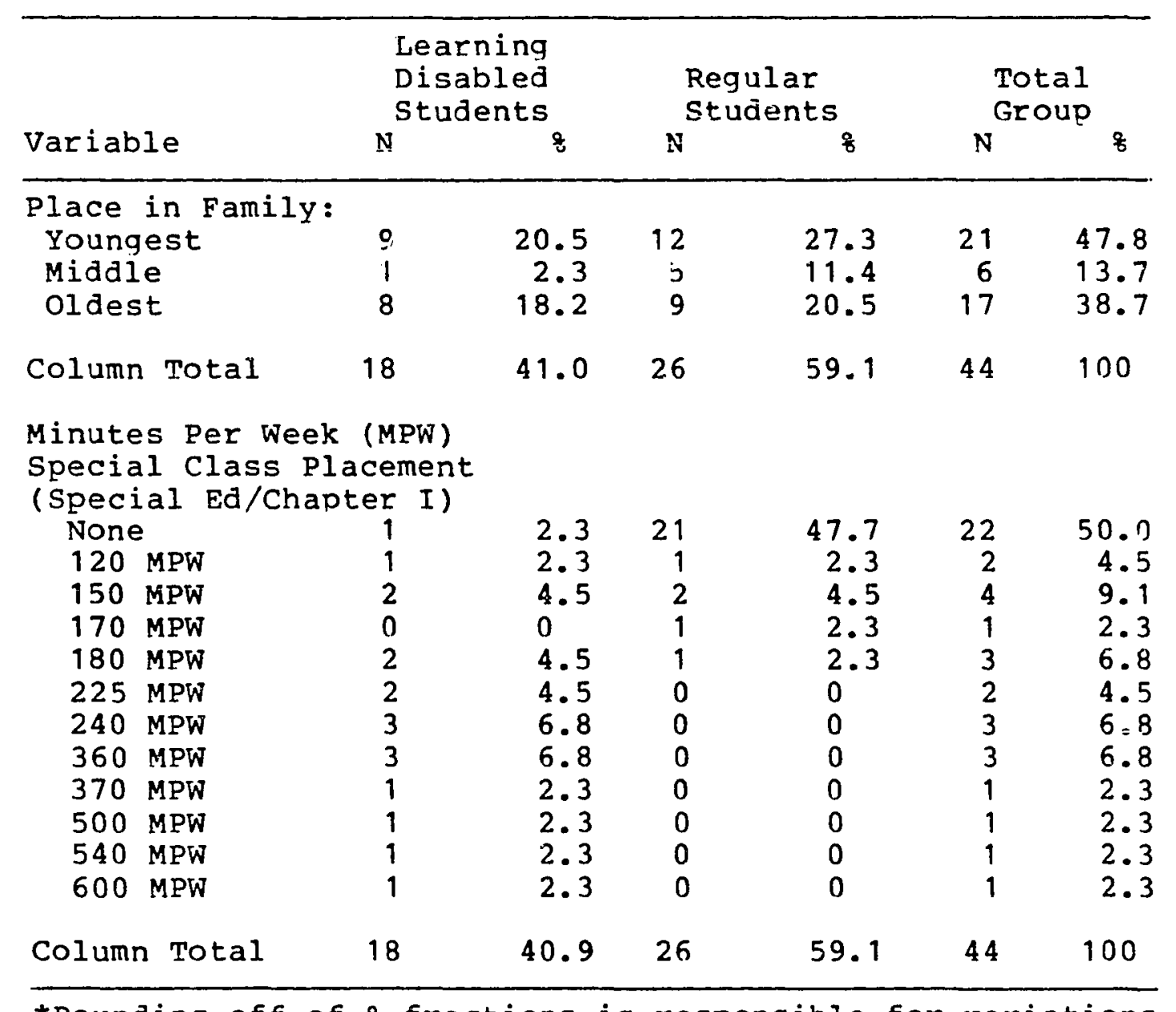

* Rounding off of 8 fractions is responsible for variations in some column totals. 
Comparisons of between-group frequency scores in Table I indicated some sharp variations from one respondent group to the other. LD students represented a greater percentage of the older subjects. Sex crosstabs showed a marked difference between both groups of respondents. Fewer females were found in the LD group as compared to the regular student group. For the "place in family" analyses, middle children were less proportionally represented in the LD group as compared to the reqular student group. Both groups showed proportional representation in the youngest and oldest "place in the family" groupings. Major between-group differences were also evident when examining the minutes per week for special class placement in special education/Chapter I services. Special education labeled students represented a heavily skewed portion of the population receiving special services. It had been expected that regular students with reading and math achievement scores equivalent to LD students would have high levels of representation in the Chapter I service recipient group. This finding was not the case, as evidenced in the highly skewed number of LD subjects receiving special services.

Key Variable Analysis

Further analysis for between group mean score differences between regular and LD student qroups, are pre- 
sented in Tables II, III, IV, and V. Here appropriate statistics for parametric and nonparametric data were used to determine whether the differences between study groups should be considered significant variables, and thus to be key variables for comparison in this study.

TABLE II

NONPARAMETRIC VARIABLE ANALYSIS USING CHI SQUARE

\begin{tabular}{llll}
\hline $\begin{array}{l}\text { Special Ed/ } \\
\text { Regular Ed w/Variable }\end{array}$ & $\mathrm{Chi}^{2}$ & DF & $\mathrm{p}$ \\
\hline Family Place & 1.75762 & 2 & .4153 \\
Ethnic Origin & & & \\
$($ corrected Chi & \\
Sex & 2.140 & 2 & .343 \\
\hline
\end{tabular}

*Significant $p<.05$ region of rejection.

of the three variables for which non-parametric statistical analyses were necessary, only one gave any indication of a relationship which could be proven strong enough to exert an important influence upon self-concept for one of the two groups. The variable of concern was sex (see Table II). Variation between groups approached significance for sex at $p=.0741(p<.05)$. Neither family place nor ethnic origin could be considered to be a potentially confounding variable to the self-concepts of students from either group since the variation between groups for these variables was far from significant. Parametric variables are analyzed on Tables III, IV, and V. 
TABLE III

t-TEST PARAMETRIC VARIABLE ANALYSIS

\begin{tabular}{|c|c|c|c|c|c|c|c|}
\hline Variable & $\mathrm{n}$ & $\mathrm{m}$ & SD & $\mathrm{SE}$ & $\frac{t}{v a l u e}$ & $\mathrm{DF}$ & $\begin{array}{l}2 \text { Tail } \\
\text { Proba- } \\
\text { bility }\end{array}$ \\
\hline
\end{tabular}

Student Age In Months

$\begin{array}{llllllll}\text { Special Ed } & 18 & 138.667 & 6.607 & 1.557 & & \\ \text { Regular Ed } & 26 & 132.5 & 6.383 & 1.252 & & & .003 *\end{array}$

Income (Socioeconomic status)

$\begin{array}{llllllll}\text { Special Ed } & 18 & 4.3889 & 1.852 & .436 & & \\ \text { Regular Ed } & 26 & 4.4231 & 1.474 & .289 & & & .946\end{array}$

Placement

\begin{tabular}{|c|c|c|c|c|c|c|c|}
\hline Special & Ed & 18 & 280.0 & 156.12 & 36.798 & & \\
\hline & Ed & 26 & 29.6154 & 62.57 & $12.272^{6.45}$ & 20.82 & $.000 *$ \\
\hline
\end{tabular}

Significant Others

$\begin{array}{llllllll}\text { Special Ed } & 18 & 673.1667 & 482.776 & 113.791 & & \\ \text { Regular Ed } & 26 & 546.9231 & 506.787 & 99.389 & 42 & .412\end{array}$

*Significant $p<.05$ region of rejection.

Analysis of the parametric variables, deemed by the literature as being capable of having an impact upon selfconcept, was two-pronged. Due to the small sample size (44 participants) a t-test was first used because of its widespread use with samples of fifty or fewer subjects. Later ANOVA was also used to help in the building of a profile of 
the variables. The data were manipulated statistically using both methods, as each analysis offered a different dimension needed for a complete examination of the multiple variables addressed by this study. T-test analysis of the data was appropriate as the number of participants was less than fifty. ANOVA, not the most appropriate measure for this sized sample, allowed for a number of variables to be analyzed together.

of the four variables for which the $\underline{t}$-test was useä, only age and special class placement indicated significant $(D<.05)$ difference between groups. Student aqe was significant at $p=.003$ with LD subjects tending to be older than regular education subjects. Special class placement difference between groups was highly significant $(p=.000)$ with LD subjects receiving considerably more special class services than their regular education counterparts who had equivalent achievement scores in reading and mathematics.

Findings using the $t$-test and ANOVA were closely similar for the variables: student age, SES, placement and significant others. Data using both statistical measures were compared (see Tables III and IV). 
TABLE IV

ANOVA ANALYSIS

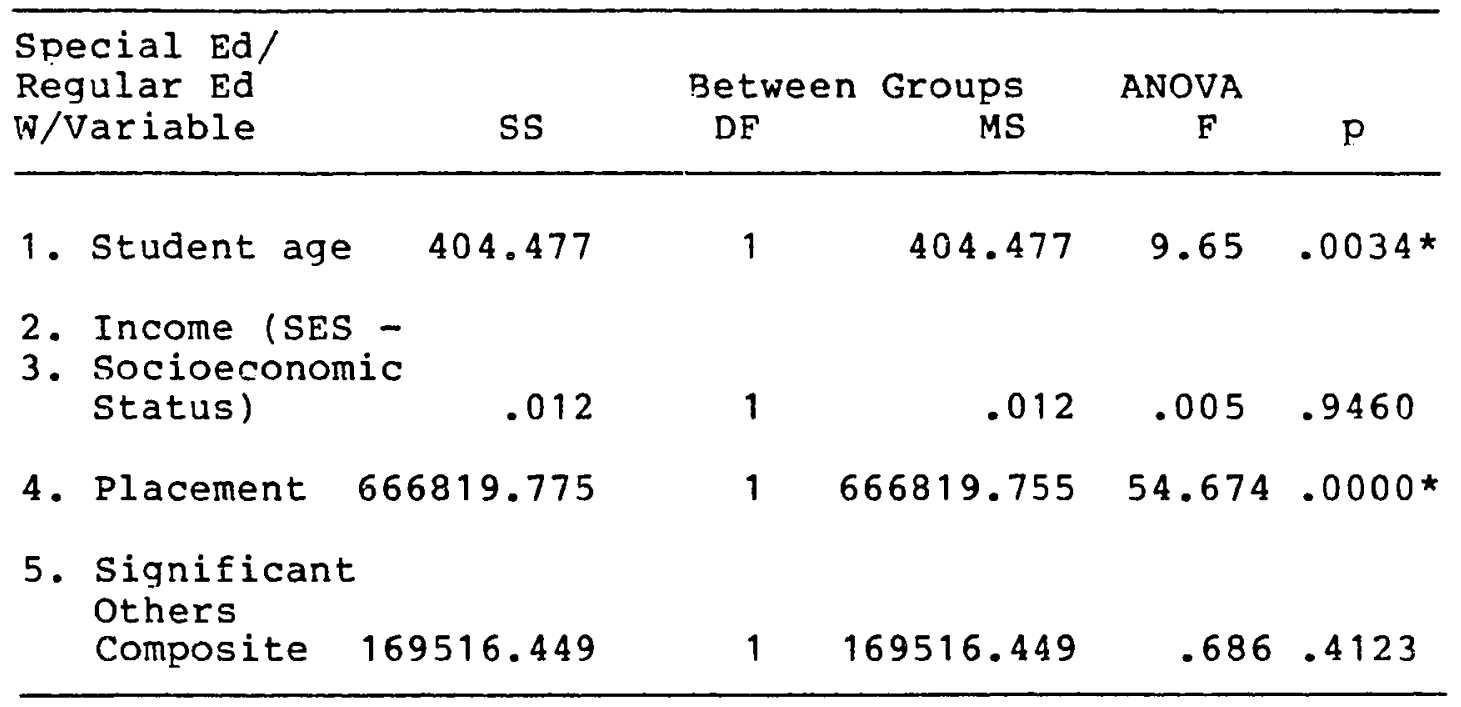

*Significant to $p<.05$ region of rejection.

From the analysis of control variables using the ttest and ANOVA, some significant between-group findings should be noted. Using both statistics, findings for student age were significant at $p=.0034$, and special class placement was highly significant at $p=.0000(p<0.05)$. Comparisons of the study's (dependent variable) total Piers-Harris scores indicated that both the $\underline{t}$-test and ANOVA findings did vary somewhat (see Tables $V$ and VI). 
Hypothesis Data Analysis

TABLE V

t-TEST SELF-CONCEPT MEASURE TOTAL SCORE ANALYSIS

\begin{tabular}{lcccccccc}
\hline $\begin{array}{l}\text { Total Piers- } \\
\text { Harris } \\
\text { Scores }\end{array}$ & N & M & SD & SE & Value & DF & $\begin{array}{l}\text { Praba- } \\
\text { bility }\end{array}$ \\
\hline Special Ed & 18 & 51.3889 & 16.964 & 3.998 & & & \\
Reqular Ed & 26 & 59.5385 & 9.981 & 1.957 & & & \\
\hline
\end{tabular}

*Significant $p<.05$ region of rejection

TABLE VI

ANOVA SELF-CONCEPT MEASURE TOTAL SCORE ANALYSIS

\begin{tabular}{|c|c|c|c|c|c|}
\hline $\begin{array}{ll}\text { Special Ed/ } \\
\text { Regular Ed W/ }\end{array}$ & SS & $\mathrm{DF}$ & MS & $F$ & $\mathrm{P}$ \\
\hline $\begin{array}{l}\text { Total Piers- } \\
\text { Harris }\end{array}$ & & & & & \\
\hline Score & 706.420 & 1 & 706.420 & 4.019 & $.0515^{*}$ \\
\hline
\end{tabular}

*Significant $p<.05$ region of rejection.

When the t-test was used to examine between groub variance on the total test scores from the Piers-Harris Self-Concept Scale, findings approached $p<.05$ significance with $p=.079$ (see Table V). On the same dependent variable, the Piers-Harris self-Concept scale, ANOVA analysis of the data indicated significant variance between regular student and LD student global scores. The degree of variance found 
through using ANOVA did meet the $p<.05$ region of rejection standard with significance at $p=0.0515$ (see Table VI). Due to the small sample size, these ANOVA results could not be considered conclusive unto themselves. Examination of both the $\underline{t}$-test and ANOVA findings indicated that there were considerable between group differences in the level of self-concept as reported by the Piers-Harris Self-Concept Scale. As a groud, regular education students exhibited higher global self-concepts than those of LD students with equivalent reading and math achievement.

\section{MAJOR HYPOTHESIS}

Special education students labeled "learning disabled" (LD) and regular education students, with scores within a band range of equivalent reading and mathematics achievement levels on the Portland Achievement Test and controlled on independent variables, statistically will show no significant difference between groups ( $p<.05$ ) on the Piers-Harris Children's Self-Concept Scale total scores.

Additional Analysis of Key Variables

In Table VII an analysis of covariance (ANCOVA) procedure was used to probe the interaction of total selfconcept scale scores as broken down by LD and regular student groups with the covariate student age. This ANCOVA 
approach allowed for a three variable analysis which also included the independent variables' influence when considered in conjunction with between group test score analyses. The purpose for this further investigation was to examine the grouped effects arising from new combinations of parametric variables which had shown significiant (or almost significant) variance in this study's earlier statistical analyses. Two parametric variables which indicated significant or approaching significant between group variations were age and special class placement.

TABLE VII

ANCOVA OF THE TOTAL PIERS-HARRIS SCORES BY LD AND REGULAR STUDENT GROUPS WITH THE AGE VARIABLE

\begin{tabular}{lccccc}
\hline $\begin{array}{l}\text { Source of } \\
\text { Variation }\end{array}$ & SS & DF & MS & F & P \\
\hline $\begin{array}{l}\text { Covariate: } \\
\text { Student Age }\end{array}$ & 36.266 & 1 & 36.266 & .202 & .655 \\
$\begin{array}{l}\text { Main Effects: } \\
\begin{array}{l}\text { LD and } \\
\text { Regular } \\
\text { Students }\end{array}\end{array}$ & 706.897 & 1 & 706.897 & 3.945 & .054 * \\
Explained & 743.162 & 2 & 371.581 & 2.074 & .139 \\
Residual & 7345.997 & 41 & 179.171 & & \\
Total & 8089.159 & 43 & 188.120 & & \\
\hline
\end{tabular}

*Significant $p<.05$ region of rejection. 
Analyzing the interactive effects of student age with LD and regular students on the Piers-Harris total scores with analysis of Covariance (ANCOVA), an interesting dimension became evident. When the variables were covaried, neither the covariate nor the explained effects of student age were significant (see Table VII).

An analysis of covariance was used to test whether the between-group differences, on LD and regular student scores for self-concept, would remain significant once the effect of varied age levels was removed. With the removal of the variable effect caused by student placement, the main effects of $L D$ and regular student self-concept score variations still approached significance at $p=.074$ (see Table VIII).

TABLE VIII

ANCOVA OF PIERS-HARRIS BY LD AND REGULAR STUDENT GROUPS WITH PLACEMENT

\begin{tabular}{lccccc}
\hline $\begin{array}{l}\text { Source of } \\
\text { Variation }\end{array}$ & SS & DF & MS & F & P \\
\hline $\begin{array}{l}\text { Covariate: } \\
\text { Special Class } \\
\text { Placement }\end{array}$ & 192.701 & 1 & 192.701 & 1.083 & .304 \\
$\begin{array}{l}\text { Main Effects: } \\
\text { LD and } \\
\begin{array}{l}\text { Regular } \\
\text { Students }\end{array}\end{array}$ & 599.540 & 1 & 599.540 & 3.369 & .074 \\
$\begin{array}{l}\text { Explained } \\
\text { Residual }\end{array}$ & 792.242 & 2 & 396.121 & 2.226 & .121 \\
& 7296.917 & 41 & 177.974 & & \\
Total & 8089.159 & 43 & 188.120 & & \\
\hline
\end{tabular}

*Significant $p<.05$ region of rejection. 
Age and placement were not making a significant contribution to the between-group variations on the PiersHarris Self-Concept scale scores. When the age variable's influence was included in the multivariate model shown on Table VII, $p=.054$ remained between the $L D$ and regular student groups on the Piers-Harris Self-Concept Scale. ANOVA and ANCOVA findings indicated that there were approaching significant between group differences $(\mathrm{p}=$ $.0515)$ on the Piers-Harris Self-Concept Scale for LD and regular students. ANCOVA analysis See Tables VII and VIII of the two significant or approaching significant variables of age and placement indicated no significant contributions by these two variables to total self-conceot scores. When these two potentially contaminating variables were controlled and removed as variable influences, the approaching significant $(p=.0515)$ between-group differences for self-concept, (found through analysis by ANOVA Table VI), could be explained to be a result of sex or labeling interactive relationships with self-concept. Since it was not possible to statistically control for the approaching significant variations found for sex ( $p=$ $.0741)$, both sex and labeling remained as potentially influential variables upon self-concept. When the tight standard for statistical analysis that this study has adhered to is followed, findings for this study are somewhat modified from those described in 
the previous paragraph. Strictly-applied statistical assumptions yielded findings which indicate that LD students had (approaching significant when using both ANOVA $\mathrm{p}=$ .0515 and $t$-test $p=.079$ with $p<.05$ region of rejection) lower global self-concept scores on the Piers-Harris Self-Concept scale than regular education students having equivalent achievement band range scores in reading and mathematics. Using this same stance, further statistical manipulations of the data would have been considered inappropriate due to the small sample size of forty-four participants. Therefore, these moderately significant group variations on global self-concept scores could be explained by the four independent or interacting external variables: age, placement, sex, or labeling influences. Two cases have been built to explain the findings for this research. Each has merit and deserves careful consideration. Some incidental findings have also been described as they served to shed additional light on this study's major research findings.

Incidental Expanded Data Findings

The literature described role engulfment as a phenomenon whereby the definition for a label becomes an internalized behavior for the person who has been labeled (Cassim, 1979; MacMillan, 1972; Rosenberg \& Kaplan, 1982). Therefore, this study posed a question to parents 
to probe this possibility. On the Family Information Sheet which parents completed, handicapping condition labels were described and parental responses were collected for the following question:

QJJESTION: Does your child use a handicap label to describe himself/herself?

$\longrightarrow_{\text {No }}^{\text {No }}$

If yes, could you please 1 ist any labels

TABLE IX

ENTIRE GROUP: STUDENT USES HANDICAP LABELS FOR SELF DESCRIPTION

\begin{tabular}{lrr}
\hline & N & 8 \\
\hline No & 40 & 90 \\
Yes & 4 & 10 \\
Total & 44 & 100 \\
\hline
\end{tabular}

of the entire group, only five subjects have been heard by their parents to describe themselves through using handicap labels. The histogram in Figure 4 depicts the between-group breakdown for LD and regular student responses. Only one fourth of the responses indicated LD student use of special education labels to describe themselves. Three regular students used these terms for self-description (see Figure 4 ). 


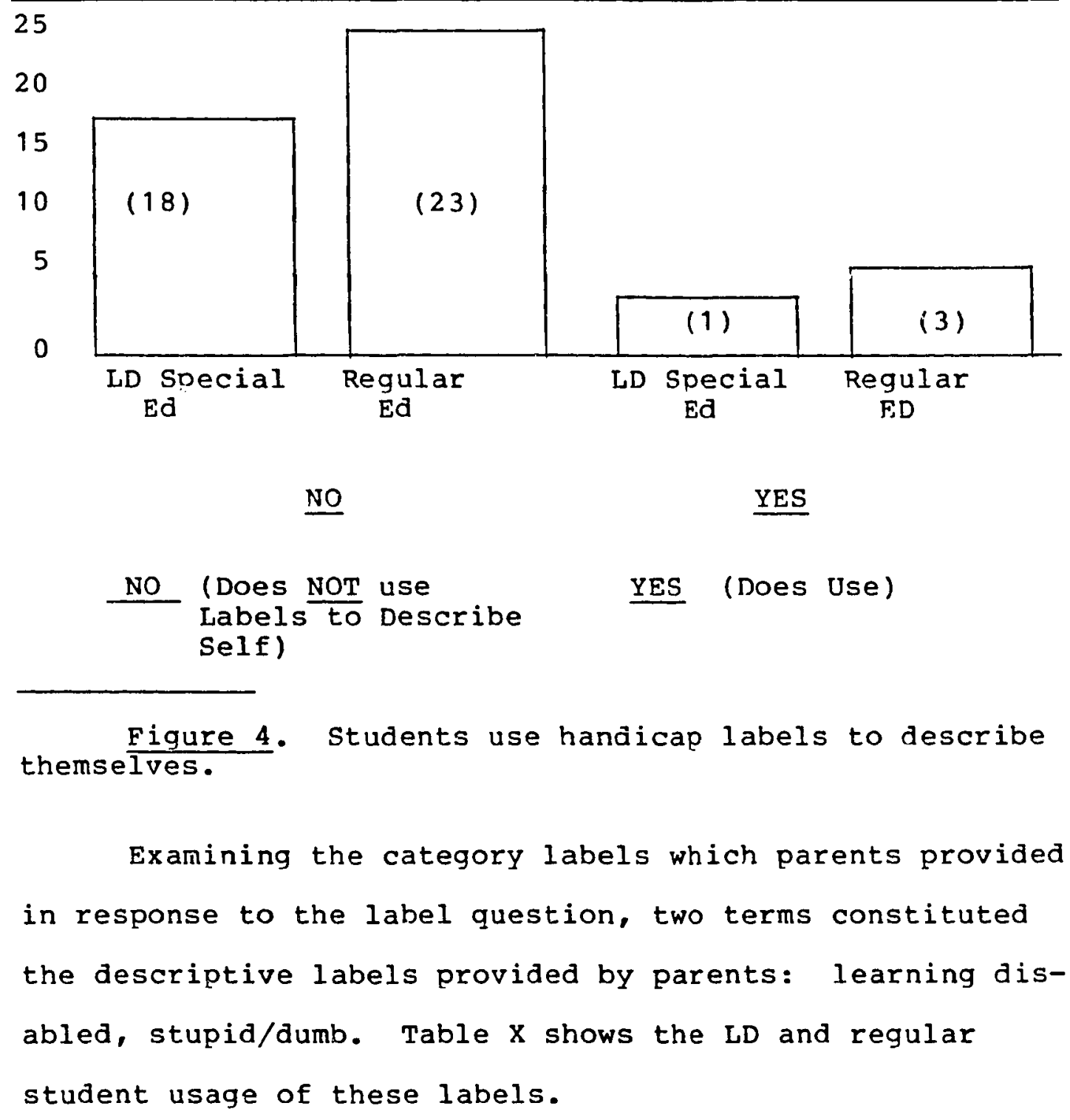


TABLE $X$

PARENTAL REPORTS OF HANDICAP LABELS

USED BY THEIR CHILD

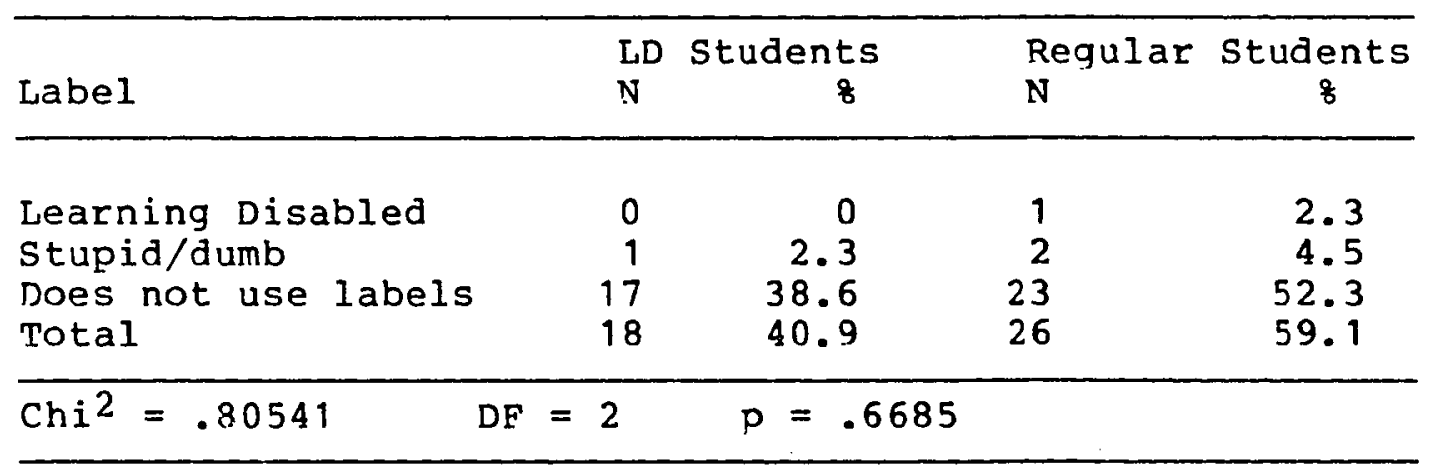

Between group analysis of self labeling by sturents, using $\mathrm{Chi}$ square, showed that there was not a significant difference in label usage by $L D$ and regular students $(p=.6685)$. Interestingly, one regular student used the LD label while no LD student used that label for selfdescription. Two regular students described themselves as stupid/dumb, while only one LD subject used either term. Therefore, role engulfment could not be related to the students' labeling of themselves as learning disabled.

other expanded data findings were derived from student perceptions of school importance and teacher relationships. All but one of these were used as a part of the "significant others" composite score. These four questions were completed by students as part of the sIs (Student Information Sheet). SIS questions and discussion of the four questions' findings are as follows: 
1. Question: Is doing well in school

Not important to you?

Somewhat important to you?

Important to you?

Very important to you?

Self-concept has many dimensions. One dimension can have more importance to one person than to another (Silvernail, 1981). One dimensional subset which involves life roles is that of categories (i.e. being a student). Attributes complement categories by being those characteristics which a student holds to be of greater importance (Purkey, 1970). Core descriptors are categories and attributes which are highiy valued by a person. A question which probes how a student wishes to do in school (see Question 1) was used to determine whether the category of being a student and the attribute of wishing to do well in school were important to students in this study (see Table XI).

TABLE XI

FREQUENCY OF STIJDENT RESPONSES OVER DOING WELL IN SCHOOL

\begin{tabular}{|c|c|c|c|c|c|c|}
\hline \multirow[t]{2}{*}{ Chosen Response } & \multirow{2}{*}{$\begin{array}{l}\text { LD } \\
\text { F }\end{array}$} & \multirow{2}{*}{$\underset{8}{\text { Students }}$} & \multicolumn{2}{|c|}{$\begin{array}{l}\text { Reqular } \\
\text { Students }\end{array}$} & \multicolumn{2}{|c|}{$\begin{array}{l}\text { Total } \\
\text { Group }\end{array}$} \\
\hline & & & $\mathrm{F}$ & 8 & $\mathrm{~F}$ & 8 \\
\hline $\begin{array}{l}\text { Doing well in Scho } \\
\text { Not important } \\
\text { Somewhat important } \\
\text { Important } \\
\text { Very Important } \\
\text { Total }\end{array}$ & $\begin{array}{r}001 \\
0 \\
2 \\
3 \\
13 \\
18\end{array}$ & is : $\begin{array}{r}0 \\
4.5 \\
6.8 \\
29.5 \\
40.8\end{array}$ & $\begin{array}{r}1 \\
2 \\
8 \\
15 \\
26\end{array}$ & $\begin{array}{r}2.3 \\
4.5 \\
18.2 \\
34.1 \\
59.1\end{array}$ & $\begin{array}{r}1 \\
4 \\
11 \\
28 \\
44\end{array}$ & $\begin{aligned} 2.3 \\
9.1 \\
25.0 \\
63.6 \\
100\end{aligned}$ \\
\hline $\mathrm{Chi}^{2}=2.02808$ & $\mathrm{DF}=$ & $\mathrm{p}=$ & & & & \\
\hline
\end{tabular}


All LD students attached some level of importance to doing well in school. In fact $72 \%$ of the LD subjects felt that doing well in school was very important to them. Doing well in school was somewhat important to $9 \%$ of all students, important to 258 of all students, and very important to 648 of all respondents. Therefore, doing well in school would appear to be important to most of these subjects' self perceptions. One regular student felt that doing well in school was not important while no LD student made this response (see Table XI). Responses to the other choices were fairly closely matched across groups. Therefore, the lack of significance in a Chi Square analysis of the two groups' responses to this question was not surprising (see Table XI). Low self-esteem persons have a greater dependency upon approval from others than do individuals with high self-esteem (Dittes, 1959; Jordan, 1953; Rosenberg, 1965). Teacher support and approval can exert considerable influence upon a child's self-concept (Brookover, Erikson \& Joiner, 1967; Burns, 1979; Davidson \& Lang, 1960 ; Erikson, 1968). Probing student feelings about the student/teacher relationship, while also testing for student perceptions of teacher behaviors towards them, Question Two failed to elicit any significant response. The frequency of 
responses were rather equally distributed, with a Chi Square analysis not significant at $p=.7647$ (see Table $X I I)$.

2. Question: My school teacher helps me to feel good about myself?

느o.

TABLE XII

FREQUENCY OF STUDENT RESPONSES TO "TEACHER HELPS ME TO FEEL GOOD ABOUT MYSELF"

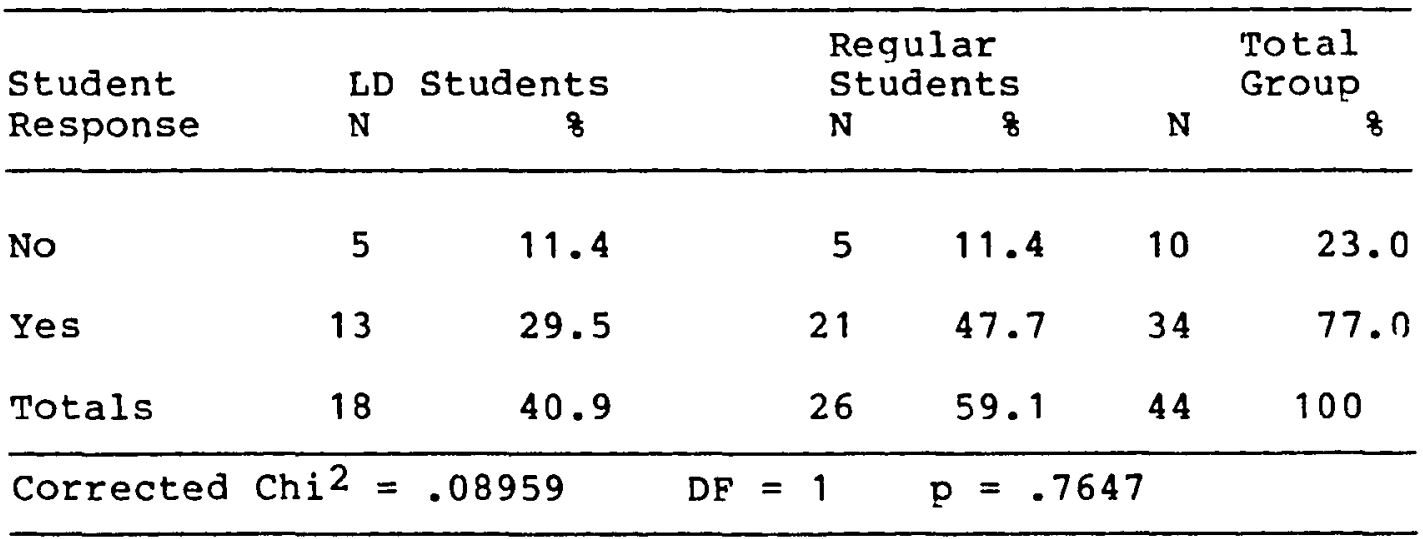

According to student perceptions of whether teachers help them to feel good about themselves, student responses indicated fairly equivalent feelings by both LD and regular students. Over one third of the LD responses and almost one fourth of those by regular students reported that teachers did not help them to feel good about them- 
selves. Question Three did not evidence significant associations for perceived teacher behaviors either.

3. Question: My teachers help me to enjoy school? No.

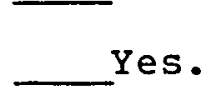

Five regular students and seven LD students did not feel that their teachers helped them to enjoy school. This was of particular interest as this represented almost 408 of the LD student responses. Analyzing these findings with a corrected Chi square procedure, no significant association was found between LD and regular student groups (see Table XIII).

TABLE XIII

FREQUENCIES FOR "MY TEACHERS HELP ME TO ENJOY SCHOOL"

\begin{tabular}{|c|c|c|c|c|c|c|}
\hline \multirow{2}{*}{$\begin{array}{l}\text { Student } \\
\text { Response }\end{array}$} & \multirow{2}{*}{$\begin{array}{l}L D \\
N\end{array}$} & \multirow{2}{*}{$\underset{8}{\text { Students }}$} & \multicolumn{2}{|c|}{$\begin{array}{l}\text { Regular } \\
\text { Students }\end{array}$} & \multicolumn{2}{|c|}{$\begin{array}{l}\text { Total } \\
\text { Group }\end{array}$} \\
\hline & & & $\mathbf{N}$ & 8 & $N$ & 8 \\
\hline No & 7 & 15.9 & 5 & 11.4 & 12 & 27.0 \\
\hline Yes & 11 & 25.0 & 21 & 47.7 & 32 & 73.0 \\
\hline Total & 18 & 40.9 & 26 & 59.1 & 44 & 100 \\
\hline Correcte & $=1$ & 19970 & $D F=$ & $p=$ & & \\
\hline
\end{tabular}


While no significant association was evident, sizable numbers of students from both groups felt that their teachers did not help them to enjoy school. In the next question, over half of all students did indicate that they felt their teachers were unhappy with their school work (see Question 4 ).

4. Question: Which sentence best tells how you feel?

My teacher is very happy with the school work that I do.

My teacher is happy with the school work that I do.

My teacher is unhappy with the school work that I do.

I really don't know what my teacher thinks of the school work that $\tau$ do.

Responses to this question evoked many more questions. Of the respondents, 26 of 44 felt that their teachers were unhappy with their work. Another 8 of 44 claimed that they did not know what their teachers think of their work. These responses indicated that over $77 \%$ of all students either perceived their teachers as having negative feelings about the quality of their schoolwork, or did not know what their teachers thought about their work. 
TABLE XIV

FREQUENCIES FOR HOW STUDENTS PERCEIVE THEIR TEACHERS AS FEELING ABOUT THEIR SCHOOLWORR

\begin{tabular}{|c|c|c|c|c|c|c|}
\hline & \multirow{2}{*}{$\begin{array}{r}\text { LD } \\
\mathrm{N}\end{array}$} & \multirow{2}{*}{$\underset{8}{\text { Students }}$} & \multicolumn{2}{|c|}{$\begin{array}{l}\text { Regular } \\
\text { Students }\end{array}$} & \multicolumn{2}{|c|}{$\begin{array}{l}\text { Total } \\
\text { Group }\end{array}$} \\
\hline & & & $\mathbf{N}$ & $\frac{8}{\gamma}$ & $\mathbf{N}$ & 8 \\
\hline Teacher unhappy & 12 & 27.3 & 14 & 31.8 & 26 & 59.1 \\
\hline Teacher happy & 0 & 0 & 1 & 2.3 & 1 & 2.3 \\
\hline Teacher very happy & 2 & 4.5 & 7 & 15.9 & 9 & 20.5 \\
\hline $\begin{array}{l}\text { Don't know what } \\
\text { thinks }\end{array}$ & 4 & 9.1 & 4 & 9.1 & 8 & 18.2 \\
\hline Total & 18 & 40.9 & 26 & 59.1 & 44 & 100 \\
\hline $\mathrm{Chi}^{2}=2.56176$ & $D F=$ & $\mathrm{p}=$ & 4642 & & & \\
\hline
\end{tabular}

A Chi Square measure of assocation indicated no significant variation in response patterns for LD and regular students (see Table XIV). Both groups reported few perceptions of positive teacher feelings about their schoolwork. 
CHAPTER V

DISCUSSION, CONCLUSIONS, IMPLICATIONS, AND RECOMMENDATIONS FOR FUTURE STUDIES

This study examined between-group differences on global self-concept for labeled and nonlabeled students. Findings indicate that LD labeled special education students appear to have lower global self-concept scores (approaching-significant with ANOVA $p=.0514$ and $\underline{t}$-test $p=.079)$ on the Piers-Harris Self-Concept Scale than regular education students having equivalent band range scores in reading and mathematics on the Portland Achievement Test $(p<.05)$. The small sample of willing participants for this study precluded the extensive use of a number of statistics which this study had been designed to use. Therefore, statistical adjustments to control for between group differences on external variables to self-concept (which indicated significant between-group differences i.e.; age, placement, and sex) were limited to building a case through examination of a data profile using a number of statistical tests rather than heavily depending upon multivariate analysis controls for covariate influences. 
Past studies examined one or two of the variables influencing self-concept (Boersma, Chapman, \& Battle, 1979; Legette, 1979; McIntrye \& Drummond, 1977; Ottenbacher, 1981). Previous labeling studies primarily probed significant others' perceptions of student self-concept rather than feelings held by the labeled student (Algozzine, Mercer \& Countermine, 1977; Budoff \& Siperstein, 1978; Foster, 1976, Smith and Greenberg, 1975). These studies only encompassed partial sections of the multifaceted influences of self-concept and labeling. In spite of the statistical limitations posed by the size of this study's group, this investigation has advanced further than its forerunners in its efforts to inspect labeling relationships with LD student self-concept. Only this study has addressed all of the major variables having the potential to impact self-concept as well as whether LD imposed labels exert strong relationships with selfconcept.

Findings derived from extensive case-building suggest that, age and placement could not be clearly determined to exert no significant between group influences upon self-concept. Researchers in agreement with the use of ANCOVA analysis for this size sample would go one step further by removing age and placement from this list. The null hypothesis could not be rejected in spite of ANOVA 
$(p=.0515)$ and $\underline{t}$-test $(p=.079)$ approaching significant between group differences of self-concept scores for LD and regular students since sex (and probably both age and placement) could not be eliminated as potentially contaminating variables having some effect upon self-concept.

\section{Conclusions}

Based upon the previous results derived from statistical analysis of the data, the following conclusions were drawn:

1. LD labeled students have approaching-significantly lower global self-concepts, as measured on the Piers-Harris Self-Concept Scale, than regular students with equivalent reading and math composite band range scores on the Portland Achievement Test.

This finding is particularly important as lower self-concept has been determined to be a highly interactive force with student achievement (BIack, 1974; Brookover, Thomas \& Patterson, 1964; Burns, 1979). Avoidance of success oriented experiences (Engel, 1959; Festinger, 1957 ) and higher anxiety levels (Bledsoe, 1964; Stanwyck \& Felker, 1973) are some characteristics found in low selfconcept students. High anxiety levels are described by Ausubel and Robinson (1969) as well as Clemens and Bean 
(1981) to interfere with learning. Additional characteristics such as lacking in competitiveness (Burns, 1979) and less assertiveness (Rosenberg, 1965) are closely linked with students evidencing low self-concepts. As can readily be deduced, characteristics commonly found for students with low self-concept have a great potential to create numerous barriers to effective learning and social interactions.

Because achievement was equivalent for both LD and regular student groups, the lower LD student findings on the self-concept measure indicate that one or more other variables is responsible for these approaching significant $(p<.05)$ between group variations (ANOVA $p=.0515$, t-test $p=.079)$. This research gives careful consideration to each of the eight variables, in addition to labeling, which are credited in the self-concept literature with having the capacity to impact self-concept levels.

2. Five of the eight variables other than iabeling, which research describes as potential influencing factors upon self-concept are not significant independent variable influences between groups according to this study's findings. These five variables are: sorioeconomic status

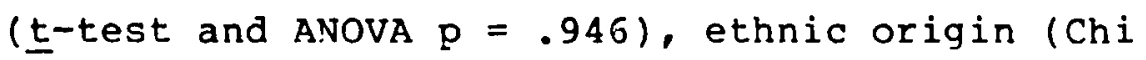
Square $p=.343$ ), Dlace in family (Chi square $p$ $=.415$ ). significant others (t-test and ANOVA $p$ 
$=.412)$, and achievement -- which had been controlled for both groups through stratified sampling.

Interpreting the findings of this research, the variations in self-concept between $L D$ and regular student groups (ANOVA $\mathrm{p}=.0515$ and t-test $\mathrm{p}=.079$ ) can be attributed to four independent or interacting external variables: age (t-test and ANOVA $p=.003$ ), placement (t and ANOVA $p=.000)$, sex $($ Chi Square $p=.0741)$, or the last remaining variable-labeling influences. It should be noted that the reported self-concept score variance could also be due to one or more additional variables which have not heretofore been described in the literature as having a major influence upon self-concept.

The findings describe additional evidence in the interpretation of these data. Because of mixed findings between ANOVA and $t$-test, this research has no basis for choosing one statistical method over the other. Since there are but forty-four subjects in this study's sample, there are some concerns over ANOVA and ANCOVA treatments of the data. If ANOVA and ANCOVA are deemed acceptable statistical measures for this sample of 44 respondents, then seven of the eight variables believed to have an impact upon self-concept can be concluded to be unimportant to the between group approaching-significant differences (using ANOVA $p=.0515$ ) on the Piers-Harris Self- 
Concept Scale's total scores. Use of ANCOVA to remove variable effects related to age and placement, results in a research finding that neither age $(p=.655)$ nor placement $(p=.304)$ make a significant contribution to the variations on $L D$ and regular student self-concept. Approaching significant between group differences ( $p=.0515$ using ANOVA) can be surmised to be related to sex/labeling, or multiple variable interactions with student self-concept. Findings interpreted by ANOVA indicate a far more direct relationship between self-concept narrations and labeling effects. Only one other variable, that of sex (Chi square $p=.074$ ), appears to exert an approaching-significant influence upon self-concept. The argument that labeling can modify selfperception (Burkhead, 1979; Rronick, 1976; Moeller, 1981; Scheff, 1975; Ullman \& Rrasner, 1975) is stronger here than when only the $t$-test and ANOVA data interpretaitions are used. Fewer variables compounding the different effects between groups would give more credibility to concerns over the negative influences which LD labels might exert upon students' self-concepts. Due to the small sample size, these ANOVA and ANCOVA findings can not be considered conclusive.

3. The majority of students labeled LD, who participated in this study, do not use handicapping condition labels to describe themselves. 
Therefore, labeling effects upon self-concept might be due to different treatments and expectancies imposed upon these students by signficiant others instead of personallyimposed recriminations resulting from an awareness of the imposition of LD label. Should this lack of awareness over having an LD label be the case, the following outcomes have increased importance.

4. The great majority of students in both groups feel that doing well in school is important to them. Valuing how well they do in school means that good school performance is a psychologically central selfconcept attribute to the majority of this study's students (Rosenberg \& Kaplan, 1982). They want to do well in school, and feedback that they are doing well has importance to these students. While a majority of participants from both groups say that their teachers help them to feel good about themselves, almost half of the LD respondents do not feel that their teachers help them to enjoy school. When the issue of perceived teacher attitudes is further probed, over 778 of the respondents describe teachers as being unhappy with their schoolwork, or state that they do not know what their teachers think of their work.

5. Over half of the students from both groups believe that their teachers are unhappy with their schoolwork. 
Teachers' support and approval can exert considerable influence upon a child's self-concept. Correlations between student perceptions of how positive teachers feel about them and student levels of self-concept are high (Brookover, Erikson \& Joiner, 1967; Burns, 1979; Davidson \& Lang, 1960; Erikson, 1968). The proliferation of selffulfilling prophecy studies initiated by Rosenthal and Jacobson (1968) do give cause for concern over altered teacher expectations and treatment of students relative to formally labeled students (Bem, 1972; Stryker, 1982; Toner, 1979; UlIman \& Krasner, 1975). LD students were seen in a less positive light by teachers in studies by Foster (1976), Good and Dembo (1973), Jones (1974), Siperstein (1985), Ysseldyke and Foster (1978). Conscious or unconscious teacher stereotypical perceptions and different treatments of students resulting from the imposition of an LD label could be largely responsible for this study's between group differences in self-concept. Additionally, different treatment due to LD labeling might be initiated by significant others from the families of this LD group.

\section{Implications for Educators}

Because this study indicates than an administrative intervention which labels a child LD could demonstrate a strong relationship with self-concept in a subsequent study evidencing more conclusive findings, educators need to be 
aware of the possible effects which they may be exerting upon a child's self-concept. Differences among children's educational needs do exist. What becomes the issue for administrators is the development of a means for conceptualizing and implementing constructive labels which are not deficit-oriented, and yet serve to describe what the child can Zo.

It would appear in this study's LD group that labeling concerns are not heavily related to conscious student internalization of labeling stereotypes. Most of the LD subjects did not use handicapping condition labels when talking about themselves, nor did they describe their definitions of LD as being negative. This study's findings do not remove the possibility that self-fulfilling prophecy may be active in the form of different student treatment resulting from preconceived stereotypical expectations which are exercised by significant others (Purkey, 1970; Rosenthal \& Jacobson, 1968; Smith \& Greenberg, 1975; Stryker, 1982).

Analysis of these findings has implications for educators if stereotypical expectations are active as a response to the imposition of a LD label. Both administrators and teachers must consciously work to remove labeling stereotypes from their daily professional practices. They also need to be prepared to work with parents and families to erase once and for all the stigma of a LD 
label. Rather than perpetuating the label by calling special classes LD classrooms, other terms such as resource room or learning center would be more appropriate. While the majority of the students from both groups of this study's population felt that doing well in school was important to them, over half of them believed that their teachers were unhappy with the school work that they do. Are we as educators conveying the messages which we intend to communicate to our students? Those teachers of the students from this study may have conveyed an unintended message to these respondents. Overwhelmingly, respondents felt that their teachers were unhappy with their school work or had no idea how their teachers felt. Teachers are significant others to students, particularly in the school setting. "If the social system of labeling is to be changed, we must seek its roots not only in the social structure but also in the individual psychology of the labelers" (Scheff, 1975, p. 75).

Imposed labels can be responsible for modified selfconcept (Rosenberg, 1979). When experiences which are inconsistent with a student's current self pictures occur, then internal struggles and resistence to the conflicting experience messages ensue. Eventually, changes in selfperception can evolve over time after these conflicting but recurrent experiences overpower previously perceived self images. It may well be that the LD labeled students in this 
study have been receiving different treatment from their teachers/families than the regular students (Dexter, 1964). Teacher training must create an awareness of the manifold labeling effects. This training should also include strategies designed to remove the stereotypical perceptions tied to labels so that each child will be treated as a unique individual (Guskin, 1974). Individual student differences and positive instructional strategies to meet LD student needs must be recognized and put into practice by both teachers and administrators. "The education system can educate children without the need for labels, and it can provide assistance appropriate to specific needs" (Barnett, 1978, p. 166). Knowing that this is possible is but the first step. Putting it into practice is the task before us today.

\section{Recommendations for Future studies}

Replication of this study with a larger study sample should prove highly informative, as a variety of sophisticated statistical analyses would then be more valid. An increase in sample size would permit controlling for sex as a possible influencing variable. This research was unable to accomplish these important controls, and its findings were colored by the possible contaminating influence of the sex variable upon the self-concept scores of the subjects. Controlling for these potentially confounding influences 
upon self-concept would allow a clear view of the labeling and self-concept interrelationships. As it were, this study's findings have been muddied by additional variables' influences which could not be removed through statistical manipulations of the data. A larger study sample would also make possible a multivariate analysis of interactive independent variable effects which this study could not do. In effect, the hypothesis should be fully tested as it was originally designed to be researched.

A more diverse geographic, socioeconomic, and ethnic sampling should increase generalizability to more LD and regular students with equivalent achievement levels in reading and math. This increased sample size combined with longitudinal information over a five to seven year time frame could prove highly constructive to educators (Wylie, 1979). From further research along the same vein as this study, a sizeable body of usable data, which has heretofore been unavailable for administrative decision making, would result. 


\section{Biblioqraphy}

Adler, A. The practice and theory of individual psychology. New York: Harcourt Brace, 1927.

Algozzine, B., Mercer, C. D., \& Countermine, T. The effects of labels and behavior on teacher expectations. Exceptional Children, 1977, 44: 131-132.

Alloort, G. W. Becoming: Basic considerations for a psychology of personality. New Haven: Yale University Press, 1955

Ames, C., \& Felker, D. W. Effects of Self-concept on children's causal attributions and self reinforcement. Journal of Educational Psychology, $1979, \underline{71}(5), 61 \overline{3-619}$.

Andrews, G. R., 7 Debus, R. L. Persistence and causal perception of failure: modifying coqnitive attributions. Journal of Educational Psychology. 1978, 70, 154-166.

Asher, S., \& Allen, A. Racial preference and social comparison processes. Journal of Social Issues, $1969,25(1), 157-166$.

Ausubel, D. P., \& Robinson, F.G. School learning. New York: Holt, 1969.

Bacher, J. H. The effect of special class placement on the self-concept of the adolescent mentally retarded in relation to certain groups of adolescents (Doctoral Dissertation New York University, 1965). Dissertation Abstracts International, 1965,25 , 2846-2847.

Barker, R. Two-success and failure in the classroom. Progressive Education 1942, 19 221-224.

Barnett, H. G. The learning disability "label" ...beneficial or detrimental. British Columbia Journal of Special Education, $1978, \underline{2}(2), 159-166$. 
Becker, H. S. Outsider-studies in the sociology of deviance. New York: The Free Press, 1963.

Beez, W. V. Influence of biased psychological reports on teacher behavior and pupil performance. proceedings of the 76th Annual Convention of the American Psychological Association, 1968, 605-606.

Bem, D. J. Self-perception theory. In L. Berkowitz (Ed.) Advances in experimental and social psychology (Vol. 6). New York: Academic Press, 1972.

Behrens, M.L. Child rearing and the character structure of mother. Child Development, 1954, 25, 225-238.

Berkowitz, L. Self-perception Theory. Advances in experimental and social psychology, 1972, $6,1-62$.

Berman, A., \& Siegal, A.W. Adaptive and learning skills in juvenile delinquents: A neuropsychological analysis. Journal of Learning Disabilities, 1977 , ‥ $583-590$

Best, J. W. Research in education. Englewood Cliffs, New Jersey: Prentice-Hall, 1977.

Black, F. W. Self-concept as related to achievement and age in learning disabled children. Child Development, 1974, 45 (4), 1137-1140.

Bledsoe, J. Self-concept of children and their intelligence, achievement, interests and anxiety. Childhood Education, 1964, 43, 436-483.

Bledsoe, Joseph C., and Garrison, Rarl C. The Self-concepts of elementary school children in relation to their academic achievement, intelliqence, interests and manifest anxiety. (Cooperative Research Project No 1008) Athens, Georgia: University of Georgia and DHEW, 1962.

Boersma, F. J., Chapman, J. W., \& Battle, J. Academic Self-concept change in special education students: Some suggestions for interpreting self-concept scores. Journal of Special Education, 1979,13 (4), 433-442.

Bohan, J.S. Age and Sex differences in self-concept. Adolescence, $1973, \underline{8}, 379-384$.

Borg, W. Ability grouping in the public schools. Madison: Educational Research Sciences, 1966. 
Boucher, C. R., \& Deno, S.L. Learning disabled and emotionally disturbed: will the labels affect teacher planning? Psychology in the Schools, 1979, 16 (3), 395-402.

Brandt, L.J., \& Hayden, M.E. Male and female teacher attitudes as a function of students' ascribed motivation and performance levels. Journal of Educational Psycholoqy, $1974, \underline{66}$ (3), 309-314.

Brookover, W. B., Erikson, E.L., \& Joiner, L.M. Self-concent of ability and school achievement III (Cooperative Research Project No. 2831). East Lansinq: Michigan State University, 1967.

Brookover, W.B., Shailer, T. \& Patterson, A. Self-Concept of ability and school achievement. Sociology of Education, 1964, 37, 271-278.

Brookover, W. B., Thomas, S., \& Patterson, A. Self-Concept and school achievement through student's selfconcept enhancement II (U.S. Office of Education Research Project No. 1636). East Lansing: Michigan State University, 1965.

Brophy, J.E. \& Good, T.L. Teachers make a difference. New York: Holt Rinehart \& Winston, 1975 .

Bryan, T. H. Social relationships and verbal interactions of learning disabled children. Journal of Learning Disabilities, 1978, 11 (2), 107-115.

Bryan, T. H., \& Pearl, R. A. Self-concepts and locus of control of learning disabled children. Educational Horizons, $1981,59(2), 9 i-96$.

Bryan, T. H., \& Pearl, R. A. Self perceptions, achievement related behaviors and social interactions of learning disabled children. New York: Paper presented at the Annual Meeting of the American Educational Research Association, 1982. (ERIC Document Reproduction Service No. 218 838)

Budoff, M., \& Siperstein, G. N. Low-income children's attitudes toward mentally retarded children: Effects of labeling and academic behavior. American Journal of Mental Deficiency, 1978, 82 (5), 474-479.

Burkhead, E. J., Domeck, A.W. \& Price, M.A. The severely handicapped person: Approaches to career development. Columbia: Working Paper Missouri University, 1979 (ERIC Document Reproduction Service No. ED 178 114) 
Burns, R. B. The self-concept in theory, measurement, development and behavior. - London: Longman Inc., 1979 .

Busby, W. A., Fillmer, H. T., \& Smittle, P. Interrelationship between self-concept, visual perception, and reading disabilities. The Journal of Experimental Education, $1974, \underline{42}(3), 1-5$.

Calhoun, G., \& Morse, W. C. Self-concept and self-esteem: Another perspective. Psychology in the Schools, $1977,14,318-322$.

Campbell, D. T., \& Stanley, J. C. Experimental and quasiexperimental designs for research. Chicago: Rand MCNally, 1963.

Caplin, M.D. The relationship between self-concept and academic achievement. Journal of Experimental Education, 1969, 37, 13-16.

Carlson, R. Stability and change in the adolescent's self image. Child Psycholoqy, 1965, 36 659-666.

Carpenter, T., \& Busse, $T$. Development of Self-concept in neqro and white welfare children. Child Development, 1969, 40, 935-939.

Carroll, A. W. The effects of segregated and partially integrated school programs on self-concept and academic achievement of educable mental retardates. Exceptional Children, 1967, 34, 92-99.

Carroll, J.L., Friedrich, D. \& Hund, J. Academic selfconcept and teacher's perceptions of normal, mentally retarded and learning disabled elementary students. Psychology in the schools, 1984, 21(3), 343-348.

Caslyn, R. J., \& Renny, D.A. Self-concept of ability and perceived evaluation of others: Cause or effect of academic achievement. Journal of Educational Psychology, 1977, 69, 136-145.

Cattell, R. B. Personality: A systematic, theoretical and factual study. New York: McGraw-Hill, 1950.

Catterall, C.D. Special education in transition - Implications for school psycholoqy. Journal of School Psychology, 1972, 10, 91-98. 
Chang, T. The relationship between children's self-concepts, teacher's rating and academic achievement. Washington, D.C.: Paper presented at the Annual Meeting of the American Educational Resarch Association, 1975. (ERIC Document Reproduction Service No. ED 106 699)

Chapman, J.W., \& Boersma, F.J. Academic Self-concept in elementary learning disabled children: A study with the student's perception of ability scale. Psychology in the Schools, 1979, 16 (2), 201-206.

Chapman, R.B., Larsen, S.C., \& Parker, R. M. Interactions of first grade teachers with learning disordered children. Journal of Learning Disabilities, 1979,12 (4): 225-230.

Chassim, L. Presson, Stager, S.F., Young, R.D., \& Light, Self-labeling by EMR high school students in their mainstream and special education classes. Tempe: Arizona State University, 1979. (ERIC Document Reproduction Service No. ED 203631 )

Cheong, L. M. A comparative study of children in selfcontained special education classrooms with children in special education resource rooms with regard to the relationship between self-concept and achievement, sex, age, and intelligence quotient (Doctoral Disseration, Texas Women's University, 1974). Dissertation Abstracts International, $1974,35(10), 6539 \mathrm{~A}$. (University Microfilms No. $759 \overline{018}, 104$ )

Cicirelli, v. Relationship of SES and ethnicity to primary grade children's self-concept. Psychology in the Schools, 1977, 14 213-215.

Clairborn, W. L. Expectancy effects in the classroom: A failure to replicate. Journal of Educational Psychology, $1969,60377-383$.

Clements, F. O., Peck, R. F., \& Green, J. L. The rich get richer... in school too. Austin: University of Texas, 1978. (ERIC Document Reproduction Service No. ED 159 $238)$.

Clemes, H., \& Bean, R. Self-esteem. New York: G.P. Putnam's Son, 1981 .

Cohen, J., \& Cohen, P. Applied multiple regression/correlation analysis for the behavioral sciences. Hillsdale, New Jersey: Lawrence Erlbaum Association, 1975.

Cohen, L. Self-concept. In M. Rosenberg \& H.B. Kaplan (Eds.) Social psychology of the self-concept. Arlington Heights, Illinois: Harlan Davidson, 1982 . 
Cohn, M., \& Kornelly, D. For better reading -- a more Dositive self-image. Elementary School Journal, $1970,70,199-201$.

Cole, J. L. The relationship of selected personality variables to academic achievement of average aptitude third graders. Journal of Educational Research, $1974,67(7), 329-333$.

Coleman, J. Relationships in adolescence. New York: Routledge, 1974 .

Coleman, J., Campbell, E., Hobson, C. and others. Equality of educational opportunity. Washington, D.C.: DHEW, U.S. Govt. Printing Office, 1966.

Coleman, J., \& Fults, B. Self-concept and the gifted classroom: the role of social comparisons. Gifted Child Quarterly, 1982, 26 (3), 116-120.

Combs, A. W. The personal approach to good teaching. Educational Leadership, 1964, 21, 369-377.

Compton, C. A guide to 65 tests in special education. Belmont, Calif: Pitman Learning Inc., 1980.

Compton, C. A guide to 65 tests in special education. Belmont, Calif.: Pitman Learning Inc., 1980.

Comptroller General of the United States, Learning disabilities: The link with delinquency should be determined but schools should do more now. Report to the Congress, GGD-75-99, March 4, 1977.

Connell, W. F., Stroobant, R.E., Sinclair, K. E., Connell, R. W., \& Rogers, R.W. Twelve to twenty. Sydney: Hicks Smith, 1975.

Convey, J., \& Koelle, W. Improving the prediction of achievement of deaf adolescents by modifying a locus of control and a self-concept instrument. philadelphia: Paper presented at the Annual Meeting of the Eastern Educational Research Association, 1981. (ERIC Document Reprodctuion Service ED 210 875)

Cookston, H. M., \& Mason, B. O. Recent studies on selfconcept in elementary students. Education Leadership. $1977,34,639-641$.

Cooley, C.H. Social process. New York: Scribner's Sons, 1912. 
Coopersmith, S. A method of determining types of selfesteem. Journal of Abnormal Psychology, 1959, 59 $87-94$.

Coopersmith, S. The Antecedents of self-esteem. San Francisco: Freeman, 1967.

Coordinating office for Regional Resource Centers. CORRC/ RRC test matrix: Individual test descriptions. Washington, D.C.: Bureau of Education for the Handicapped DHEW/OE, 1976. (ERIC Document Reproduction Service No. ED 129040 )

Covington, V., \& Beery, G. Self worth and school learning. New York: Holt, Rinehart and Winston, 1976.

Cowles, M. \& others. Comparative study of certain social and school adjustments of children in two grouping plans. New orleans: Paper presented to the American Psychological Association, 1974. (ERIC. Document Reproduction Service No. FD 126961 )

Cruikshank, W. M. Some issues facing the field of learning disabilities. Journal of Learning Disabilities, $1972, \underline{5}, 380-388$.

Davidson, H. H., \& Lang, G. Children's perceptions of their teacher's feelings toward them related to self perception, school achievement, and behavior. Journal of Exceptional Education, 1960, 29 107-118.

Delevita, D.J. The concept of identity. Paris: Mouton \& Co., 1965.

Department of Health Fducation and Welfare, Office of Education. Procedures for evaluating specific learning disabilities. Federal Register Vol. 42, No. 25), December $29,19 \overline{77 .}$

Deshler, D.D. Schumaker, J.B., Alley, G.R., Warner, M.M., \& Clark, F. L. An Epidemoloqical study of learning disabled adolescents in secondary schools: Academic self-image and attributions. Lawrence, Kansas: University of Kansas, 1980. (ERIC Document Reproduction Service No. ED 217631 )

Dexter, L.A. The tyranny of schoolina: An inquiry into the problem of stupidity. New York: Basic Books, 1964 .

Dickstein, E. Self and self-esteem: Theoretical foundations and their implications for research. Human Development, $1977, \underline{20}$ (3), 129-140. 
Dickstein, E., \& Posner, J. Self-esteem and relationship with parents. Journal of Genetic Psychology, 1978, 133 , 273-276.

Diener, C. I., \& Dweck, C.S. An analysis of learned helplessness: Continuous changes in performance, strategy and achievement cognitions following failure. Journal of Personality and Social Psychology, 1978, $36,451-462$.

Dittes, J. Attractiveness of group as a function of selfesteem and acceptance by group. Journal of Abnormal and Social Psychology, 1959, 59 77-82.

Dunn, L. M. Special education for the mildly retarded Is much of it justifiable? Exceptional Children, $1968, \underline{34} 5-22$.

Dworkin, N., \& Dworkin, Y. The legacy of Dygmalion in the classrom. Phi Delta Kappan, 1979, 60 (10), 712-715.

Edgerton, R.B. Cloak of competance. Berkeley: University of California Press, 1967.

Edgerton, R. B., \& Sabagh, G. From mortification to aggrandizement: Changing self conceptions in the careers of the mentally retarded. Psychiatry, 1962, $\underline{25}, 263-272$.

Edwards, A.L. Statistical analysis. New York: Holt, Rinehart \& Winston, 1957.

Elashoff, J.D., \& Snow, R.E. Pygmalion reconsidered: a case study in inference Reconsideration of the Rosenthal data on teacher expectancy. Worthington, Ohio: Charles A. Jones, 1971.

Engel, M. The stability of self-concept in adolescence. Journal of Abnormal and Social Psychology, 1959,58 211-215.

Erdwins, C., Small, A., \& Gross, R. The relationship of sex role to self-concept. Journal of Clinical Psychology, 1980, 39 (1), 111-115.

ikson, E.H. Identity, youth and crisis. New York: Norton, 1968 .

Erikson, E. H. Psychoanalysis and ongoing history: problems of identity hatred and nonviolence. American Journal of Psychiatry, 1969, 122, 241-250. 
Evans, J. T., \& Rosenthal, R. Interpersonal self-fulfilling prophecies: Further extrapolation from the laboratory to the classroom. Proceedings from the 77 th Annual Convention of the American Psychological Association, 1969, 8 (1), 371-372.

Eaust, V. Self esteem in the classroom. San Diego: Thomas Paine Press, 1980.

Feldhusen, J.F. \& Thurston, J.R. Personality and adjustment of hiqh and low anxious children. Journal of Educational Research, 1964, 57, 265-267.

Festinger, L.A. A theory of social comparison processes. Human Relations, 1954, I, 117-140.

Festinger, L. A. A theory of cognitive dissonance. Evanston, ILL.: Row Peterson, 1957.

Finche, E., Evaluation of elementary language arts assistance program. Alberta: Edmonton Public School Bd., 1977. (ERIC Document Reproduction Service No. ED 152837 )

Fink, M.B. Self-concept as it relates to academic underachievement. California Journal of Educational Research, 1962 . 13, 57-62.

Fitts, W., \& Hamner, W. T. The self-concept and delinquency. Nashville: Counselor Recordings and Tests, 1969.

Florio-Forslund, E. The application of a communication model to the problems of learning disabled children. 1978. (ERIC Document Reproduction Service NO. ED 151868 )

Foster, G.G. Teacher expectancies and the label learning disabilities. Journai of Learning Disabilities, $1976, \underline{9}, 111-11 \overline{4}$.

Foster, G.G., Ysseldyke, J.E. \& Reese, J. I wouldn't have seen it, if I hadn't believed it. Exceptional Children, 1975 , 41. 460-473.

Fox, D., \& Barnes, U. Racial preference and identification of blacks, chinese and white children. New York: Paper presented at the Annual American Educational Research Association meeting, 1971. 
French, J.R. The conceptualization and measurement of mental health in terms of self-identity theory. In S.B. Sells (Ed.), The definition and measurement of mental health. Washington, D.C.: U.S. Department of Health, Educaton and Welfare, 1968.

Frostiq, M., \& Maslow, P. Learning problems in the classroom. New York: Grune and Stratton Subsidary of Harcourt Brace Jovanovich, 1973.

Gabbler, R.G., \& Gibby, R. The self-concept of negro and white children. Journal of Clinical Psychology, $1967, \underline{23}, 144-148$.

Gershman, J. The evaluation of special education programs: past attempts and present directions. Toronto: Toronto Board of Education, 1975. (ERIC Document Reproduction Service No. ED 119 415)

Gibby, R.G., \& Gibby, R.G. The effects of stress resulting from academic failure. Journal of Clinical Psychology, 1967, 23, 35-37.

Ginott, H.G. Between parent and child-new solutions to old problems. New York: MacMillan, 1965.

Goffman, E. Stigma-Notes on the management of spoiled identity. Englewood Cliffs, New Jersey: Prentice-Hall, 1963.

Gold, M. Scholastic experiences, self-esteem and delinquent behavior. In M. Rosenberg \& H.B. Kaplan (Eds.) Social psychology of the self-concept. Arlington Heights, Illinois: Harlan Davidson, 1982.

Good, T.L. \& Dembo, M.H. Behavioral expression of teacher attitudes. Journal of Educational Research, 1973, 63 ; $697-624$.

Goodman, H., Gottlieb, J., \& Harrison, R.H. Social acceptance of EMRs integrated into a nongraded elementary school. American Journal of Mental Deficiency, 1972,76 412-417.

Goodman, M. Race attitudes in young children. Cambridge: Addison-Wesley, 1952 .

Goodyear, R.R., \& Parish, T.S. Perceived attributes of the terms client, patient and typical person. Journal of Counseling Psychology, 1978, 25 (4), 356-358. 
Gordon, D.A. Children's beliefs in internal, external control of self-esteem as related to academic achievement. Journal of Personality Assessment, $1977, \underline{41}, 383-386$.

Gordon, I.J. \& Combs, A.W. Learner: Self and perception. Educational Research, 1958, 28, 433-444.

Gordon, T. Parent effectiveness training. New York: Plume, 1975.

Gottlieb, J. Attitudes toward retarded children: Effects of labeling and academic performance. American Journal of Mental Deficiency, 1974,79 (3), 268-273.

Grant, C. H. Age differences in self-concept from early adul thood through old aqe. Lincoln Nebraska: University of Nebraska, 1969. (ERIC Document Reproduction Service No. ED 079613 )

Griffiths, A. Self-concepts of dyslexic children. Academic Therapy, 1975, 11, 83-90.

Guardo, C.J. Sociometric status and self-concept in 6 th graders. Journal of Educational Research, 1969, $62,(7) 320-322$.

Guskin, S. L. Research on labeling retarded persons: Where do we go from here? American Journal of Mental Deficiency, 1974, 79 (3), 262-264.

Guskin, S.L., Theoretical and empirical strategies for the study of the labeling of mentally retarded persons. In N. R. Ellis (Ed.), International review of research in mental retardation (Vol. 9). New York: Academic Press, 1978.

Guskin, S.I. Bartel, N.R., \& MacMilian, D.L. The perspective of the labeled child. In $\mathbf{N}$. Hobbs (Ed.) Classification of exceptional children. New York: Academic Press, $19 \%$.

Guskin, S. L., \& Spicker, H. Educational research in mental retardation. In N.R. Ellis (Ed.) International review of research in mental retardation. (Vol. 3). New York: Academic Press, 1968 . 
Gutknecht, B. The label syndrome. Language Arts, 1976. $\underline{53}(4), 419-421$.

Hallahan, D.P., \& Kauffman, J. M. Labels, categories, behaviors: ED, ILD, and EMR reconsidered. Journal of Special Education, 1977, 11, 139-147.

Hamilton, $\bar{k}$. W., Counseling the handicapped in the rehabilitation process. New York: Ronald, 1950 .

Hawk, T. L. Self-concepts of the socially disadvantaged. Elementary School Journal, 1967, 67(4), 196-206.

Haywood, H. C. Labeling efficacy, evils and caveats. Paper Dresented at the Joseph P. Kennedy Jr., Foundation International Symposium on Human Rights, Retardation and Research, Washington, D.C., October, 1971.

Healy, G. W. Self-concept: A comparison of negro, anqlo and Spanish-American students across ethnic, sex and socio-economic variables. San Francisco: $R \& E$ Research Assoc., 1969 .

Hobbs, N., Egerton, J., \& Matheny, M. Classifying children. Children Today, 1975, $\underline{4}(4), 21-25$.

Horney, K. Our inner conflicts. New York: Norton, 1945.

Horowitz, F.D. The relationship of anxiety, self-concept and sociometric status among fourth, fifth and sixth grade children. Journal of Abnormal and Social Psychology, 1962, 65, 212-214.

Houck, C., \& Houck, E. Investigation of the relationships between academic achievement and self-concept in children with specific learning disabilities. Chicago: Paper presented at the Annual International Council for Exceptional Children Convention, 1976. (ERIC Document Reproduction Service No. ED 125 204)

Hurstfeld, J. Internal colonialism: White, black and chicano self-concept. Ethnic and Racial Studies, $1978,1,60-79$.

Hyatt, I.R. Mental labels and tatoos. Intellect, 1977, $106(2387), 74-75$.

Ivarie, J., Hogue, D., Brulle, A.R. An investigation of mainstream learner time spent with students labeled learning disabled. Exceptional Children, 1984, 51(2), 142-147. 
Jackson, G. \& \& Cosca, C. Inequality of educational opportunity in the southwest: an observational study of ethnically mixed classrooms. American Educational Research Journal, $1974,11, \overline{219-229}$.

jumes, w. Principles of psychology. New York: Holt, 1890 .

Jersild, A.T. In search of self. New York: Teacher's College of Columbia University, 1952.

Johnson, D., \& Myklebust, H. Learning disabilities: Educational principles and practices. New York: Grune \& Stratton, 1967.

Johnson, L.S., Johnson, D.L., Olson, M.R., \& Newman, J. P. The uses of hypnotherapy with learning disabled children. Journal of Clinical Psychology, 1981 , $37(2), 291-\overline{299 .}$

Johnston, G. O., \& Kirk, S.A. Are mentally handicapped children segregated in the regular grades? Exceptional Children, 1950, 17, 65-68, 87-88.

Johntz, W. F. Innovation and the new concern for the disadvantaged. CTA Journal, 1967, 63(1), 5-32.

Jones, J. G. \& \& Grieneeks, L. Measures of self-perception as predictors of scholastic achievement. Journal of Educational Research, 1970, 63, 201-203.

Jones, J. G., \& Strowick, R. W. Adolescent identity and self-perception as predictors of scholastic achievement. Journal of Educational Research. $1968, \underline{62}, 78-8 \overline{2}$.

Jones, R. L. New labels in old bags: Research on labeling blacks, culturally deprived, and mentally retarded. Paper presented at the Annual Convention of Black Psychologists, Miami Beach, September, 1970 .

Jones, R. L. Labels and stigma in special education. Exceptional Children, 1972, 38, 553-564.

Jones, S.C. Self and interpersonal evaluations: esteem theories versus consistency theories. In $M$. Rosenberg \& H.B. Kaplan (Eds.), Social psychology of the self-concept. Arlington Heights, Illinois: Harlan Davidson, 1982. 
Jordan, H. Behavioral forces that are a function of attitudes and of cognitive organization. Human Relations, 1953, 6, 273-287.

Jose, J. Teacher-pupil interation as it relates to attempted changes in teacher expectancy of academic ability and achievement. American Educational Research Journal, 1971, 8 39-49.

Kaplan, H.B. Self-derogation and social position: Interaction effects of sex, race, education and age. Social Psychiatry, 1973, 8, 92-99.

Kaplan, H. B. Deviant behavior in defense of self. New York: Academic Press, 1980.

Kaplowitz, M. L. Self-concept of mainstreamed learning disabled children in resource rooms and regular classrooms (Doctoral Dissertation, Boston University, ;981). Dissertation Abstracts Internationel, $1981,42(07), 3106 \mathrm{~A}$. (University Microfilms iso. 81-2660

Kelly, D.H. Labeling and the consequences of wearing a delinquent label in a school setting. Education, $1977,97,371-380$.

Kelly, D. H., \& Pink, W. T. School crime and individual responsibility: Perpetuation of a myth. Urban Review, 1982, 14(1), 47-63.

Rerlinger, F. N. Multiple regression in behavioral research. New York: Holt, Rinehart \& Winston, 1982 .

Kerman, S. Teacher expectations and student achievement. Phi Delta Kappan, 1979, 60(10), 716-718.

Kleinfeld, J. The relative importance of teachers and parents in the formation of negro and white student's academic self-concepts. Journal of Educational Research, 1972,65 211- 212 .

Knapp, J. A selection of self-concept measures. Princeton: Educational Testing Service, 1973. (ERIC Document Reproduction Service No. ED 080 534)

Knaus, W. \& \& MeKeever, C. Rational-emotive educaton with learning disabled children. Journal of Jearning Disabilities, $1977,10(1), 10-14$. 
Kolstoe, O.P. Implications of research findings on vocational and career education for the mentally handicapped. Columbus: Ohio State University Center for Vocational Education, 1977. (ERIC Document Reproduction Service No. ED 147637 )

Kronick, D. Importance of a sociological perspective toward learning disabilities. Journal of Learning Disabilities, 1976,9 , 115-119.

Kugle, C.I., \& Clements, R.O. Self-esteem and academic behavior among second graders. Austin: Texas University, 1980. (ERIC Document Reproduction Service NO. ED 192 926)

Kuhn, M. H., \& McPartland, T. An empirical investigation of self attitudes. American Sociological Review, $1954,1968-76$.

LaBenne, W., \& Green, B. Educational implications of self-concept theory. Pacific Palisades: Goodyear Publishing Co., 1965.

Laing, R.D. Knots. New York: Vantage Books, 1970.

Langer, E.J., \& Abelson, R. P. A patient by any other name...: Clinical group difference in labeling bias. Journal of Consulting and Clinical Psychology, 1974, 42, 4-9.

Leacock, S. Teaching the unteachable. Monday Morning, $1969,4(3), 26-27$.

Lecky, P. Self-consistency: A theory of personality. New York: Island Press, 1934.

Leacock, S. Teaching the unteachable. Monday Morning, $1969, \underline{4}(3), 26-27$.

Legette, H. R. Self-concept and academic achievement, a comparison of intellective and non-intellective variables as predictors of scholastic performance and analysis of subgroup differences in self-concept (Doctoral dissertation, University of North 
Carolina, 1979). Dissertation Abstracts International, $197 \overline{9}, 40(4), 1877 \mathrm{~A}$.

Lemert, E. M. Human deviance, social problems and social control (2nd ed.). Englewood Cliffs, New Jersey: Prentice-Hall, 1972.

Lerner, J. Children with learning disabilities (2nd ed.). Boston: Houghton Mifflin, 1976.

Leviton, H. The implications of the relationship between self-concept and academic achievement. Child Study Journal, 1975, 51 25-34.

Leviton, H., \& Kirally, J. Achievement and self-concept in young LD children. Academic Therapy, 1975, $10(4), 453-455$.

Leviton, T.A., \& Chananie, J.D. Responses of female primary school teachers to sex-typed behaviors in male and female children. Child Development, 1972, 43, 1309-1316.

Lewin, K. Resolving social conflicts. New York: Harper and Brothers, 1948 .

Lewin, K., Lippitt, R., \& White, R. Patterns of agressive behavior in experimentally created social climates. Journal of American Psychology, 1939, 10 271-299.

Linton, T. H. A study of the relationship of global selfconcept, academic self-concept, and academic achievement among anqlo and Mexican-American sixth grade students. Chicago: Paper presented to the Annual American Educational Research Association, 1972. (ERIC Document Reproduction Service No. ED $063053)$

Long, B. H., Henderson, E.H., \& Ziller, R. C. Developmental changes in the self-concept during middle childhood. Merrill-Palmer Quarterly of Behavior and Development, 1967, 13(3), 201-215.

Ludwig, D.J., \& Maehr, M.L. Changes in self-concept and stated behavioral preferences. Child Development, $1967, \underline{38}, 453-467$.

Luftig, R.L. Effects of peer labeling on the metamnemonic estimates of mentally retarded and nonretarded children. American Journal of Mental Deficiency, 1983, $87(5), \overline{522-527}$ 
Maccoby, E.E., \& Jacklin, C.N. The psychology of sex differences. Stanford: Stanford University Press, 1974 .

Macmillan, D.L. \& Jones, R.L. Lions in search of more christians. Journal of Special Education, 1972, 6 , $81-91$.

Macmillan, D.L., Jones, R.L., \& Aloia, G.F. The Mentally retarded label: A theoretical analysis and review of research. American Journal of Mental Deficiency, $1974, \underline{79}(3), 2 \overline{41-261 .}$

Mahoney, A.R. The effect of labeling upon youths in the juvenile justice system: A review of evidence. Law and Society Review, 1974, 8 583-614.

Mann, M. What does ability grouping do to the selfconcept? Childhood Education, 1960, 26 357-360.

Mannarino, A.F. Friendship patterns and self-concept development in pre-adolescent males. Pittsburgh: Pittsburgh Child Guidance Center, 1976. (ERIC Document Reproduction Service No. ED 159558 )

Many, M.A., \& Many, W.A. The relationship between selfesteem and anxiety in grades 4 through 8 . Educational and Psychological Measurement, 1975, 35, 1017-1021.

Maragalit, M. \& Zak, I. Anxiety and self-concept of learning disabled children. Journal of Learning Disabilities, 1984, 17(9), 537-593.

Marecek, J., \& Mettee, D.R. Avoidance of continued success as a function of self-esteem, level of certainty, and responsibility for success. Journal of Personality and Social Psycholoqy, 1972. 22 98-107.

Marx, R. W., \& Winne, P.H. Self-concept and achievement: Implications for educational programming. Integrated Education, $1975,13,30-31$.

Maslow, A.H. Cognition of the particular and of the generic. Psychological Review, 1948, 55, 22-40.

Maslow, A.H. Motivation and personality. New York: Harper and Rowe, 1954.

Maslow, A.H. A theory of metamotivation: The biological rooting of the value of life. Journal of Humanistic Psychology, 1967, $7,93-127$. 
Matza, D. Becoming deviant. Englewood Cliffs, New Jersey: Prentice-Hall, Inc., 1969.

Mauser, A. Learning disabiities and delinquent youth. Academic Therapy, 1974, 9 (6), 389-402.

Mayer, C.L. The relationship of early special class placement and the self-concepts of mentally handicapped children. Exceptional Children, 1965, 34, 77-81.

McAdoo, H.P. The development of self-concept and race attitudes of young black children over time. New York: Cornell University, Paper presented at the Conference on Empirical Research in Black Psychology, 1976. (ERIC Document Reproduction Service No. ED 148 944)

McCormick, C. H., \& Rarabinus, R.A. Relationship of ethnic groups, self-esteem, and anxiety to school success. Educational and Psychological Measurement, $1976, \underline{36}$, 1093-1100.

McDaniel, E., Ball, L., \& Fortunato, B. A longitudinal study of the effects of parental attitudes on the development of self-concepts and attitudes toward school. Toronto, Canada: Paper presented at the Annual Meeting of the American Psychological Association, 1978. (ERIC Document Reproduction Service No. ED 164560 )

McDaniel, E., \& Leddick, G. Elementary children's selfconcepts, factor strucures and teacher ratings. Toronto Canada: Paper presented at the Annual Meeting of the American Psychological Association, 1978. (ERIC Document Reproduction Service No. ED 175 919)

McIntyre, W. G. \& Drummond, R.J. Multiple predictors of self-concept in children. Psychology in the Schools, 1977, 14(3), 295-298.

Mckeown, R. Modifying student's perceptions of school ability and role through classroom intervention. Journal of Experimental Education, 1976, $45(2)$, 27-32.

Mead, G. H. Mind, self and society. Chicago: University of Chicago Press, 1934 .

Meichenbaum, D. H., Bowers, K.S., \& Ross, R.R. A behavioral analysis of teacher expectancy effect. 
Journal of Personality and Social Psychology, 1969, $13,306-316$.

Mercer, J.R. Labeling the mentally retarded. Berkley: University of California Press, 1973.

Merton, R. The self-fulfilling prophecy. Antioch Review, $1948,8,193-210$.

Meyerowitz, J. Self-derogations in young retardates and special class placement. Child Development, 1962, 33, 443-451.

Mirels, H. L. \& McPeek, R.W. Self-advocacy and selfesteem. Journal of Consulting and Clinical

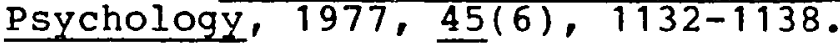

Moeller, C.R. The effects of labeling on self-esteem, self description, and behavior (Doctoral

Dissertation, Ball State University, 1981).

Dissertation Abstracts International, 1981, 42(10), 4245B. (University Microfilms No. 82-07614)

Morse, R.N., \& Piers, E.V. Variables affecting selfconcept in black disadvantaged boys. Washington, D.C.: Paper Presented to the Eastern Psychological Association, 1973. (ERIC Document Reproduction Service No. ED 090330 )

Morse, S.J. \& Gergin, K.J. Social comparison, self consistency, and the concept of self. In $M$. Rosenberg \& H.B. Kaplan (Eds.), Social psychology of the self-concept. Arlington Heights, Illinois: Harlan Davidson, 1982.

Myers, D.G., \& Ridle J. Aren't all Children Gifted? Today's Education, 1981, $70(1), 30-33$.

Nie, N.H., Hull, C.H., Jenkins, Steinbrenner, K., \& Bent, D.H. Statistical package for the social sciences (2nd ed). New York: McGraw-Hill, 1975.

Nisbett, R.E., \& Gordon, A. Self-esteem and susceptibility to social influence. Journal of Personality and Social Psychology, 1967, $\underline{5}, 268-276$.

O'Connor, J.L. Perceptions of self, ideal self, and teacher feelings in preadolescent children. Elementary School Guidance and Counseling, 1978, 13(2), 88-92.

Olavarri, M. Some relationships of ability grouping to student self-concept (Doctoral Dissertation, Univer- 
sity of California Berkeley, 1966). Dissertation Abstracts International, 1966, 28) (University Microfilms No. 68-00130,121)

Oregon Department of Education, Specific learning disabilities technical assistance paper 4. Salem: Oregon Department of Education, 1982.

Ottenbacher, $\mathrm{K}$. An investigation of self-concept and body image in the mentally retarded. Journal of Clinical Psychology, 1981, 37(2), 415-418.

Palardy, J.M. What teachers believe-what children achieve. Elementary School Journal, 1969, 69, 370-374.

Patten, M.D. Relationships between self-esteem, anxiety, and achievement in young learning disabled students. Journal of Learning Disabilities, $1983,16(1), 43-45$.

Patterson, M.L., \& Sechrest, L.B. Interpersonal distance and impression formation. Journal of Personality, 1970, $38,161-166$.

Pearl, R. Bryan, T., \& Donahue, M. Learning disabled children's attributions for success and failure. Learning Disability Quarterly, 1980, 3, 3-9.

Peterson, B., \& Ramirez, M. Real-ideal self-disparity in Negro and Mexican-American children. Psychology, 1971, $\underline{8}, 22-26$.

Piers, E.V. Children's self-ratings by others. In E.V. Piers, \& D. Harris. Manual for the Piers-Harris Children's self-concept scale. Nashville, Tennessee: Counseior Recording and Tests, 1969.

Piers, E.V. Parent prediction of children's self-concepts. Journal of Consuilting and Clinical Psychology, 1972, $38(3), 428-433$.

Piers, E.V., \& Harris, D. Age and other correlates of selfconcept in children. Journal of Educational Psychology, $1964, \underline{55}, 91-95$

Piers, E.V., \& Harris, D. Manual for the Piers-llarris Children's self-concept scale. Nashville, Tennessee: Counselor Recording and Tests, 1969.

Pihl, R.0., Parkes, M., Drake, H., \& Vrana, F. The intervention of a modulator with learning disabled children. Journal of Clinical Psychology, 1980, 36(4) 972-976. 
Polloway, E.A., \& Snell, M.E. Efficacy revisited. Education and Training of the Mentally Retarded, $1975, \underline{10(4),}$ 276-283.

Porter, J. Black child, white child: The development of racial attitudes. Cambridge: Harvard University Press, 1971.

Porter, J.F. Action and reaction in labeling the stutterer: Reviewing our responsibility. Australian Journal of Education, 1975, 19(3), 231-235.

Prieto, A.G. \& McCoy, K. Perceived roles and educable mentally handicapped minority students. 1979, (ERIC Document Reproduction Service No. 171 014)

Primavera, I. H., Simon, W.E., \& Primavera, A.M. The relationship between self-esteem and academic achievement: An investigation of sex differences. Psychclogy in the Schools, 1974, 11 213-216.

Proshansky, H., \& Newton, P. The nature and meaning of negro self-identity. In M. Deutsch, I. Katz, \& A.R. Jensen (Eds.), Social class, race and psychological development. New York: Holt, Rinehart and winston, 1968 .

Public Law 94-142 Education for all handicapped children act of 1975. ( 94 th Congress, ist session). Wahington, D.C., 1975)

Purkey, W.W. Self-concept and school achievement. Englewood Cliffs, New Jersey: Prentice Hall, 1970.

Rea, R.E. An analysis of academic achievement of economic groups and race as categories in grades five and six when need achievement, intelligence, and sex are held constant. (Doctoral Dissertation, Southern Illinois University, 1966). Dissertation Abstracts International, 1966, 27 (09), 2747A. University Microfilms wo. $67-3 i 7 \overline{9}, 133$ )

Reck, U. M. Self-concept, school and social setting: Anin depth view of rural Appalachian and urban nonAppalachian sixth graders. New York: Paper presented at the Annual Meeting of the American Educational Research Association, 1982. (ERIC Document Reproduction Service No. ED 215849 )

Reckless, W., \& Dinitz, S. Pioneering with self-concept as a vulnerability factor in delinquecy. Journal of Criminal Law, Criminology and Police Science, 1967, 58, 515-523. 
Reynolds, M.C., \& Balow, B. Categories and variatises in special education. Exceptional Children, 1972, 38, $357-365$.

Ribner, S. Self-concept in mainstreamed and self contained classes. Journal of Learning Disabilities, 1978, 11 (5), 319-3 $\overline{23}$.

Richardson, S.A., Hasdorf, A.H. \& Dornbush, S. M. The effect of pnysicai disability on a child's description of himself. Child Development, 1964, 35, 893-907.

Ringness, T. A. Self-concept of children of low, average, and high intelligence. American Journal of Mental Deficiency, $1961,65,45 \overline{5-461 .}$

Rist, R.C. Student social class and teacher expectations: The self-fulfilling prophecy in ghetto education. Harvard Educational Review, 1970, 40, 411-450.

Robbins, R. C., Mercer, J.R., \& Meyers, C.E. The school as a selecting-labeling system. Journal of School Psychology, 1967, 94, 270-279.

Robinson, J.P., \& Shaver, P.R. Measures of social psychological attitudes. Ann Arbor, Michigan: Institute for Social Research, 1973.

Rochlin, G. Griefs and discontents: The forces of change. Boston: Little, Brown \& Co., 1965.

Rochlin, G. Man's agression; the defense of the self. Boston: Gambit, 1973.

Rodin, J. \& Langer, E. Aging labels: the decline of control and the fall of self-esteem. Journal of Social Issues, $1980,8(2), 12-29$.

Rogers, A.H. \& Walsh, T.M. Defensiveness and unwitting self-evaluation. Journal of Clinical Psychology, 1959, $15,302-304$.

Rogers, C.R. Client centered therapy: Its current practice, implications and theory. Boston: Houghton Mifflin, 1951.

Rogers, C.R. A theory of therapy, personality and interpersonal relationships as developed in the client-centered framework. In S. Koch (Ed.), Psychology: A study of science (Vol. 3). New York: McGraw-Hill, 1959.

Rogers, C.R., Kell, B.L. \& McNeil, H. The role of selfunderstanding in the prediction of behavior. Journal of Consulting Psychology, 1948, 12 174-186. 
Rogers, C. M., Smith, M.D., \& Coleman, J.M. Social comparison in the classroom: The relationship between academic achievement and self-concept. Journal of Educational Psychology, 1978, 70, 50-57.

Rosenberg, M. Society and the adolescert self-image. Princeton: Princeton University Press, 1965.

Rosenberg, M. Conceiving the self. New York: Basic Books, 1979.

Rosenberg, M., \& Kaplan, H.B. (Ed.) Social psychology of the self-concept. Arlington Heights, Illinois: Harlan Davidson, 1982.

Rosenberg, M. \& Pearlin, L.J. Social class and selfesteem among children and adults. In M. Rosenberg \& H.B. Kaplan (Eds.) Social psychology or the selfconcept. Arlington Heights, Illinois: Harlan s=cison, 1982.

Rosenberg, M., \& Simmons, R. Black and white selfesteem: The urban school child. Washington, D.C.: American Sociological Association, 1971.

Rosenthal, R., \& Jacobson, L. Pygmalion in the classroom. New York: Holt, Rinehart and winston, 1968 .

Rosenthal, R. \& Rubin., D.B. Pygmalion reaffirmed. Washington, D.C.: National Science Foundation, 1971.

Ross, A. O. Psychological aspects of learning disabilities and reading disorders. New York: McGraw Hill, 1976.

Roth, R.M. The role of self-concept in achievement. Journal of Exceptional Education, 1959, 27, 265-281.

Rotter, J. Social learning and clinical psychology. New York: Prentice-Hall, 1954.

Samuels, S.C. Enhancing self-concept in early childhood: Theory and practice. New York: Human Sciences, 1977.

Samuels, S.C. An investigation into the relation between self-concept and achievement of lower and middle class black and white children: kindergarten through eighth grade. New York: Manhattanville College, 1977. (ERIC Document Reproduction Service No. ED 190 202) 
Scheff, T. J. Labeling madness. Englewood Cliffs, New Jersey: Prentice-Hall Inc., 1975.

Schrank, W. R. Further study of the labeling effect of ability grouping. Journal of Educational Resarch, $1970,63,358-360$.

Schur, E.M. Labeling deviant behavior-Its sociological implications. New York: Harper \& Row, 1971.

Schurr, K. \& Brookver, W. The effect of special class placement on the self-concept of ability of the educable mentally retarded child. East Lansing:

U.S.O.E., 1967. (ERIC Document Reproduction Service No. ED 027658 )

Schurr, K., Towne, R., \& Joiner, L. Trends in selfconcept of ability over 2 years of special class placement. Journal of Special Education, 1972, 6 , . $161-166$.

Scott, R. A. The making of blind men: a study of adult socialization. New York; Russell Sage Foundation, 1969.

Sears, R.R. Relation of early socialization experiences to self-concept and gender role in middle childhood. Child Development, 1970, 41, 267-289.

Secord, P.F., \& Backman, C.W. An interpersonal approach to personality research $(\overline{V o l} .2)$. New York: Academic Press, 1965.

Shakespeare, R. The psychology of handicap. London: Methuen \& CO., 1975.

Shavelson, R.J., Hubner, J.J., \& Stanton, G.C. Selfconcept: Validation of construct interpretations. Review of Educational Research, 1976, $\underline{46}$ 407-441.

Shaw, M.C., \& Dutton, B. The use of the parent attitude research inventory with the parents of bright academic underachievers. Journal of Educational Psychology, 1962, 53, 203-208.

Sheerer, E.T. An analysis of the relationship between acceptance of the respect for self and acceptance of and respect for others. Journal of Consulting Psychology, 1949, 13, 176-180.

Silvernail, D.L. Developing positive student selfconcept. Washington, D.C.: National Education Association, 1981. 
Simon, W.E., \& Simon, W.G. Self-esteem, intelligence and standardized academic achievement. Psychology in the schools, 1975,12 97-100.

Siperstein, G.N., Goding, M.J. Teacher's behavior toward LD and non-LD children: a strategy for change. Journal of Learning Disabilities, $1985,18(3)$, 129-184.

Skinner, B.F. The behavior of organisms. New York: Appleton Century Crofts, 1938.

Slaughter, D.T. Relation of early parent-teacher socialization influences to achievement orientation and self-esteem in middle childhood among low-income black children. In J.C. Glidewell (Ed.), The social context of learning and development. New York: Gardner Press, 1977.

Smith, I. L., \& Greenberg, S. Teacher attitudes and the labeling process. Exceptional Children, 1975, 41 319-324.

Smith, M. Affective reactions to academic outcomes: a social comparison perspective. Montreal, Canada: Paper presented at American Psychological Association Meeting, 1980. (ERIC Document Reproduction Service No. ED 201 132)

Smith, M., Coleman, J.M., Dokecki, P.R., \& Davis, E.E. Intellectual characteristics of school labeled learning disabled children. Exceptional Children, $1977, \underline{43}, 352-357$.

Smith, M.D., Dokecki, P.R., \& Davis, E.E. School related factors influencing the self-concepts of children with learning problems. Peabody Journal of Education, 1977, 54, 185-195.

Smith, M.D., \& Rogers, C.M. Item instability on the Piers-Harris Children's Self-Concept Scale for academic undersachievers with high middle and low self-concepts: Implications for constrict validity . Educational and Psychological Measurement, $1977,37,553-558$.

Smith, M.D., \& Rogers, C.M. Reliability of standardized assessment instruments when used with learning disabled children. Learning Disability Quarterly, $1978,1(3), 23-31$.

Smith, M.D., Zingale, S.A., \& Coleman, J.M. Trie influence of adult expectancy/child performance discrepancies 
upon children's self-concepts. American Educaional Research Journal, 1978, 15, 259-265.

Snyder, C.R. "A patient by any other name" revisited: Maladjustment or attributional locus of problem. Journal of Consulting and Clinical Psychology, 1977, 45, 101-103.

Snyder, E.E. (Ed.) Self-concept theory-An approach to understanding the behavior of disadvantaged pupils. Clearinghouse, 1965, 40, 242-246.

Soares, L.M., \& Soares, A.T. Self-concepts of disadvantaged and advantaged students. Child Study Journal, $1971,1(2), 69-73$.

Stanwyck, D.J. \& Felker, D.W. Measuring the self-concept: A factor analytic study. New York: Paper presented to the National Council on Measurement in Education, 1971. (ERIC Document Reproduction Service No. ED $053161)$

Stanwyck, D.J., \& Felker, D.W. Intellectual achievement, responsibility and anxiety as functions of self-concept of third to sixth grade boys and girls. New York: Paper presented to the American Educational Research Association, 1973 (ERIC Document Reproduction Service No. ED 080903)

Stephans, T.W. An evaluation study of the efficacy of pupil educational plans as developed by school assessment teams in the Sequoia Union High School district. Sacramento: California state Dept. of Education, 1977. (ERIC Document Reproduction Service No. ED 149499 )

Stewart, D.J., Crump, W.D., \& McLean, J.E. Response instability on the Piers-Harris Children's SelfConcept Scale. Journal of Learning Disability, $1979,12(5), 35 \overline{1-355}$.

Stoller, L. Algozzine, B., \& Ysseldyke, J. Expectations and attributions for a handicaped child: Teachers pay attention to classroom performance. Educational Research Quarterly, 1981, ㄸ (2), 53-59.

Stott, L.H. Some family life patterns and their relation to personality development in children. Journal of Experimental Education, 1939, 8, 148-160.

Strang, L. Smith, M.D., \& Rogers, C.M. Social comparison, multiple reference groups and the self-concepts of academically handicapped children before and 
after mainstreaming. Journal of Educational Psychology, 1978, 70, 487-497.

Stryker; S. Identity salience and role performance: the relevance of symbolic interaction theory for family research. In M. Rosenberg \& ․‥B. Kaplan (Eds.), Social Psychology of Self-concept. Arlington Heights, Illinois: Harlan Davidson, 1982.

Sullivan, H.S. Interpersonal theor $y$ of Psychiatry. New York: Norton, 1953.

Thomas, A. Learned helplessness and expectancy factors: Implications for research in learning disabilities. Review of Educational Researcin, 1979, 49, 208-22i.

Thomas, A. Attribution training for children with learning difficulties. St. Catharines, Ontario: Brock University, 1980 (ERIC Document Reproduction Service No. ED 198673 )

Thorndyke, R. Revie of R. Rosenthal and L. Jacobson Pygmalion in the classroom. American Educational Research Journal, $1968, \underline{5}, 70 \overline{8-711 .}$

Thurlow, M., Graden, J., Greener, J., \& Ysseldyke, J. LD and non-LD students' opportunities to learn. Learning Disability Quarterly, 1983, 6, 172-183.

Toner, I. J., Moore, L.P. \& Emmons, B.A. The effect of being labelled as "patient" on subsequent selfcontrol in chldren. San Francisco: Paper presented at the Biennial Meeting of the Society for Research in Child Development, 1979. (ERIC Document Reproduction Service) No. ED 178 178)

Towne, R.C., \& Joiner, L.M. Some negative implications of special placement for children with learning disabilities. Journal of Special Education, 1968, 2 , 217-222.

Trowbridge, N. Self-concept and socioeconomic status in elementary school children. American Educational Research Journal, 1972, 9, 527-537.

Ullman, L. P., \& Krasner, L. A psychological approach to abnormal behavior. Englewood Cliffs, New Jersey: Prentice-Hall, Inc., 1975.

U.S. Office of Education. Assistance to states for education of handicapped children: procedures for evaluating specific learning disabilities. Federal Register, 1977, 느, 65082-65085. 
Van Koughnett, B.C., \& Smith, M.E. Enhancing the selfconcept in the school. Educational Leadership, $1969,27,253-255$.

Vereen, M. Reading achievement and self-concept of fifth grade students. New Jersey: Kean College, 1980. (ERIC Document Reproduction Service No. ED 192 264)

Wanat, P.E. Social skills: An awareness program with learning disabled adolescents. Journal of Learning Disabilities, 1983, 16(1), 35-38.

Ward, S., \& Braun, J. Self-esteem and racial preference in black children. American Journal of Othopsychiatry, 1972, 42 (4), 64-74.

Warner, F., Thrapp, R., \& Walsh, S. Attitudes of children toward their special class placement. Exceptional Children, 1973, 40 37-38.

Wattenberg, W.W., \& Clifford, C. Relation of self-concept to beginning achievement in reading. Child Development, $1964, \underline{35} 461-467$.

Wells, L.E. Theories of deviance and the self-concept. Social Psychology, 1978, 41(3), 189-204.

Wiatrowski, M.D. Curriculum tracking and delinquency: Toward an integration of educational and delinquency research. Washington, D.C.: NIE DHEW, 1981. (ERIC Document Reproduction Service No. ED 204 687)

Williams, J.H. The relationship of self-concept and reading achievement in first grade children. Journal of Educational Research, 1973, 66 (8), 378-381.

Williams, R.L., \& Cole, S. Self-concept and school adjustment. American Personnel and Guidance Journal, $1968, \underline{46}, 478-481$.

Wilson, w. Social psychology and mental retardation. In N.R. Ellis (Ed.), International review of research in mental retardation (Vol. 4). New York: Academic Press, 1970.

Wylie, R.C. The self-concept. Lincoln Nebraska: University of Nebraska Press, 1974.

Wylie, R.C. The self-concept (Vol. 2). Lincoln, Nebraska: University of Nebraska Press, 1979.

Yamamoto, $K$. The child and $h$ is image. Boston: Houghton Mifflin, 1972 . 
Yauman, B. E. Special education placement and the self-concepts of elementary school age children. Learning Disability Quarterly, 1980, $3(3), 30-35$.

Ysseldyke, J.E., \& Foster, G.E. Bias in teacher's observations of emotionally disturbed and learning disabled children. Exceptional Children, 1978, 44, 613-615.

Zachofsky, T., Reardon, D., \& O'Connor, G. Response of institutionalized retarded adults to social pressure in small groups. American Journal of Mental Deficiency, 1974, 79(1), 10-15.

Zigler, E., \& Phillips, L. Psychiatric diagnosis: A critique. Journal of Abnormal and Social Psychology, $1961,63,607-618$.

Zimmerman, I.L., \& Allebrand, G.N. Personality characteristics and attitudes towards achievement of good and poor readers. Journal of Educational Research, $1965,59,28-30$.

Zito, R.J., \& Bardon, J. I. Achievement motivation among negro adolescents in regular and special education programs. American Journal of Mental Deficiency, $1969,74,20-26$.

Zucker, S.H. \& Prieto, A.G. Ethnicity and teacher bias in educational decisions. Journai of instructional psychology, 1977, ㄴ, 2-5.

Zuercher, L.A., The mutable self: A self-concept for social change (Vol. 59). Beverly Hills: Sage Publications, 1977. 
APPENDIX A 
PARENT CONSENT. FORM

Please sign this form and mail it in the attached envelope if you are willing to help us in this research.

DAVID DOUGLAS SCHOOL DISTRICT

INFORMED CONSENT

I hereby agree for my child to participate in a research project conducted by David Douglas School District and the Portland State university Department of Special Education. I understand that the study involves my answering some questions related to our family, and my child completing questions on a selfconcept scale. I also understand that this study might make some demands on our time for the purpose of answering questions.

It has been explained to me that the purpose of the study is to learn whether arrangements in support of the education of my child may have a significant impact on my child's self-concept. I understand that the self-concent scale which my child will answer has been widely used across the United States for fourteen years. I am aware that the information provided by me and the questions answered by my child are very important to control for influences which could affect self-concept.

I have been assured that all information I give will be kept totally confidential and that the identity of all 
subjects will remain anonymous. I realize that no one will know that my or my child's answers belong to us. A number will be used to protect our identity and the researcher will not know our names. Only the researcher will see our answers to the questions. All information collected for this study will be reported without my or my child's privacy being violated.

The Researcher, Kathy Godinet, has offered to answer any questions that I may have about this study. She can be reached evenings after 6:00 p.m. and weekends at $297-6819$.

I realize that although my child and I may not receive any direct benefit from our participation it will help to increase knowledge which may benefit others in the future. I understand that I am free to withdraw from participation in this study at any time.

I have read and understand the preceding information.

PARENTAL SIGNATURE DATE CHILD'S SIGNATURE DATE

If you experience problems that are the result of your participation in this study, please contact Johr Lorenze, Office of Graduate Studies and Research, 105 Neuberger Hall, Portland State University, 229-3423. 
APPENDIX B 


\section{DEMOGRAPHIC INFORMATION SHEET}

Please complete this form and mail it in the attached envelope if you are willing to help us in this research. Family Information

Date Information which you provide on this sheet will be held confidential. Your name will never be tied to this information. The number at the corner of this page will be used to match these answers with your child's self-concept scale.

1. How old is your child? years months

(Please mark the one appropriate answer)

One

Only
2. Is this child your oldest child middle child youngest child

3. Which ethnic group best describes your child? American Indian

Asian or Pacific Islander
Black
White
Other (Please fill in)

4. Has your child been evaluated by a school district and been found to have a handicapping condition? No (if no, please move on to question number 9). Yes

5. If yes, please check the one major handicapping condition label which best fits your child.

Deaf/Hard of Hearing Deaf/Blind Emotionally Disturbed Learning Disabled Mentally Retarded Multi-Handicapped Or thopedically Impaired (Physically Impaired) Speech Impaired Visually Handicapped other Health Impaired (Please specify) other nonlisted handicapping condition labels (Please specify) 
6. How long has your child been receiving district provided special education services? years (approximately)

7. Does your child have a special education Individualized Education Plan (IEP)

No
Yes Yes, does your child have:

$\overline{\text { one }}$

Only

instruction only in reqular classes
instruction in regular class and a resource
room instruction in a resource room and a special
education class
instruction in a special education class
instruction in a special education class and
a regular class
other (please specify)

8. Does our child know that he/she has a handicapping conữition?

No, my child does not have a handicapping condition

No, my child does not know

Yes, my child does know

9. Does your child use handicap labels to describe herself/himself?

No

Yes

If Yes, could you please 1 ist any labels:

10. Does your child have any regularly reoccurring health problems?

No

Yes

If yes, please describe the health problem:

11. How many other children do you have?

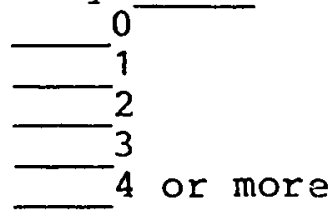


12. Which category best describes your family's annual income?

$\begin{array}{lll} & \$ 100 & \text { to } \$ 4,999 \\ \text { One } & \$ 5,000 & \text { to } \$ 9,999 \\ \text { Only } & \$ 10,000 \text { to } \$ 14,999 \\ & \$ 15,000 \text { to } \$ 19,999 \\ & \$ 20,000 \text { to } \$ 29,999 \\ & & \$ 30,000 \text { to } \$ 44,999 \\ & & \$ 4,000 \text { and above }\end{array}$

While some of the information collected here is of a very personal nature, your privacy will always be protected. Research findings will never reveal individual answers tied to either you or your child. If you have any questions please call Kathy Godinet (weekends and evenings after 6:00 pm) at 297-6819.

Thank you very much for your time and cooperation in completing these forms! 
APPENDIX C 


\section{PIERS-HARRIS SELF-CONCEPT SCALE SAMPLE ITEMS}

1. My classmates make fun of me.................... no

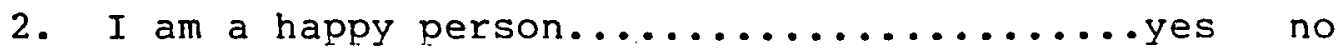

3. It is hard for me to make friends..........yes no

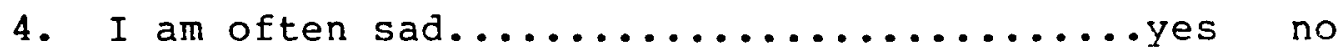

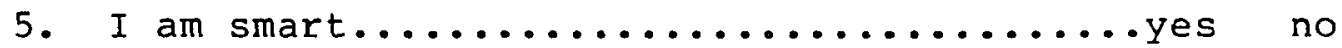

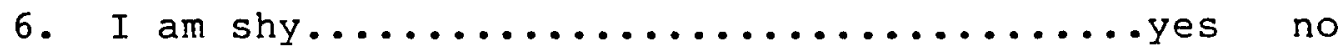


APPENDIX D 


\section{STUDENT INFORMATION SHEET}

Number

Please complete all of the following questions by marking one answer.

1. Are you a

Boy

Girl

2. Is doing well in school

not important to you

somewhat important to you

important to you

very important to you

3. My school teachers help me to feel good about myself. Yes No

4. My teachers help me to enjoy school. No

Yes

5. Which sentence best tells how you feel? I do. My teacher is very happy with the school work that

My teacher is happy with the school work that I do

My teacher is unhappy with the school work that I

I really don't know what my teacher thinks of the work that I do.

6. Do you receive any kind of special education help in school?

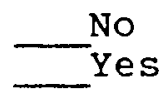

7. Have any of the following words been used to describe you?

Deaf/Hard of Hearing

Deaf/Bl ind

Emotionally Disturbed

Learning Disabled

Mentally Retarded

Multi-Handicapped

Orthopedically Impaired (Physically Impaired)

Speech Impaired

Visually Handicapped

Other Health Impaired

None of these words 
8. Write your definition for this word:

Learning Disabled:

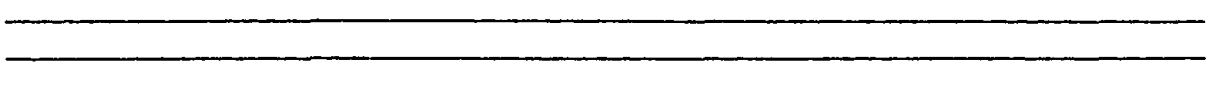

Thank you for your help in this research! 